\title{
Evaluation of climate simulations produced with the Brazilian Global Atmospheric Model version 1.2
}

Article

Accepted Version

Coelho, C. A. S., de Souza, D. C., Kubota, P. Y., Coelho, S. M. S. C., Menezes, L., Guimarães, B. S., Figueroa, S. N., Bonatti, J. P., Cavalcanti, I. F. A., Sampaio, G., Klingaman, N. P. ORCID: https://orcid.org/0000-0002-2927-9303 and Baker, J. C. A. (2021) Evaluation of climate simulations produced with the Brazilian Global Atmospheric Model version 1.2. Climate Dynamics, 56. pp. 873-898. ISSN 0930-7575 doi: https://doi.org/10.1007/s00382-020-05508-8 Available at https://centaur.reading.ac.uk/93653/

It is advisable to refer to the publisher's version if you intend to cite from the work. See Guidance on citing.

To link to this article DOI: http://dx.doi.org/10.1007/s00382-020-05508-8

Publisher: Springer

All outputs in CentAUR are protected by Intellectual Property Rights law, including copyright law. Copyright and IPR is retained by the creators or other copyright holders. Terms and conditions for use of this material are defined in the End User Agreement. 


\section{www.reading.ac.uk/centaur}

\section{CentAUR}

Central Archive at the University of Reading

Reading's research outputs online 


\title{
Evaluation of climate simulations produced with the Brazilian Global Atmospheric Model version 1.2
}

\author{
Caio. A. S. Coelho, Dayana C. de Souza, Paulo Y. Kubota, Simone M. S. C. Coelho, \\ Layrson Menezes, Bruno S. Guimarães, Silvio N. Figueroa, José P. Bonatti, \\ Iracema F. A. Cavalcanti, Gilvan Sampaio \\ Centro de Previsão de Tempo e Estudos Climáticos (CPTEC), Instituto Nacional de Pesquisas Espaciais \\ (INPE), Rodovia Presidente Dutra, Km 40, SP-RJ, Cachoeira Paulista, SP 12630-000, Brazil
}

Nicholas P. Klingaman

National Centre for Atmospheric Science-Climate and Department of Meteorology, University of Reading, Earley Gate, P.O. Box 243, Reading, Berkshire RG6 6BB, UK

Jessica C. A. Baker

School of Earth and Environment, Institute for Climate and Atmospheric Science, University of Leeds, Leeds, UK

Corresponding author: Caio A. S. Coelho, e-mail: caio.coelho@inpe.br,

Phone number: +55 12 31868670, Fax number: +55 1231012835 
This paper presents an evaluation of climate simulations produced by the Brazilian Global Atmospheric Model version 1.2 (BAM-1.2) of the Center for Weather Forecast and Climate Studies (CPTEC). The model was run over the 1975-2017 period at two spatial resolutions, corresponding to $\sim 180$ and $\sim 100 \mathrm{~km}$, both with 42 vertical levels, following most of the Atmospheric Model Intercomparison Project (AMIP) protocol. In this protocol, observed sea surface temperatures (SSTs) are used as boundary conditions for the atmospheric model. Four ensemble members were run for each of the two resolutions. A series of diagnostics was computed for assessing the model's ability to represent the top of the atmosphere (TOA) radiation, atmospheric temperature, circulation and precipitation climatological features. The representation of precipitation interannual variability, El Niño-Southern Oscillation (ENSO) precipitation teleconnections, the Madden and Julian Oscillation (MJO) and daily precipitation characteristics was also assessed. The model at both resolutions reproduced many observed temperature, atmospheric circulation and precipitation climatological features, despite several identified biases. The model atmosphere was found to be more transparent than the observations, leading to misrepresentation of cloud-radiation interactions. The net cloud radiative forcing, which produces a cooling effect on the global mean climate at the TOA, was well represented by the model. This was found to be due to the compensation between both weaker longwave cloud radiative forcing (LWCRF) and shortwave cloud radiative forcing (SWCRF) in the model compared to the observations. The model capability to represent inter-annual precipitation variability at both resolutions was found to be linked to the adequate representation of ENSO teleconnections. However, the model produced weaker than observed convective activity associated with the MJO. Light daily precipitation over the southeast of South America and other climatologically similar regions was diagnosed to be overestimated, and heavy daily precipitation underestimated by the model. Increasing spatial resolution helped to slightly reduce some of the diagnosed biases. The performed evaluation identified model aspects that need to be improved. These include the representation of polar continental surface and sea ice albedo, stratospheric ozone, low marine clouds, and daily precipitation features, which were found to be larger and last longer than the observed features. 


\section{Introduction}

The strategy for evaluating simulations produced by climate models developed as part of the Atmospheric Model Intercomparison Project (AMIP, Gates et al., 1998) provides a framework for model diagnosis, validation and intercomparison (Toh et al., 2018). AMIP-type simulations are routinely performed in global climate prediction and weather forecast centers (e.g., Muzita et al., 2012; Kodama et al. 2015) during the model development process to evaluate atmospheric global circulation models' (AGCMs) performance and identify errors to facilitate future improvements. AMIP has a standard experimental protocol, enabling the scientific community to evaluate these models systematically, with a simple design: an AGCM is constrained by realistic (observed) SSTs and sea ice conditions and run over a climatological (historical) period (usually for the past 30 years), with a comprehensive set of variables archived for diagnostic research. This experimental design enables the scientific investigation to focus on the AGCM without the added complexity of ocean-atmosphere feedbacks in the climate system.

Since 1995, the Centre for Weather Forecast and Climate Studies (CPTEC) of the National Institute for Space Research (INPE) in Brazil has performed climate research using an AGCM originally obtained from the Center for Ocean-Land-Atmosphere Studies (COLA) in the USA. Cavalcanti et al. (2002) and Marengo et al. (2003) evaluated and documented the performance of the first AMIP-type climate simulation performed with CPTEC/COLA AGCM. Over the years, this model has been further developed and adapted for Brazilian climate conditions by CPTEC/INPE scientists and collaborators for use in both diagnostics research and routine (operational) predictions, being renamed to CPTEC AGCM. Coelho et al. (2012) reported the ability of CPTEC AGCM in predicting drought events in the Amazon. Coelho et al. (2013) documented the performance of CPTEC AGCM probabilistic seasonal precipitation forecasts produced for Brazil over a period of 10 years. Although the last CPTEC AGCM version was able to simulate the climatological atmospheric circulation features, unacceptable systematic errors at high latitudes (spurious precipitation) were found in short (10 days) and long (30 years) integrations. To overcome these errors, a new CPTEC global model has been developed, called the Brazilian Global Atmospheric Model (BAM). This model evolved recently from the first version 1.0 (BAM-1.0, Figueroa et al. 2016) to the current version 1.2 (BAM-1.2), which is evaluated in this paper when run for performing climate AMIP-type simulations. Cavalcanti and Raia (2017) and Cavalcanti et al. (2020) investigated the ability of a predecessor BAM version with simplified and fast physical parameterizations (known as BAM version 0.0, BAM-0.0) in simulating the lifecycle of the South American monsoon system and climate variability over South America, respectively. Guimarães et al. (2020) defined a configuration and performed the first assessment of BAM-1.2 for sub-seasonal predictions, which is the same version currently used at CPTEC for global operational numerical weather prediction. However, the performance of BAM-1.2 climate simulations is yet to be documented.

This study aims to evaluate the performance of the CPTEC model (BAM-1.2) when producing AMIPtype climate simulations (see section 2 for additional information about the performed simulations). The atmospheric features produced with BAM-1.2 AMIP-type simulations at two spatial resolutions, corresponding to around 180 and $100 \mathrm{~km}$, both with 42 vertical levels, are compared. The paper addresses the following questions: How well does BAM-1.2 represent the top of the atmosphere (TOA) radiation, temperature, atmospheric circulation and precipitation climatological features? What are BAM-1.2 biases for the features listed above? How well does BAM-1.2 represent precipitation interannual variability, El Niño-Southern Oscillation (ENSO) precipitation teleconnections, the Madden and Julian Oscillation (MJO) and daily precipitation characteristics? What is the impact of increasing spatial resolution in all of the above?

The manuscript is organized as follows. Section 2 describes the model (BAM-1.2), the experimental design and observational reference datasets used for model evaluation. Section 3 presents the assessment of how BAM-1.2 represents the global annual mean TOA radiation and vertical zonal mean temperature profile. Sections 4 and 5 describe how BAM-1.2 simulates the climatological seasonal mean atmospheric circulation and precipitation features, respectively. Section 6 assesses how BAM-1.2 represents ENSO precipitation teleconnections and precipitation interannual variability on the seasonal time scale. Section 7 
describes how BAM-1.2 simulates the MJO and daily precipitation characteristics. Section 8 provides a summary and concludes the manuscript.

\section{The Brazilian global atmospheric model version 1.2 (BAM-1.2), experimental design and observational references}

\subsection{Model description}

The study uses the Brazilian global atmospheric model version 1.2 (BAM-1.2), which is CPTEC's spectral model developed for numerical weather forecasting, climate simulations and predictions. BAM1.2 provides several physical parameterizations options that can be selected depending on computational efficiency requirements (e.g., single-moment and double-moment microphysics schemes). Prior to performing the climate simulations evaluated here, a series of sensitivity tests was performed to define an optimal model configuration for an adequate representation of the main global climatological features. For deep convection, a modified version of the Grell-Dévényi (2002) and the revised version of the simplified Arakawa-Shubert (Han and Pan. 2011) parameterization schemes were tested. For the planetary boundary layer (PBL), the modified Mellor-Yamada dry diffusion scheme, which is based on Mellor-Yamada (1982), and the Bretherton-Park moist diffusion scheme (Bretherton and Park, 2009) were tested. For short-wave (SW) and long-wave (LW) radiation, the Rapid Radiative Transfer Model for General Circulation Models (RRTMG, Iacono et al. 2008) scheme, the long-wave radiation scheme (Chou et al. 2001, CLIRAD-LW), and the short-wave radiation scheme developed by Chou and Suarez (1999) (CLIRAD-SW), the latter modified by Tarasova and Fomin (2000), were tested. After performing these tests, the chosen model configuration to be used in this study is similar to the configuration described in Guimarães et al. (2020). The BAM-1.2 physical processes components used for performing the simulations here evaluated are indicated in Table 1: microphysics from Morrison et al. (2005, 2009); the IBIS-CPTEC surface model (Kubota, 2012); the long-wave radiation scheme developed by Chou et al. (2001) (CLIRAD-LW); the short-wave radiation scheme developed by Chou and Suarez (1999) (CLIRAD-SW), modified by Tarasova and Fomin (2000); the Bretherton-Park moist diffusion scheme (Bretherton and Park, 2009) for the planetary boundary layer (PBL), which is referred to as moist-PBL; and the revised version of the simplified Arakawa-Shubert deep convection scheme (Han and Pan. 2011).

The moist-PLB used here in BAM-1.2 includes the thermal plume scheme for the convective boundary layer developed by Rio and Hourdin (2008), and the following adjustments with respect to Bretherton and Park (2009): (1) interactive calculation between stratiform cloudiness and the vertical diffusion coefficient, and (2) improved saturation vapour pressure calculation (Souza et al. 2019). The simplified Arakawa-Shubert deep convection scheme implemented in BAM-1.2 has the following adjustments with respect to Han and Pan (2011): (1) momentum calculation including pressure gradient generated by convective cells, (2) entrainment parameters calibration, (3) cloud fraction calculation based on probability distribution functions (pdfs), and (4) optical properties calculations based on liquid water and ice predictive variables. 
sigma vertical levels ( 32 in the troposphere and 10 in the stratosphere) and a model top at $2 \mathrm{hPa}$. The coarser resolution (TQ62) was chosen because it was used in previous BAM studies (Cavalcanti and Raia, 2017 and Cavalcanti et al. 2020) and it was computationally efficient. The other resolution (TQ126) was chosen because it allows almost doubling the spatial refinement of the simulations, therefore providing more detailed information, potentially leading to improved representation of some regional climate features. Aerosol optical depth in the first $2 \mathrm{~km}$ of the atmosphere is specified as 0.22 and 0.14 over the continents and oceans, respectively, as estimated by $\mathrm{Yu}$ et al. (2006). Carbon dioxide $\left(\mathrm{CO}_{2}\right)$ concentration was kept constant at 370 parts per million (ppm) in all simulations because this is the standard configuration in BAM-1.2. This procedure differs from the current AMIP protocol in which $\mathrm{CO}_{2}$ concentration is prescribed with the global annual mean values during the simulation period. As we do not follow exactly the current AMIP protocol, our simulations are called AMIP-type rather than AMIP. Ozone was initialized with seasonally varying mean climatological values, for the four seasons of the year, compiled by the National Meteorological Center (NMC) Development Division Staff (1988).

\subsection{Experimental design and observational reference datasets}

Two sets of 4-member ensemble AMIP-type climate simulations for the period from 1975 to 2017 were performed with BAM-1.2, one set for each of the two model resolutions (TQ126L42 and TQ62L42) investigated in this study. ERA-40 reanalysis (Uppala et al. 2005) atmospheric initial conditions for the $1^{\text {st }}$ January, $1^{\text {st }}$ April, $1^{\text {st }}$ July and $1^{\text {st }}$ October 1975 were used to initialize the model and produce the 4member ensemble for each model resolution. The atmospheric variables needed to initialize the model are zonal and meridional wind, specific humidity and virtual temperature in 23 vertical levels between 1000 and $1 \mathrm{hPa}$, and surface pressure. The horizontal ERA-40 resolution chosen for initialization of all above listed variables was $1.125^{\circ}$ in latitude and longitude, which was interpolated to the model spectral resolution (TQ126L42, $100 \mathrm{~km}$, and TQ62L42, 180 km). Following the AMIP protocol, monthly observed SSTs and sea ice conditions from Taylor et al. (2000) at $1^{\circ}$ in latitude and longitude were prescribed as boundary conditions for the model. The first six years of simulations (from 1975 to 1980) were discarded; most of the assessment presented concentrates in the 30-year (1981-2010) climatological period. ERA-40 reanalysis was used as initial conditions because these data were readily available and already interpolated at the two investigated model resolutions. However, the use of another reanalysis dataset for generating initial conditions would not be expected to produce major changes in the climatological features analyzed here, particularly because this study investigates long climate simulations forced with observed sea surface temperatures. The role of boundary conditions (sea surface temperature) dominates the role of initial conditions in such simulations. The TOA radiation and the daily precipitation characteristics assessments were based on the 2001-2016 and 1998-2017 periods, respectively, due to the reference satellite data availability.

The following observational references were used for model evaluation. ERA-5 reanalysis (Hersbach et al., 2018, 2019) was used for the atmospheric circulation and temperature assessment. The International Satellite Cloud Climatology Project (ISCCP) dataset (Schiffer and Rossow 1983) was used for cloud amount evaluation. The Clouds and the Earth's Radiant Energy System (CERES) dataset (Loeb et al., 
dataset (Adler et al. 2003) was used for precipitation evaluation. GPCP was chosen because this dataset is composed of surface observations and satellite precipitation estimates, as opposed to the ERA-5 reanalysis precipitation dataset that is composed of model-produced precipitation values, as the latter are known to be less representative of real-world observations. The National Oceanic and Atmospheric Administration (NOAA) Southern Oscillation Index (SOI) was used for evaluating ENSO precipitation teleconnections. The NOAA Outgoing Longwave Radiation (OLR) dataset (Liebman and Smith 1996) and (ERA-5) reanalysis 850 and $200 \mathrm{hPa}$ zonal winds (Hersbach et al., 2018, 2019) datasets were used for assessing MJO activity. For the daily precipitation analysis, the Tropical Rainfall Measuring Mission (TRMM) dataset was used (3B42 product, version 7A, Kummerow et al., 1998; Huffman et al., 2007, 2010). Table 2 summarizes the observational reference datasets and variables used in this study.

\section{Global annual mean climatological top of the atmosphere radiation features and vertical zonal mean temperature profile}

An adequate representation of atmospheric radiation in climate models is fundamental for successful

climate simulations. This section starts by assessing how well BAM-1.2 represents the global annual mean climatological TOA radiation under clear sky and cloudy conditions, which is important for investigating how well the model simulates cloud-radiation interactions. Next, this section assesses model fidelity for the vertical profile of zonal-mean annual mean climatological temperatures.

Figure 1 shows in panel a) the global climatological (2001-2016) annual mean TOA outgoing longwave radiation (OLR) under clear sky conditions derived from satellite (CERES), and in panels b) and c) the corresponding OLR under clear sky conditions simulated by BAM TQ62L42 $(\sim 180 \mathrm{~km})$ and BAM TQ126L42 ( 100 km). The model climatological mean spatial patterns (panels $b$ and c) resemble the observed pattern (panel a), with model global mean values of $267.33 \mathrm{~W} . \mathrm{m}^{2}$ for BAM TQ62L42 and of $269.45 \mathrm{~W} . \mathrm{m}^{2}$ for BAM TQ126L42 close to the reference (CERES) value of $266.11 \mathrm{~W} . \mathrm{m}^{2}$. Panel d) shows the zonal means of the maps of panels a) for CERES (black line), b) BAM TQ62L42 (blue line), and c) BAM TQ126L42 (red line), which further illustrates the close match between CERES and BAM. Panel d) also reveals the small biases of $1.23 \mathrm{~W} \cdot \mathrm{m}^{2}$ and $3.37 \mathrm{~W} \cdot \mathrm{m}^{2}$ for BAM TQ62L42 and BAM TQ126L42, respectively (see also supplementary Figure S1 panels a to d for the bias and root mean squared error (RMSE) spatial patterns). The model is able to detect the reduced OLR values around the equator associated with the large atmospheric water vapor concentration in the Intertropical Convergence Zone (ITCZ) region, which absorbs more OLR than the drier high-latitude atmosphere. The model is also able to produce two maximum OLR values around $25^{\circ} \mathrm{S}$ and $25^{\circ} \mathrm{N}$ near the subtropical high-pressure systems and desert regions. As temperatures over these high pressure systems and desert regions are higher than over extratropical regions, OLR also tends to be higher in these regions than over extratropical regions.

Panels e) to h) of Figure 1 show similar figures to panels a) to d), but for the global climatological annual mean TOA outgoing shortwave radiation (OSR) under clear sky conditions. While OLR can identify the amount of energy absorbed by the atmosphere and re-emitted at its own temperature at the top of the atmosphere, OSR can identify the amount of energy reflected back to space at the TOA. Comparing panels f) and g) with panel e) shows that OSR under clear sky conditions is generally well represented by the model, except in polar regions where OSR is underestimated due to polar continental surface and sea 
mismatches between CERES and BAM zonal mean OSR occur over polar regions, leading to a negative bias of $-4.08 \mathrm{~W} \cdot \mathrm{m}^{2}$ in both BAM TQ62L42 and BAM TQ126L42. The model simulated global mean OSR values were $49.72 \mathrm{~W} \cdot \mathrm{m}^{2}$ for BAM TQ62L42 and $49.71 \mathrm{~W} \cdot \mathrm{m}^{2}$ for BAM TQ126L42 while the reference (CERES) value was $53.78 \mathrm{~W} . \mathrm{m}^{2}$ (see also supplementary Figure S1 panels e to $\mathrm{h}$ for the bias and RMSE spatial patterns).

Panels i) to p) of Figure 1 show similar figures to panels a) to h), but for global climatological annual panels j) and k) with panel i) for OLR and of panels $n$ ) and o) with panel $\mathrm{m}$ ) for OSR reveals that the model climatological mean spatial patterns resemble CERES patterns, but with clear biases (see also supplementary Figure S1 panels i to $\mathrm{p}$ for the bias and RMSE spatial patterns). The model overestimates global mean cloudy sky OLR, with values of $255.12 \mathrm{~W} . \mathrm{m}^{2}$ for BAM TQ62L42 and $258.05 \mathrm{~W} . \mathrm{m}^{2}$ for BAM TQ126L42, while the reference (CERES) value was $240.28 \mathrm{~W} . \mathrm{m}^{2}$. This OLR overestimation is also illustrated in panel 1), which shows the zonal mean values with a mean bias of $14.86 \mathrm{~W} . \mathrm{m}^{2}$ for BAM TQ62L42 and $17.80 \mathrm{~W} . \mathrm{m}^{2}$ for BAM TQ126L42. Note that both simulated and CERES values of OLR under cloudy conditions are smaller than the clear sky OLR values reported in the previous paragraph. Such a reduction in OLR is due to the fact that clouds in the atmosphere absorb longwave radiation emitted by the surface and lower atmospheric layers, and emit longwave radiation at lower temperatures to the TOA. The model underestimates global mean OSR values under cloudy conditions, with values of 82.11 W.m ${ }^{2}$ for BAM TQ62L42 and 80.02 W.m² for BAM TQ126L42, while the reference (CERES) value was $99.12 \mathrm{~W} . \mathrm{m}^{2}$. This OSR underestimation feature is also illustrated in panel $\mathrm{p}$ ), which shows the zonal mean values with a mean negative bias of $-17.08 \mathrm{~W} . \mathrm{m}^{2}$ for BAM TQ62L42 and $-19.15 \mathrm{~W} . \mathrm{m}^{2}$ for BAM TQ126L42. Note also that both simulated and CERES cloudy-sky OSR values are larger than clearsky OSR values reported in the previous paragraph. Such an increase in OSR is due to the fact that clouds in the atmosphere reflect shortwave radiation at the top of the atmosphere much more than the atmosphere under clear sky conditions. Overall, the model in both spatial resolutions is able to detect the maximum and minimum values of OLR and OSR at the TOA but overestimates OLR (due to having an atmosphere unable to absorb enough longwave radiation) and underestimates OSR (due to having an atmosphere unable to reflect enough shortwave radiation). In other words, the model atmosphere is more transparent than the observations, leading to misrepresentation of cloud radiation interactions. Note that the largest differences between both simulated and observed OLR and OSC are noticed over regions where stratocumulus clouds are usually observed (over the oceans to the west of the continents). This is a problem previously identified in other models (e.g., Brient et al., 2019 and references therein) and will be further diagnosed when discussing Figure 2. The model OLR overestimation over the Amazon and Indonesia regions is related to underestimation of convective clouds, a feature also noticed in BAM version 0.0 (Cavalcanti et al. 2020).

Panel a) of Figure 2 shows the global climatological (2001-2016) annual mean TOA longwave cloud radiative forcing (LWCRF) derived from satellite (CERES), and panels b) and c) show the corresponding LWCRF simulated by BAM TQ62L42 $(\sim 180 \mathrm{~km})$ and BAM TQ126L42 $(\sim 100 \mathrm{~km})$. The LWCRF is defined as the difference between OLR under clear sky (first row in Figure 1) and OLR under cloudy (third row in Figure 1) conditions. The LWCRF assesses the impact of clouds on longwave radiation at the TOA. The observed LWCRF (panel a) is positive; it represents the atmospheric warming effect from clouds that absorb longwave radiation. The model (panels $b$ and c) underestimates global mean LWCRF by more than a factor of two, with values of $12.11 \mathrm{~W} . \mathrm{m}^{2}$ for BAM TQ62L42 and $11.40 \mathrm{~W} . \mathrm{m}^{2}$ for BAM TQ126L42 compared with the reference (CERES) value of $25.84 \mathrm{~W} . \mathrm{m}^{2}$ (see also supplementary Figure S2 panels a to $d$ for the bias and RMSE spatial patterns). Such an underestimation in LWCRF is further illustrated in the zonal means shown in panel d) and is due to the model atmosphere having reduced capability to absorb longwave radiation than the real world atmosphere, as discussed in the previous paragraph. Misrepresentation of cloud radiation interactions in the model led to the mean LWCRF bias of $-13.63 \mathrm{~W} \cdot \mathrm{m}^{2}$ for BAM TQ62L42 and of $-14.43 \mathrm{~W} . \mathrm{m}^{2}$ for BAM TQ126L42, indicating that LWCRF is weaker in the model than observed. 
Panel e) in Figure 2 shows the global climatological annual mean TOA shortwave cloud radiative forcing (SWCRF) derived from satellite (CERES), and in panels b) and c) the corresponding SWCRF simulated by BAM TQ62L42 $(\sim 180 \mathrm{~km})$ and BAM TQ126L42 $(\sim 100 \mathrm{~km})$. The SWCRF is defined as the difference between OSR under clear sky (second row in Figure 1) and OSR under cloudy (fourth row in Figure 1) conditions. The SWCRF assesses the impact of clouds on shortwave radiation at the TOA. The global mean SWCRF is negative; it represents the atmospheric cooling effect from cloud-reflected shortwave radiation. The model (panels $\mathrm{f}$ and $\mathrm{g}$ ) overestimates the observed (panel e) SWCRF. Global mean SWCRF values were $-32.39 \mathrm{~W} . \mathrm{m}^{2}$ for BAM TQ62L42 and $-30.31 \mathrm{~W} \cdot \mathrm{m}^{2}$ for BAM TQ126L42, while the reference (CERES) value was $-45.34 \mathrm{~W} . \mathrm{m}^{2}$ (see also supplementary Figure S2 panels e to $\mathrm{h}$ for the bias and RMSE spatial patterns). Such an overestimation in SWCRF is further illustrated in the zonal means shown in panel $\mathrm{h}$ ); it is due to the model atmosphere being too transparent to shortwave radiation, as discussed earlier. Misrepresentation of cloud radiation interactions in the model led to the mean SWCRF bias of $13.00 \mathrm{~W} . \mathrm{m}^{2}$ for BAM TQ62L42 and of $15.07 \mathrm{~W} . \mathrm{m}^{2}$ for BAM TQ126L42, indicating that SWCRF is weaker in the model than observed.

Panel i) in Figure 2 shows the global climatological annual mean TOA net cloud radiative forcing (NETCRF) derived from satellite (CERES), and in panels $\mathrm{j}$ ) and $\mathrm{k}$ ) the corresponding NETCRF simulated by BAM TQ62L42 $(\sim 180 \mathrm{~km})$ and BAM TQ126L42 $(\sim 100 \mathrm{~km})$. The NETCRF is defined as the sum of LWCRF (first row in Figure 2) and SWCRF (second row in Figure 2). The NETCRF assesses the net impact of clouds on both longwave and shortwave radiation at the TOA. The global mean NETCRF is negative, representing the net cooling effect from clouds. The NETCRF is reasonably well represented by the model (panels $\mathrm{j}$ and $\mathrm{k}$ ) when compared to the CERES (panel i), even though some biases are apparent. The global mean NETCRF values were $-20.18 \mathrm{~W} \cdot \mathrm{m}^{2}$ for BAM TQ62L42 and $-18.91 \mathrm{~W} . \mathrm{m}^{2}$ for BAM TQ126L42 while the reference (CERES) value was $-19.51 \mathrm{~W} . \mathrm{m}^{2}$. This leads to NETCRF biases of -0.63 $\mathrm{W} . \mathrm{m}^{2}$ for BAM TQ62L42 and $0.64 \mathrm{~W} . \mathrm{m}^{2}$ for BAM TQ126L42 (pane 1), which are much smaller compared to LWCRF (panel d) and SWCRF (panel h) biases. These small biases in NETCRF are due to the compensation between the weaker LWCRF and SWCRF discussed in the previous two paragraphs. Panel 1) also illustrates larger negative NETCRF biases over polar regions compared to other regions.

Panel $\mathrm{m}$ ) of Figure 2 shows the global climatological annual mean low cloud fraction from ISCCP. To illustrate the misrepresentation of cloud-radiation interactions in BAM, panels $n$ ) and o) of Figure 2 show NETCRF biases for BAM TQ62L42 and BAM TQ126L42, respectively, computed as the difference between the simulated NETCRF maps of panels $j$ ) and $k$ ) and the CERES NETCRF map of panel i). The largest positive NETCRF biases are found over oceanic regions near the western coast of North and South America, Africa and Oceania. These oceanic regions are characterized by low cloud (Brient et al. 2019). The comparison of panels $\mathrm{n}$ ) and o) with panel $\mathrm{m}$ ) shows a remarkable coincidence of regions with large positive NETCRF biases and high fraction of low clouds over ocean regions near the western coasts. This suggests that much of the identified NETCRF biases are likely related to misrepresentation of low marine clouds in the model. Panel p) shows the NETCRF bias difference between BAM TQ126L42 and BAM TQ62L42 (i.e., the difference between the map shown in panel o and the map shown in panel $n$ ). The positive values in the tropics shown in panel $\mathrm{p}$ ) indicate regions where the higher resolution model version (panel o) has smaller biases than the lower resolution (panel $n$ ). These final three panels of Figure 2 reveal that increasing the model spatial resolution reduces the negative NETCRF bias identified over the eastern tropical Indian Ocean, the Maritime Continent, and the South Pacific and South Atlantic Convergence Zones.

Figure 3 shows in panel a) the vertical climatological (1981-2010) annual zonal mean temperature profiles (isolines) from 1000 to $10 \mathrm{hPa}$ (in ${ }^{\circ} \mathrm{C}$ ) derived from ERA-5 reanalysis, and in panels b) and c) the corresponding profiles simulated by BAM TQ62L42 $(\sim 180 \mathrm{~km})$ and BAM TQ126L42 $(\sim 100 \mathrm{~km})$. The model (panels b and c) represents well the observed (panel a) zonal mean temperature vertical structure, including meridional and vertical temperature gradients, as well as the temperature minima near the equator around $100 \mathrm{hPa}$. The shading in panels $\mathrm{b}$ and $\mathrm{c}$ highlights warm biases at around $100 \mathrm{hPa}$ near the Equator, due mainly to ultra-violet (UV) radiation absorption by ozone in the low stratosphere, which is 
overestimated in the model (not shown). As the model atmosphere is too transparent to longwave radiation, this allows more energy to be absorbed by stratospheric ozone and warm the high-level atmosphere (around $100 \mathrm{hPa}$ ). However, at the top of the stratosphere ozone is underestimated by the model (not shown), leading to cold biases likely due to the model top atmosphere being unable to absorb enough longwave radiation emitted by lower atmospheric and cloud layers. These two panels also reveal cold biases in the equatorial mid-troposphere, likely due to misrepresentation of low and middle clouds, which reduces long wave radiation absorption. Panel d) shows the vertical profile of the zonal mean temperature bias difference between BAM TQ126L42 (panel c) and BAM TQ62L42 (panel b), which reveals that increasing spatial resolution increases temperature biases near the top model levels.

\section{Atmospheric circulation seasonal climatological features}

Another important aspect of climate model simulations is to investigate how well models represent atmospheric circulation. This section assesses how well BAM-1.2 simulates atmospheric circulation climatological features on the seasonal scale.

Figure 4 shows low level $(850 \mathrm{hPa})$ circulation climatological (1981-2010) means for austral summer (DJF, first row), autumn (MAM, second row), winter (JJA, third row) and spring (SON, fourth row) derived from ERA-5 (first column), simulated by BAM TQ62L42 ( 180 km, second column), and BAM TQ126L42 ( 100 km, third column). The model (second and third columns) adequately represents the observed lower level climatological circulation features (first column). The comparison of these figure panels shows that the sub-tropical westerlies in the Southern Hemisphere oceans are accordingly represented by the model. The sub-tropical westerlies observed over the Northern Hemisphere Pacific and Atlantic Oceans are also well represented by the model. Equatorial easterly trades are adequately represented by the model, but are stronger than observed, particularly over the Pacific Ocean. The semipermanent anticyclones over the Pacific, Atlantic and Indian Oceans are also well placed by the model. In addition, the model is able to locate the semi-permanent anticyclones over the South Atlantic toward the South American continent during the austral winter and toward the central south Atlantic during the austral summer, as observed. The low level easterlies over the Indian peninsula is also adequately represented during the austral winter, closely resembling the observations. The fourth column of Figure 4 shows the zonal-mean zonal wind from the panels in the first 3 columns. Although the model (blue line for BAM TQ62L42 and red line for BAM TQ126L42) reproduces the observed (black line for ERA-5) westerly maxima in mid-latitudes and easterly maxima in the tropics, the intensity of these features are generally stronger in the model when compared to the observations. See also supplementary Figure S3 for the low-level $(850 \mathrm{hPa})$ circulation biases.

Figure 5 shows upper level (200 hPa) circulation climatological (1981-2010) means for austral summer (DJF, first row), autumn (MAM, second row), winter (JJA, third row) and spring (SON, fourth row) derived from ERA-5 (first column), simulated by BAM TQ62L42 ( 180 km, second column), and by BAM TQ126L42 $(\sim 100 \mathrm{~km}$, third column). The model (panels in the second and third columns) adequately represents the observed (panels in the first column) upper-level climatological circulation features, including the sub-tropical and polar westerly jets, the anti-cyclone over Bolivia (known as the Bolivian high) during the austral summer (first row) and the associated trough over northeast Brazil and the tropical south Atlantic. During the austral spring (SON, fourth row), however, the model fails to reproduce the initial formation of the Bolivian high and associated trough over northeast Brazil. The anticyclonic circulations over Indonesia and South Africa during austral summer (DJF), as well as the Tibetan and Mexican highs, other typical anticyclonic boreal summer (JJA) circulation features, are well represented by the model.

The fourth column of Figure 5 shows the zonal-mean zonal wind from the panels in the first 3 columns. Although the model (blue line for BAM TQ62L42 and red line for BAM TQ126L42) reproduces the observed jets (black line for ERA-5), including the stronger subtropical jets in the winter hemispheres than the summer hemispheres, there are also some model biases. During DJF (panel d) in the northern hemisphere, the simulated subtropical jet is weaker than observed at both resolutions, while the southern 
hemisphere polar jet is stronger than observed for BAM TQ126L42 but better matches the observations in weaker than observed and the southern hemisphere simulated polar jet is stronger than observed at both resolutions. Meanwhile, the southern hemisphere subtropical jet is slightly weaker than observed for BAM TQ126L42 and matches the observations closely in BAM TQ62L42. During JJA (panel 1), the northern hemisphere model simulated subtropical jet is weaker than observed and the southern hemisphere polar jet is stronger than observed at both resolutions, while the southern hemisphere subtropical jet is slightly weaker than observed for BAM TQ62L42 and matches the observations closely in BAM TQ126L42. During SON (panel p) the northern hemisphere simulated subtropical jet is slightly stronger and displaced northwards when compared to the observations at both resolutions. The southern hemisphere subtropical jet is slightly weaker than observed in BAM TQ62L42 and resembles the observations in BAM TQ126L42, while the southern hemisphere polar jet is slightly stronger than observed for BAM TQ126L42 and matches the observations in BAM TQ62L42. Overall the mean biases shown in the bottom right of the fourth column panels in Figure 5 are similar, suggesting little impact from changing the model horizontal resolution. See also supplementary Figure S4 for the upper level (200 hPa) circulation biases.

Figure 6 shows the vertical profile of climatological (1981-2010) seasonal-mean, zonal-mean zonal wind for austral summer (DJF, first row), autumn (MAM, second row), winter (JJA, third row) and spring (SON, fourth row) derived from ERA-5 reanalysis (first column), simulated by BAM TQ62L42 ( 180 $\mathrm{km}$, second column), and simulated by BAM TQ126L42 ( 100 km, third column). The comparison of the simulated profiles (second and third column) with the observed profile (first column) reveals that the model adequately simulates the main features of the zonal mean wind. This includes the maximum westerlies around $200 \mathrm{hPa}$ (the subtropical jets) in both hemispheres, the high-latitude polar jets above $200 \mathrm{hPa}$ in the winter hemispheres, and the equatorial easterlies above $100 \mathrm{hPa}$. The shading in the second and third column panels illustrate that the model tends to simulate stronger than observed westerly winds around $45^{\circ} \mathrm{S}$ and $45^{\circ} \mathrm{N}$ through most of the troposphere at both resolutions. In other words, around these latitudes the model overestimates the subtropical westerly jets, and in some seasons (e.g. JJA and SON) the northern hemisphere jets are displaced poleward. These central shaded panels also reveal that the equatorial easterlies above $100 \mathrm{hPa}$ are stronger in the model when compared to the observations. The zonal mean bias difference between BAM TQ126L42 (third column) and BAM TQ62L42 (second column) shown in the fourth column highlights that during JJA and DJF the westerly subtropical jets between 400 and $100 \mathrm{hPa}$ are intensified when increasing the model resolution. These fourth column panels also reveal that increasing the model resolution strengthens the equatorial easterlies above $100 \mathrm{hPa}$ and the westerly high-latitude polar jets above $200 \mathrm{hPa}$ in the southern hemisphere in JJA and SON. The stronger equatorial easterlies are also noticeable over a large portion of the equatorial region in JJA and SON when increasing resolution from TQ62L42 to TQ126L42.

\section{Precipitation seasonal climatological features}

Precipitation is a variable of great relevance for the activities of a number of societal sectors (e.g. agriculture, energy production and tourism). Therefore, it is essential to assess how well climate models represent this variable. This section presents an assessment of seasonal precipitation climatological features simulated by BAM-1.2.

Figure 7 shows the climatological (1981-2010) mean accumulated precipitation for austral summer (DJF, first row), autumn (MAM, second row), winter (JJA, third row) and spring (SON, fourth row) derived from GPCP (first column), simulated by BAM TQ62L42 ( 180 km, second column), and BAM TQ126L42 ( 100 km, third column). Despite some biases discussed below and illustrated in Figure 8, the model simulated climatological mean spatial patterns (second and third columns) resemble the observed patterns (first column) for the most relevant features, including: low precipitation over the semipermanent sub-tropical high pressure systems in the Pacific and Atlantic oceans, high precipitation over the South Pacific, South Atlantic and South Indian ocean convergence zones, as well as around the equator over the ITCZ. The zonal mean accumulated precipitation shown in the fourth column for GPCP 
(black line), BAM TQ62L42 (blue line) and BAM TQ126L42 (red line) illustrates that the model, despite some biases, is able to simulate the primary and secondary precipitation maxima around the Equator and in the mid-latitudes, the latter associated with the storm tracks, due to its capability to represent precipitation from the ITCZ and baroclinic weather systems and associated fronts. The global mean accumulated precipitation is larger in the model simulations than observed (see numbers on the bottom left of the first four column panels). The latter numbers reveal that the model run at higher resolution (BAM TQ126L42) has much larger biases than the model run at lower resolution (BAM TQ62L42). The zonal means shown in the fourth column illustrate that much of these biases in BAM TQ126L42 are due to the precipitation overestimation around the equator. Two possible reasons why the higher resolution model version (BAM TQ126L42) has larger precipitation biases than the lower resolution model version (BAM TQ62L42) are: 1) The used time step for running the higher resolution model version (600 s) is half of the time step used for the lower resolution (1200 s). The deep convection scheme is called at each time step, while the shortwave radiation scheme is called every hour and the long wave radiation scheme is called every three hours. This implies that the convection scheme is called more often in the higher resolution model version without the radiative warming/cooling contribution, because of having a shorter time step than the lower resolution model version, which can lead to an imbalance between diabatic heating by convection and radiative cooling. This imbalance can directly affect atmospheric thermodynamics and instability, leading to precipitation impacts. 2) The higher-resolution model version is better able to resolve sub-grid processes at the expense of allowing more intense horizontal gradients and waves interactions across scales. This may generate intense convective precipitation systems, which interact with the atmosphere and again can directly impact atmospheric thermodynamics and instability.

Figure 8 shows the accumulated precipitation mean bias over 1981-2010 for austral summer (DJF, first row), autumn (MAM, second row), winter (JJA, third row) and spring (SON, fourth row), for BAM TQ62L42 ( 180 km, first column) and BAM TQ126L42 ( 100 km, second column). This figure confirms the previous finding that the identified excess precipitation biases are concentrated around the equator, where the positive biases are largest. Large positive biases are found predominantly over the Indian Ocean and western equatorial Pacific in both investigated model resolutions (first and second columns). Along the South Pacific convergence zone biases are positive. Along the South Atlantic convergence zone, and the southwestern South Atlantic, biases are predominantly negative. The model also shows negative biases over the Maritime Continent and eastern Indian Ocean, particularly in DJF, JJA and SON. See also supplementary Figure S5 for the precipitation RMSE. The panels on the third column of Figure 8 show the mean bias differences between the higher resolution BAM TQ126L42 $(\sim 100 \mathrm{~km}$, second column) version and the lower resolution BAM TQ62L42 ( 180 km, first column) version. These panels (third column) illustrate that increasing spatial resolution reduces precipitation biases over the central and eastern Indian Ocean in DJF and MAM, and over most South America and the South Pacific convergence zone in MAM, JJA and SON. However, over other equatorial regions, including northern South America, the eastern equatorial Pacific and the western Indian Ocean, increasing spatial resolution increases precipitation biases. Therefore, depending on the region the impact of increasing spatial resolution is positive (i.e., decreases the bias) or negative (i.e., increases the bias).

Figure 9 shows the standard deviation of accumulated precipitation over the 1981-2010 period for austral summer (DJF, first row), autumn (MAM, second row), winter (JJA, third row) and spring (SON, fourth row), derived from GPCP (first column), and simulated by BAM TQ62L42 ( 180 km, second column) and by BAM TQ126L42 ( 100 km, third column). At both spatial resolutions (second and third columns) the model produces a pattern similar to the observations (first column). Higher variability is observed over the equatorial region and over the South Atlantic and South Pacific convergence zones, and lower variability over the ocean regions where semi-permanent sub-tropical high-pressure systems are located. However, over the regions of higher precipitation variability, the model tends to overestimate the observed variability, particularly over the South Pacific convergence zone (see also supplementary Figure S6 for precipitation standard deviation biases). 


\section{El Niño Southern Oscillation precipitation teleconnections and interannual precipitation variability on the seasonal time scale}

El Niño Southern Oscillation (ENSO) precipitation teleconnections manifest through changes in the equatorial Walker circulation and the propagation of Rossby waves excited by anomalous equatorial heat sources (deep convective activity) associated with SST anomalies in the equatorial Pacific (Wallace and Gutzler, 1981; Karoly, 1989). The Southern Oscillation Index (SOI) is a well known atmospheric index used for diagnosing the sea level pressure seesaw between Tahiti (in the central Pacific) and Darwin (in northern Australia) established during the two phases of ENSO (El Niño and La Niña; Philander, 1985). The SOI is defined as the standardized sea level pressure difference between Tahiti and Darwin. During El Niño events (when equatorial Pacific SSTs are anomalously warm) sea level pressure tends to be lower in the central Pacific and higher in northern Australia, leading to negative SOI values. During La Niña events (when equatorial Pacific SSTs are anomalously cool) sea level pressure tends to be higher in the central Pacific and lower in northern Australia, leading to positive SOI values. These sea level pressure conditions in the equatorial region are associated with changes in the Walker circulation, with anomalous ascent and development of deep convection and precipitation over the regions of lower sea level pressure, and subsidence and absence of clouds and precipitation over the regions where sea level pressure is higher (Philander, 1990). Analysing the relationship between SOI and global precipitation in this section allows identifying so-called ENSO precipitation teleconnections, which are typical conditions associated with El Niño and La Niña events in the equatorial Pacific.

Figure 10 shows the correlation between the SOI and precipitation anomalies over the 1981-2010 period for austral summer (DJF, first row), autumn (MAM, second row), winter (JJA, third row) and spring (SON, fourth row), derived from observations (NOAA SOI and GPCP, first column) and simulated by BAM TQ62L42 ( 180 km, second column) and by BAM TQ126L42 $(\sim 100 \mathrm{~km}$, third column). The positive correlations in the observed patterns (first column) reveal consistency between El Niño (negative SOI) and precipitation deficits over the Maritime Continent, northern Australia and northeast Brazil. The negative correlations shown in the observed patterns (first column) reveal consistency between El Niño and excess precipitation over the equatorial Pacific and southeastern South America. During La Ninã (positive SOI) these correlations translate into opposite precipitation conditions over these regions. In other words, La Niña is usually consistent with precipitation excess over the Maritime Continent, northern Australia and northeast Brazil, and precipitation deficit over the equatorial Pacific and southeastern South America. Although individual El Niño and La Niña events may produce differences in the sign, location and magnitude of precipitation anomalies, these are examples of precipitation patterns typically manifested through well-documented global ENSO teleconnections (Ropelewski and Halpert, 1987, 1989). The panels on the second and third columns show that ENSO precipitation teleconnections are adequately represented by the model at both spatial resolutions, as most of the correlations described above resemble those in observations (first column). Increasing the spatial resolution from BAM TQ62L42 to BAM TQ126L42 slightly improves the representation of ENSO-precipitation teleconnections. This is illustrated by the slight increase in pattern correlation values between the simulated patterns (second and third columns) and the observed pattern (first column) shown in the bottom left of each figure panel. Although most tropical teleconnection features are reasonably well represented by the model, there are still missing or weak features requiring better representation in the model, such as the negative correlations over the Great Horn of Africa in DJF, and the positive correlations over southern Africa in MAM.

Another important aspect to be evaluated in climate models is how well they represent the year-to-year (inter-annual) precipitation variability. Figure 11 shows the correlation between observed precipitation anomalies (GPCP) and simulated precipitation anomalies by BAM TQ62L42 ( 180 km, first column) and BAM TQ126L42 ( 100 km, second column), over the 1981-2010 period for austral summer (DJF, first row), autumn (MAM, second row), winter (JJA, third row) and spring (SON, fourth row). This analysis measures the strength of linear association between the simulated and observed seasonal precipitation anomalies. The mean biases for each season are removed when computing anomalies (i.e. when 
subtracting the model simulated seasonal precipitation for each of the 30 seasons analyzed from the correlation analysis measures how well the model simulates seasonal precipitation anomalies compared to the observed seasonal precipitation anomalies, which, if the model turns out to be well-calibrated, should both oscillate in the same direction (i.e. at each grid point positive anomalies simulated when positive anomalies are observed and negative anomalies simulated when negative anomalies are observed). These figures show that the model simulated precipitation anomalies have a strong linear association (indicated by large positive correlation values) over tropical regions, mainly due to the model's ability to represent ENSO teleconnections as illustrated in Figure 10. Note that the tropical regions over the Pacific, South America and the Maritime Continent, where correlations are large and positive in Figure 11, coincide with the regions in Figure 10 where ENSO teleconnections manifest. Increasing spatial resolution from BAM TQ62L42 to BAM TQ126L42 does not substantially change the tropical mean and global mean correlations shown at the bottom left of the figure panels in the first and second columns of Figure 11. Looking at the difference between the correlation maps for the higher and lower resolution model versions, one can have an idea about where the increase in resolution can help improve the representation of this year-to-year (interannual) precipitation variability. We have tested if these correlation differences are statistically significant at the $10 \%$ level, using a bootstrap resampling procedure with replacement. For performing this test, the correlation maps for both model resolutions were recomputed 1000 times, and checked if the $90 \%$ confidence intervals of these 1000 correlation samples for each model resolution overlapped or not. Non-overlapping grid-points are showed in colors in Figure 11 (third column), indicating regions where the differences in correlations are statistically significant at the $10 \%$ level. The positive correlation differences between BAM TQ126L42 (second column) and BAM TQ62L42 (first column) shown in yellow, orange and red in the third column are limited to small regions illustrating that the increase in spatial resolution has little impact in improving the representation of precipitation interannual variability.

\section{Madden and Julian Oscillation and daily precipitation climatological characteristics}

The previous sections presented an assessment of BAM for reproducing annual and seasonal mean climatological features. In this section, we use higher frequency (daily) data to first assess the model's ability to simulate the climatological features (i.e. the typical patterns during the phases) of an intraseasonal phenomenon (the MJO) based on daily OLR and daily $200 \mathrm{hPa}$ and $850 \mathrm{hPa}$ zonal wind. The MJO is characterized by the eastward equatorial propagation of tropical convection from the Indian Ocean towards the Pacific, taking about 40 to 50 days to complete a full cycle around the world (Madden and Julian, 1972). Next we assess model representation of daily precipitation climatological characteristics, including frequency, persistence, intermittency, size and orientation of rainfall features over southeastern South America.

Figure 12 shows the MJO life cycle composite represented by the mean anomalies of OLR (shading) and the zonal wind at $200 \mathrm{hPa}$ (contours) using all days during November to April 1981-2010 when the MJO was in phases 1 to 8 (as defined by Wheeler and Hendon, 2004), derived from observations (NOAA OLR and ERA-5 $200 \mathrm{hPa}$ zonal wind, first column) and simulated by BAM TQ62L42 (second column) and BAM TQ126L42 (third column). MJO phases for both observations and model simulations were computed using the diagnostics package described in Waliser et al. (2009). This diagnostics package performs combined empirical orthogonal function analyses for determining the MJO phases by combining zonal winds (at $850 \mathrm{hPa}$ and $200 \mathrm{hPa}$ ) with OLR averaged between $15^{\circ} \mathrm{S}$ and $15^{\circ} \mathrm{N}$. The model (second and third panels) reasonably represents the observed (first panel) MJO propagation from the tropical Indian Ocean towards the western equatorial Pacific. The phenomenon is depicted by negative OLR anomalies (representing anomalous convective activity) moving east from phases 2 to 8 from the tropical Indian Ocean towards the western equatorial Pacific. However, the model at both spatial resolutions (second and third panels) simulates weaker anomalous convection than observed (first panel). In order to be able to visualize the spatial structure of anomalous convection in BAM, in Figure 12 the colour scale for the model simulations is different from the colour scale for the observations. This optimised data visualization was also used in Figure 12 of Kodama et al. (2015) and in Figure 5 of Liu et al. (2017) when examining similar MJO features in other models. Increasing resolution improves the amplitude of anomalous convection associated with the MJO, but the simulated convection remains 
weaker than observed. BAM TQ62L42 (second column) also shows a faster eastward propagation of the anomalous convection from the Indian Ocean to the western equatorial Pacific from phase 4 to 5 than observed (first column). Increasing spatial resolution from BAM TQ62L42 (second column) to (BAM TQ126L42, third column) reduces this phase speed bias and also strengthens the anomalous convection, which was too weak in BAM TQ62L42, leading to an improved representation of the MJO life cycle. However, increasing spatial resolution reversed the anomalous convection signal over Brazil in phases 3 , 4 and 7 of the MJO. The upper level $(200 \mathrm{hPa})$ zonal winds are adequately represented in the model (second and third panels) when compared to the observations (first panel) through the MJO phases, consistently showing easterly wind anomalies to the east of the maximum equatorial negative OLR anomaly and westerly wind anomalies to the west of this maximum. This accordingly represents the upper level circulation divergence associated with the deep MJO convective activity eastward propagation. The model is also able to represent the upper-level convergence with easterly wind anomalies to the east and westerly wind anomalies to the west of the maximum equatorial positive OLR anomaly, where a lack of convection and subsidence prevail.

To analyze daily precipitation features, and following Klingaman et al. (2017) and Martin et al. (2017), Figure 13 (panels a to d) shows joint (two-dimensional, 2-D) probability density functions (colors) of binned values of daily precipitation at the same grid point on consecutive days, and one dimensional (1D) probability density function (dashed line) of daily precipitation, aggregated over all grid points within southeast South America $\left(15-40^{\circ} \mathrm{S}, 60-35^{\circ} \mathrm{W}\right)$ for the period 1998-2017, derived from TRMM (first column) and simulated by BAM (second right column). To compare TRMM with BAM, TRMM precipitation was interpolated to the same horizontal resolutions as BAM (TQ62, 180 km, first row, and TQ126, $100 \mathrm{~km}$, second row). This region of South America, which includes large portions of Brazil and Paraguay, northeast Argentina and Uruguay was selected because of its economic importance in terms of food and energy production; it also has a large population heavily affected by daily precipitation events. Besides, this is one of the world's most active regions in terms of mesoscale convective activity (Velasco and Fritsch, 1987).

High probability values along the diagonal in panels a) to d) of Figure 13 suggest persistent precipitation rates on consecutive days at the same grid point. The comparison of panels b) and d) with panels a) and c), respectively, reveals that the model simulated daily precipitation is more persistent than observed by TRMM, particularly for low to moderate rain rates ( $<20 \mathrm{~mm} /$ day). The 1-D probability density function (dashed lines) of daily precipitation in panels b) and d), when compared to those shown in panels a) and c), show that the model overestimates light precipitation $(<20 \mathrm{~mm} /$ day $)$ and underestimates heavy precipitation $(>20 \mathrm{~mm} /$ day). This comparison also reveals that increasing spatial resolution from BAM TQ62L42 $(\sim 180 \mathrm{~km})$ to BAM TQ126L42 $(\sim 100 \mathrm{~km})$ produces slightly more frequent heavy precipitation, events, but still not as many events as observed by TRMM at the same resolution. High probabilities in the lower right and upper left corners of panels a) to d) suggest intermittent precipitation at a grid point. In other words, high probabilities in the lower right corner indicate that days of moderate or heavy precipitation are frequently followed by days of light or no precipitation, while high probabilities in the upper left indicate that light or no precipitation is frequently followed by moderate or heavy precipitation. Panels b) and d) show that the model simulated precipitation is similarly intermittent to the observations (panels a and c) up to $60 \mathrm{~mm} /$ day, but for heavier than $60 \mathrm{~mm} /$ day the model becomes less intermittent (more persistent) than TRMM. This is related to the underestimation of heavy precipitation in the model when compared to the observations, as discussed above.

As described in Klingaman et al. (2017) and Martin et al. (2017), Figure 13 (panels e to h) shows instantaneous (lag-0) correlations computed over non-overlapping 7 × 7 grid point sub-regions within the southeast South America region $\left(15-40^{\circ} \mathrm{S}, 60-35^{\circ} \mathrm{W}\right)$. Within each sub-region, the daily gridded precipitation (1998-2017) time series at each point is correlated against the time series at the central grid point $(0,0)$. The plots shown in panels e) to $h$ ) are correlations averaged over the sub-regions. These four panels show this diagnostic for TRMM (first column) and for the mean of all four BAM ensemble members (second column). For the lower spatial resolution ( $180 \mathrm{~km}$; panels e and f) these figures contain the mean of four $7 \times 7$ grid point sub-regions within the southeast South America region. For the higher spatial resolution ( $100 \mathrm{~km}$; panels $\mathrm{g}$ and $\mathrm{h}$ ) these figures contain the mean of nine $7 \times 7$ grid point 
sub-regions within the southeast South America region. These four panels illustrate the typical size and orientation of daily precipitation features as observed by TRMM and simulated by BAM. Panels $f$ ) and $h$ ) show that precipitation features in BAM are oriented preferentially in the southeast to northwest direction as in TRMM (panels e and g). These panels also reveal that precipitation features in BAM are larger than those in TRMM. Increasing spatial resolution from BAM TQ62L42 $(\sim 180 \mathrm{~km})$ to BAM TQ126L42 $(\sim 100$ $\mathrm{km})$ reduces this size bias, but BAM precipitation features (panel h) are still slightly larger than those in TRMM (panel g), and the orientation is again consistent with TRMM.

In order to provide a global assessment supplementary Figures S7 and S8 show results of the same analysis performed for southeastern South America (Figure 13) to other five same-sized (25 degrees in longitude by 25 degrees in latitude) and climatologically similar regions (Southern Australia $\left[45-20^{\circ} \mathrm{S}\right.$, $\left.110-135^{\circ} \mathrm{E}\right]$, Southern Africa $\left[35-10^{\circ} \mathrm{S}, 15-40^{\circ} \mathrm{E}\right]$, Eastern Asia $\left[20-45^{\circ} \mathrm{N}, 105-130^{\circ} \mathrm{E}\right]$, Southern Europe $\left[20-45^{\circ} \mathrm{N}, 5^{\circ} \mathrm{W}-20^{\circ} \mathrm{E}\right]$ and Southeast North America $\left.\left[20-45^{\circ} \mathrm{N}, 100-75^{\circ} \mathrm{W}\right]\right)$. Consistent results with those described above for Figure 13 were found for all these regions, suggesting systematic biases in the model representation of daily precipitation features.

\section{Summary and conclusions}

This study evaluated the performance of CPTEC model (BAM-1.2) when producing AMIP-type climate simulations at two spatial resolutions corresponding to around 180 and $100 \mathrm{~km}$, both with 42 vertical levels. Such simulations performed under observed boundary conditions (i.e. using observed SSTs when running the model) provided a valuable framework for addressing the questions raised in the introductory section, and also helped to identify area for model improvement. The main findings and conclusions are summarized below.

At both spatial resolutions, BAM-1.2 reproduced well the observed vertical profile of the zonal annual mean temperature, the seasonal mean atmospheric circulation and main climatological features of precipitation, although some biases were identified, particularly in top of the atmosphere radiation. Both OLR and OSR climatological features under clear sky conditions were adequately represented, indicating that radiation interactions with atmospheric gases were well represented. The OSR assessment under clear sky conditions also revealed that polar continental surface and sea ice albedo are misrepresented. Under cloudy conditions, the model at both spatial resolutions overestimated OLR and underestimated OSR. These deficiencies were attributed to a simulated atmosphere that was too transparent to longwave and shortwave radiation under cloudy conditions, which led to a misrepresentation of cloud-radiation interactions. Both LWCRF and SWCRF were found to be weaker in the model than in the observations. This led to a weaker TOA warming effect in the global mean climate, due to the model having a less absorptive atmosphere, and a weaker TOA cooling effect due to the model atmosphere being less reflective. Nevertheless, the net cloud radiative forcing, which produces the TOA cooling effect in the global mean climate, was well represented by the model at both spatial resolutions, with small global mean biases. This was achieved by a compensation between both weaker LWCRF and SWCRF in the model, leading to an adequate representation of atmospheric circulation and precipitation conditions. The net cloud radiative forcing assessment also revealed that low marine clouds are misrepresented in the model.

El Niño-Southern Oscillation (ENSO) precipitation teleconnections were also found to be well represented by the model, including the typical patterns during El Niño (La Niña) events of excess (deficit) precipitation over the equatorial Pacific and southeast South America and deficient (excess) precipitation over the Maritime Continent, northern Australia and northern South America. Increasing the spatial resolution slightly improved the representation of ENSO precipitation teleconnections. The representation of inter-annual precipitation variability in the model at both spatial resolutions was linked to the ability of the model to represent ENSO atmospheric teleconnections.

Despite some biases in the phase speed propagation, the eastward propagation of the MJO life cycle was adequately simulated by the model. However, the model produced weaker than observed associated 
tropical convective activity (a common feature among climate models), which propagates from the Indian Ocean to the western Pacific during MJO events. Increasing spatial resolution helped to reduce the phase speed bias and also strengthen the MJO convective activity, leading to an improved representation of the life cycle, although simulated convection was still found to be much weaker than observed.

The analysis of daily simulated precipitation over the southeast of South America region revealed that the model tends to overestimate light precipitation and underestimate heavy precipitation. Increasing spatial resolution produced slightly heavier precipitation, but still not as much as observed. Daily precipitation features were found to be larger and last longer in the model simulations than in the observations. Increasing spatial resolution helped to reduce precipitation feature sizes, diminishing the size bias, but the simulated precipitation features at higher resolution were still found to be slightly larger than observed. The dominant spatial orientation of model simulated precipitation features at both spatial resolutions was southeast to northwest, as in observations. Repeating this analysis to other five same-sized and climatologically similar regions to southeastern South America, over Southern Australia, Southern Africa, Eastern Asia, Southern Europe and Southeast North America revealed consistent results to all these regions, suggesting systematic biases in the model representation of daily precipitation features.

Overall, BAM-1.2 simulated adequately most climate aspects here evaluated, despite the identified biases. The performed evaluation identified model aspects that need to be improved. These include the representation of polar continental surface and sea ice albedo, stratospheric ozone, low marine clouds, and daily precipitation features. Improving cloud representation in the model is likely the key aspect needed for addressing the identified transparency bias and associated cloud radiation interactions misrepresentation. Tackling all of the above mentioned aspects in future model versions is expected to produce an improved representation of the global climatological features discussed here.

\section{Acknowledgements}

We thank two anonymous reviewers for providing valuable comments and suggestions that contributed to improving the quality of this manuscript. We thank Bárbara Yamada for the technical support in obtaining part of the observational datasets used in this study. This research was partially supported by the Climate Science for Services Partnership Brazil project (CSSP-Brazil) funded by the Newton Fund. CASC thanks Conselho Nacional de Desenvolvimento Científico e Tecnológico (CNPq), process 305206/2019-2, and Fundação de Amparo à Pesquisa do Estado de São Paulo (FAPESP), process 2015/50687-8 (CLIMAX Project) for the support received. DCS was supported by CNPq (process 167804/2018-9). BSG was supported by CNPq and Coordenação de Aperfeiçoamento de Pessoal de Nível Superior (CAPES). NPK was supported by an Independent Research Fellowship from the UK 
Adler RF, Huffman GJ, Chang A, Ferraro R, Xie P, Janowiak J, Rudolf B, Schneider U, Curtis S, Bolvin D, Gruber A, Susskind J, Arkin P (2003) The Version 2 Global PrecipitationClimatology Project (GPCP) Monthly Precipitation Analysis (1979-Present). J. Hydrometeor., 4,1147-1167.

Bretherton CS, Park S (2009) A new moist turbulence parameterization in the Community Atmosphere Model. Journal of Climate. 22: 3422-48. model using short-term hindcasts. Journal of Advances in Modeling Earth Systems,11, 127-148. https://doi.org/10.1029/2018MS001461

Cavalcanti IFA, Raia A (2017) Lifecycle of South American Monsoon System simulated by https://doi.org/10.1002/joc.5044. CPTEC/COLA AGCM. J. Clim. 15: 2965-2988.

Cavalcanti IFA, Silveira VP, Figueroa SN, Kubota PY, Bonatti JP, Souza DC (2020) Climate variability (BAM-v0). International Journal of Climatology. 40, 5, 2845-2869. https://doi.org/10.1002/joc.6370

Chou MD, Suarez MJ, Liang XZ, Yan MM, Cote C (2001) A thermal infrared radiation parameterization

Chou MD, Suarez, MJ (1999) A solar radiation parameterization (CLIRAD-SW) for atmospheric studies. pp.

Coelho CAS (2013) Comparative skill assessment of consensus and physically based tercile probability seasonal precipitation forecasts for Brazil. Meteorological Applications, 20, 236-245. (2012) Climate diagnostics of three major drought events in the Amazon and illustrations of their seasonal precipitation predictions. Meteorol. Appl. 19: 237-255.

Figueroa SN, Bonatti JP, Kubota PY, Grell GA, Morrison H, Barros SRM, Fernandez JPR, Ramirez E, Siqueira L, Luzia G, Silva J, Silva JR, Pendaharkar J, Capistrano VB, Alvim DS, Enoré DP, Diniz FLR, Satyamurti P, Cavalcanti IFA, Nobre P, Barbosa HMJ, Mendes CL, Panetta J (2016) The Brazilian global atmospheric model (BAM): performance for tropical rainfall forecasting and sensitivity to convective scheme and horizontal resolution. Weather Forecast. 31: 1547-1572.

Gates WL, Boyle J, Covey C, Dease C, Doutriaux C, Drach R, Fiorino M, Gleckler P, Hnilo J, Marlais S, Phillips T, Potter G, Santer B, Sperber K, Taylor K, Williams D (1998) An Overview of the Results of the Atmospheric Model Intercomparison Project (AMIP I ). Bull. Amer. Meteor. Soc., 73, 1962-1970.

Grell G, Devenyi D (2002) A generalized approach to parameterizing convection combining ensemble and data assimilation techniques. Geophys. Res. Lett., 29, doi:10.1029/2002GL015311.

Guimarães B S, Coelho CAS, Woolnough SJ, Kubota PY, Bastarz CF, Bonatti JP, Figueroa SN, de Souza DC (2020) Configuration and hindcast quality assessment of a Brazilian global sub-seasonal prediction system. QJRMS, 146, Issue 728, Part A, 1067-1084. https://doi.org/10.1002/qj.3725. 
Han J, Pan HL (2011) Revision of convection and vertical diffusion schemes in the NCEP global forecast system. Weather and Forecasting. 26: 520-33.

Hersbach H, de Rosnay P, Bell B, Schepers D, Simmons A, Soci C, Abdalla S, Balmaseda MA, Balsamo G, Bechtold P, Berrisford P, Bidlot J, de Boisséson E, Bonavita M, Browne P, Buizza R, Dahlgren P, Dee D, Dragani R, Diamantakis M, Flemming J, Forbes R, Geer A, Haiden T, Hólm E, Haimberger L, Hogan R, Horányi A, Janisková M, Laloyaux P, Lopez P, Muñoz-Sabater J, Peubey C, Radu R, Richardson D, Thépaut J-N, Vitart F, Yang X, Zsótér E, Zuo H (2018) Operational global reanalysis: progress, future directions and synergies with NWP. ERA Report Series, 27. https://www.ecmwf.int/node/18765 Newsletter 159, 17-24. DOI 10.21957/vf291hehd7

Huffman GJ, Adler RF, Bolvin DT, Gu G, Nelkin EJ, Bowman KP, Hong Y, Stocker EF, Wolff DB (2007) The TRMMmulti-satellite precipitation analysis: quasi-global, multiyear, combined-sensor precipitation estimates at fine scale, J. Hydrometeorol., 8, 38-55.

Huffman GJ, Adler RF, Bolvin DT, Nelkin EJ (2010) The TRMM multi-satellite precipitation analysis (TMPA), in: Satellite rainfall applications for surface hydrology, edited by: Hossain, F. and Gebremichael, M., 3-22, Springer Verlag.

Iacono M, Delamere J, Mlawer E, Shephard M, Clough S, Collins W (2008) Radiative forcing by longlived greenhouse gases: Calculations with the AER radiative transfer models. J. Geophys. Res., 113, D13103, doi:10.1029/2008JD009944.

Karoly DJ (1989) Southern Hemisphere circulation features associated with El Niño-Southern Oscillation events. J. Climate, 2, 1239-1252

Klingaman NP, Martin GM, Moise A (2017): ASoP (v1.0): a set of methods for analyzing scales of precipitation in general circulation models. Geosci. Model Dev., 10, 57-83.

Kodama C, Yamada Y, Noda AT, Kikuchi K, Kajikawa Y, Nasuno T, Tomita T, Yamaura T, Takahashi TG, Hara M, Kawatani Y, Satoh M, Sugi M (2015) A 20-year climatology of a NICAM AMIP-type simulation. J. Meteor. Soc. Japan, 93, 393-424, doi:10.2151/jmsj.2015-024.

Kubota PY (2012) Variability of storage energy in the soil-canopy system and its impact on the definition of precipitation standard in South America (in Portuguese with abstract in English). Ph. D. thesis, Instituto Nacional de Pesquisas Espaciais (INPE), São José dos Campos, Brazil.

813 Kummerow C, Barnes W, Kozu T, Shiue J, Simpson J (1998) The Tropical Rainfall Measuring Mission 814 (TRMM) sensor package, J. Atmos. Ocean. Technol., 15, 809-817.

815 Liebmann B, Smith CA (1996) Description of a Complete (Interpolated) Outgoing Longwave Radiation 816 Dataset. Bulletin of the American Meteorological Society, 77, 1275-1277.

817 Liu, X., Wu, T., Yang, S. and co-authors (2017) MJO prediction using the sub-seasonal to seasonal 818 forecast model of Beijing Climate Center. Clim Dyn 48, 3283-3307. https://doi.org/10.1007/s00382-016$819 \quad 3264-7$ 
Madden RA, Julian PR (1972) Description of global-scale circulation cells in the Tropics with a 40-50 day period. J. Atmos. Sci., 29, 1109-1123.

Marengo JA, Cavalcanti IFA, Satyamurty P, Trosnikov I, Nobre CA, Bonatti JP, Camargo H, Sampaio G, Sanches MB, Manzi AO, Castro CAC, D'Almeida C, Pezzi LP, Candido L. (2003) Assessment of regional seasonal rainfall predictability using the CPTEC/COLA atmospheric GCM. Clim. Dyn. 21: 459475 .

Martin GM, Klingaman NP, Moise AF (2017) Connecting spatial and temporal scales of tropical precipitation in observations and the MetUM-GA6.Geosci. Model Dev., 10, 105-126.

Mellor GL, Yamada T (1982) Development of a turbulence closure model for geophysical fluid problems. Rev. Geophys. Space Phys. 20: 851-875

Mizuta R, Yoshimura H, Murakami H, Matsueda M, Endo H, Ose T, Kamiguchi K, Hosaka M, M Sugi, Yukimoto S, Kusunoki S, Kitoh A (2012) Climate Simulations Using MRI-AGCM3.2 with 20-km Grid, Journal of the Meteorological Society of Japan. Ser. II, 2012, Volume 90A, Pages 233258, Released June 07, 2012, Online ISSN 2186-9057, Print ISSN 00261165, https://doi.org/10.2151/jmsj.2012-A12

Morrison G, Curry JA, Khvorostyanov VI (2005) A new double-moment microphysics parameterization for application in cloud and climate models. Part I: Description. J. Atmos. Sci., 62, 1665-1677, doi:https://doi.org/10.1175/JAS3446.1.

Morrison H, Thompson G, Tatarskii V (2009) Impact of cloud microphysics on the development of trailing stratiform precipitation in a simulated squall line: Comparison of one-and two-moment schemes. Monthly weather review. 137: 991-1007.

NMC Development Division Staff (1988) Research version of the medium range forecast model. NMC Documentation Series 1,339 pp. [Available from the Development Division, NCEP, Washington, DC 20233.]

Philander, SGH (1985) El Niño and La Niña. J. Atmos. Sci., 42, 2652-2662.

Philander, SGH (1990) El Niño, La Niña, and the southern oscillation. Princeton University, Princeton, New Jersey. Academic Press, Inc, 291pp

Rio C, Houdin F (2008) A Thermal Plume Model for the Convective Boundary Layer: Representation of Cumulus Clouds. Journal of The Atmospheric Sciences. 65: 407-425.

Ropelewski CF, Halpert MS (1987) Global and regional scale precipitation patterns associated with the El Nino/ Southern Oscillation. Mon. Wea. Rev., 115, 1606-1626.

Ropelewski CF, Halpert MS (1989) Precipitation patterns associated with the high index phase of the Southern Oscillation. J. Climate, 2, 268-284.

Schiffer RA, Rossow WB (1983) The International Satellite Cloud Climatology Project (ISCCP): The first project of the World Climate Research Programme. Bull. Amer. Meteorol. Soc., 64, 779-784.

Souza DC, Kubota PY, Figueroa SN, Gutierrez EMAR, Coelho CAS (2019) Impacto da resolução horizontal na simulação dos jatos de baixos níveis na América do Sul usando o modelo global do CPTEC. Estudos Interdisciplinares nas Ciências Exatas e da Terra e Engenharias 4. E82ed.: Atena Editora, 205217. http://dx.doi.org/10.22533/at.ed.22519110919

Tarasova TA, Fomin BA (2000) Solar radiation absorption due to water vapor: Advanced broadband parameterizations. Journal of Applied Meteorology. 39: 1947-1951. 
Taylor KE, Williamson D, Zwiers F (2000) "The sea surface temperature and sea ice concentration boundary conditions for AMIP II simulations” PCMDI Report 60, Program for Climate Model Diagnosis and Intercomparison, Lawrence Livermore National Laboratory, $25 \mathrm{pp}$

Toh YY, Turner AG, Johnson SJ , Holloway CE (2018). Maritime Continent seasonal climate biases in AMIP experiments of the CMIP5 multimodel ensemble Clim Dyn (2018) Volume 50, Issue 3-4, 777800. https://doi.org/10.1007/s00382-017-3641-x

Uppala SM and Coauthors (2005) The ERA-40 Re-Analysis. Quart. J. Roy. Meteor. Soc., 131, 29613012.

Velasco, I, Fritsch JM (1987) Mesoscale convective com-plexes in the Americas.J. Geophys. Res., 92, 9591-9613.

Yu H, Kaufman YJ, Chin M, Feingold G, Remer LA, Anderson TL, Balkanski Y, Bellouin N, Boucher O, Christopher S, DeCola P, Kahn R, Koch D, Loeb N, Reddy MS, Schulz M, Takemura T, Zhou M (2006) A review of measurement-based assessments of the aerosol direct radiative effect and forcing. Atmos. Chem. Phys. 6: 613-666.

Waliser D, Sperber K, Hendon H, Kim D, Maloney E, Wheeler M, Weickmann K, Zhang C, Donner L, Gottschalck J, Higgins W, Kang I-S, Legler D, Moncrieff N, Schubert S, Stern W, Vitart F, Wang B, Wang W, Woolnough S (2009): MJO Simulation Diagnostics. J. Climate, 22, 3006-3030.

Wallace JM, Gutzler DS (1981) Teleconections in the geopotential height field during the Northern Hemisphere winter. Mon.Wea.Rev., 109, 785-812.

Wheeler MC, Hendon HH (2004) An all-season real-time multivariate MJO index: Development of an index for monitoring and prediction. Mon . Wea . Rev., 132, 1917-1932. 
1 Table 1: Physical processes components of the Brazilian global atmospheric model version 1.2 (BAM-1.2) used

2 for performing the AMIP-type climate simulations to be evaluated in this study.

\section{BAM-1.2 physical processes components}

Microphysics

Land Surface

Morrison et al. (2005, 2009)

Long-wave radiation

IBIS-CPTEC (Kubota, 2012)

Short-wave radiation

CLIRAD-LW (Chou et al., 2001)

CLIRAD-SW (Chou and Soarez, 1999, modified by Tarasova and Fomin, 2000)

Planetary boundary layer

Moist diffusion scheme (Bretherton and Park, 2009)

Deep convection

Aerosol optical depth

Revised simplified Arakawa-Shubert (Han and Pan, 2011)

Yu et al. (2006)

Thermal plume for convective boundary layer Rio and Hourdin (2008)

3

5 Table 2: Summary of observational reference datasets and variables used in this study

\begin{tabular}{|c|c|c|}
\hline Reference dataset & Variables & Reference \\
\hline ERA-5 reanalysis & $\begin{array}{l}\text { Atmospheric } \\
\text { circulation } \\
\text { Temperature } \\
850 \text { and } 200 \mathrm{hPa} \text { zonal } \\
\text { winds }\end{array}$ & (Hersbach et al., 2018, 2019) \\
\hline $\begin{array}{l}\text { The International Satellite } \\
\text { Cloud Climatology Project } \\
\text { (ISCCP) }\end{array}$ & Cloud amount & (Schiffer and Rossow 1983) \\
\hline $\begin{array}{l}\text { The Clouds and the Earth's } \\
\text { Radiant Energy System } \\
\text { (CERES) }\end{array}$ & TOA radiation & (Loeb et al., 2018) \\
\hline $\begin{array}{l}\text { The Global } \text { Precipitation } \\
\text { Climatology } \\
\text { (GPCP) }\end{array}$ & Precipitation & (Adler et al., 2003) \\
\hline $\begin{array}{l}\text { The National Oceanic and } \\
\text { Atmospheric } \\
\text { Administration (NOAA) } \\
\text { Southern Oscillation Index } \\
\text { (SOI) }\end{array}$ & $\begin{array}{l}\text { Southern Oscillation } \\
\text { Index (SOI) } \\
\text { Outgoing Longwave } \\
\text { Raditaion (OLR) }\end{array}$ & https://www.cpc.ncep.noaa.gov/data/indices/soi \\
\hline $\begin{array}{ll}\text { Tropical } & \text { Rainfall } \\
\text { Measuring } & \text { Mission } \\
\text { (TRMM), 3B42 } & \text { product, } \\
\text { version 7A. } & \end{array}$ & Daily precipitation & $\begin{array}{l}\text { (Kummerow et al., 1998; Huffman et al., 2007, } \\
\text { 2010) }\end{array}$ \\
\hline
\end{tabular}

6 

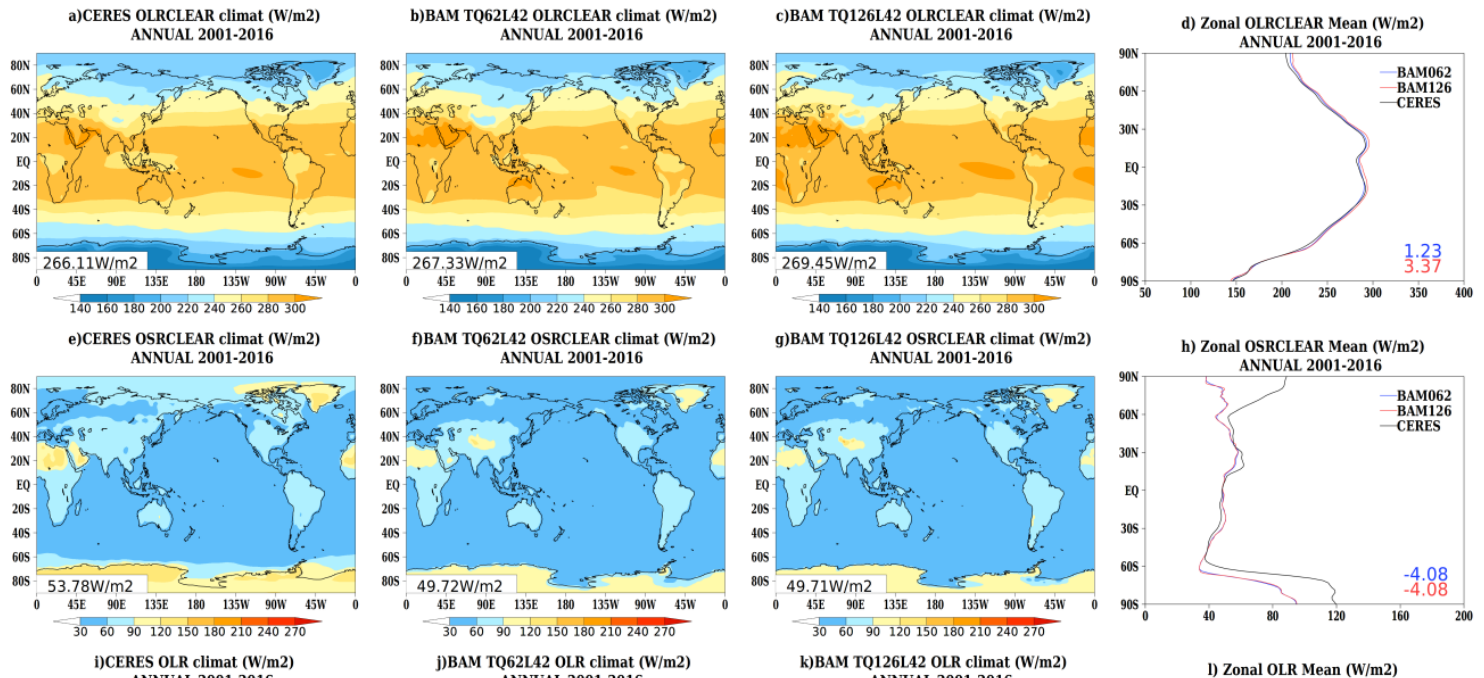

CERES OLR climat $(\mathrm{W} / \mathrm{m} 2)$
ANNUAL 2001-2016
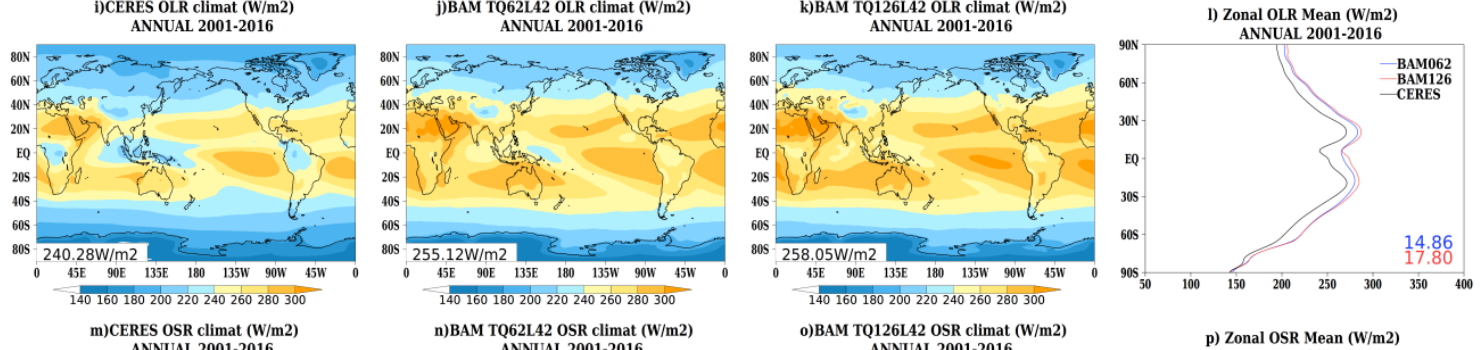

m)CERES OSR climat (W/m
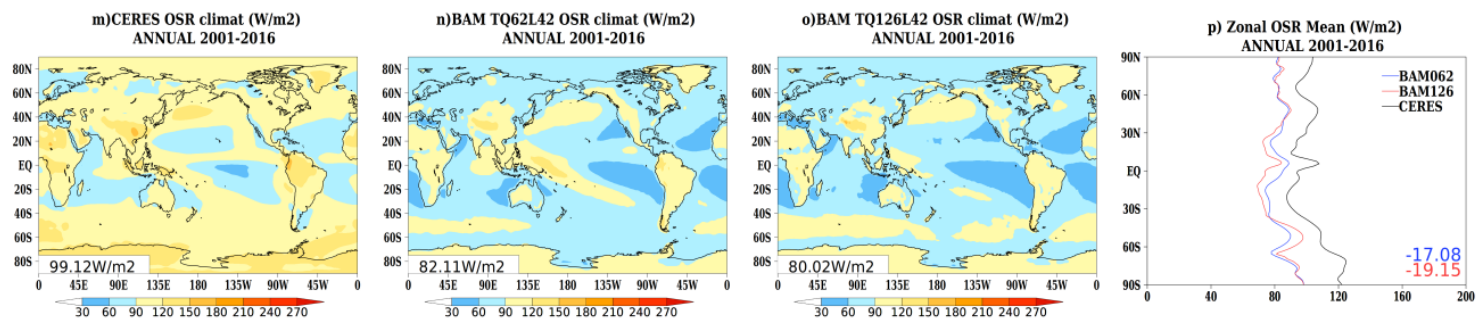

Figure 1: Global climatological (2001-2016) annual mean top of the atmosphere outgoing longwave radiation (OLR) under clear sky conditions a) derived from satellite (CERES, Loeb et al., 2018), b) simulated by BAM TQ62L42 $(\sim 180 \mathrm{~km})$, c) simulated by BAM TQ126L42 $(\sim 100 \mathrm{~km})$, and d) zonal means of values shown in the maps of panels a), b) and c) for CERES (black line), BAM TQ62L42 (blue line), BAM TQ126L42 (red line). BAM results shown in this figure correspond to the ensemble mean of the performed 4-member simulations. Panels e) to $h$ ) are similar to panels a) to d) but for global climatological annual mean top of the atmosphere outgoing shortwave radiation (OSR) under clear sky conditions. Panels i) to l) are similar to panels a) to d) but for global climatological annual mean top of the atmosphere outgoing longwave radiation (OLR) under cloudy conditions. Panels $\mathrm{m}$ ) to $\mathrm{p}$ ) are similar to panels a) to d) but for global climatological annual mean top of the atmosphere outgoing shortwave radiation (OSR) under cloudy conditions. The values shown at the bottom left hand corner of each map displayed in this figure are the global means (i.e. the mean of all values shown in the map). The values shown in the panels on the fourth column figures are the mean biases for BAM TQ62L42 (in blue) and BAM TQ126L42 (in red). Units in all panels are W.m. ${ }^{-2}$. 

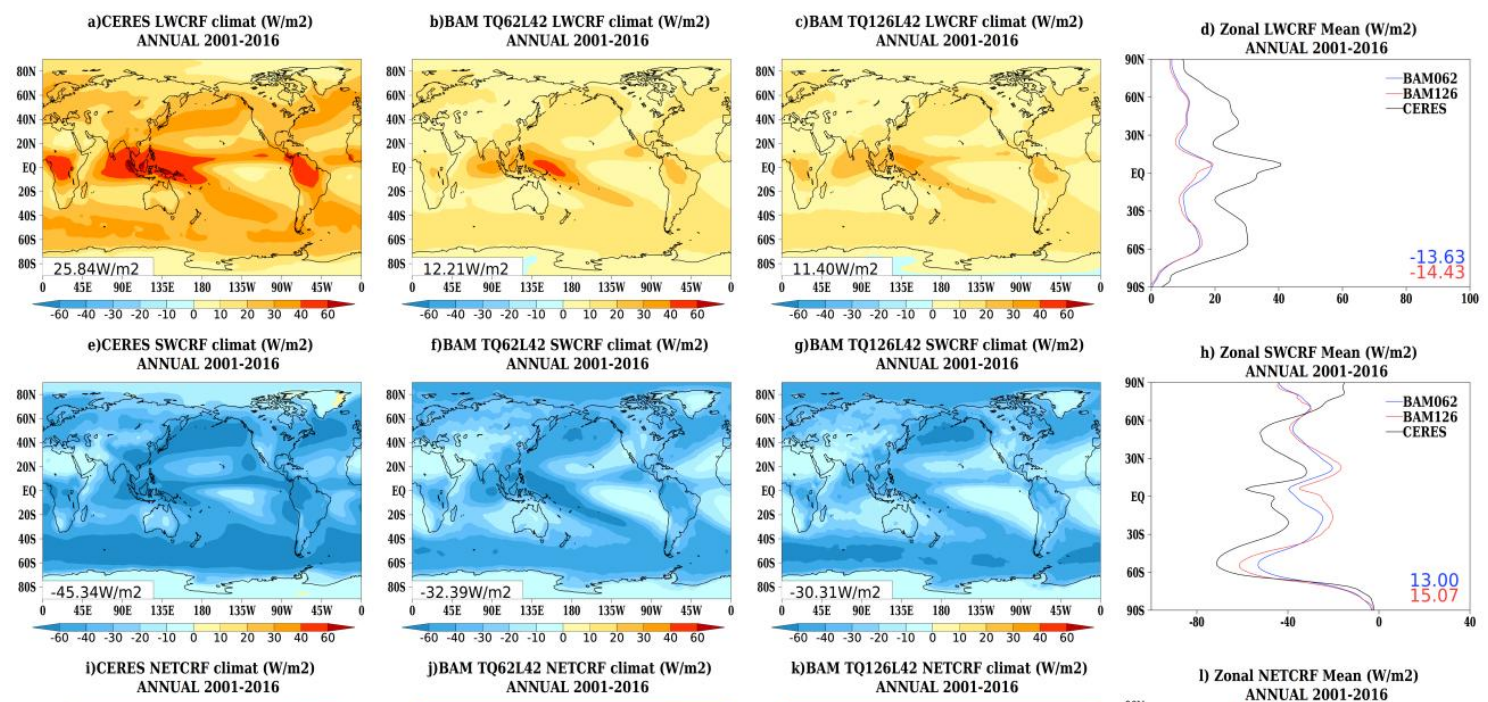

h) Zonal SWCRF Mean (W/m2)
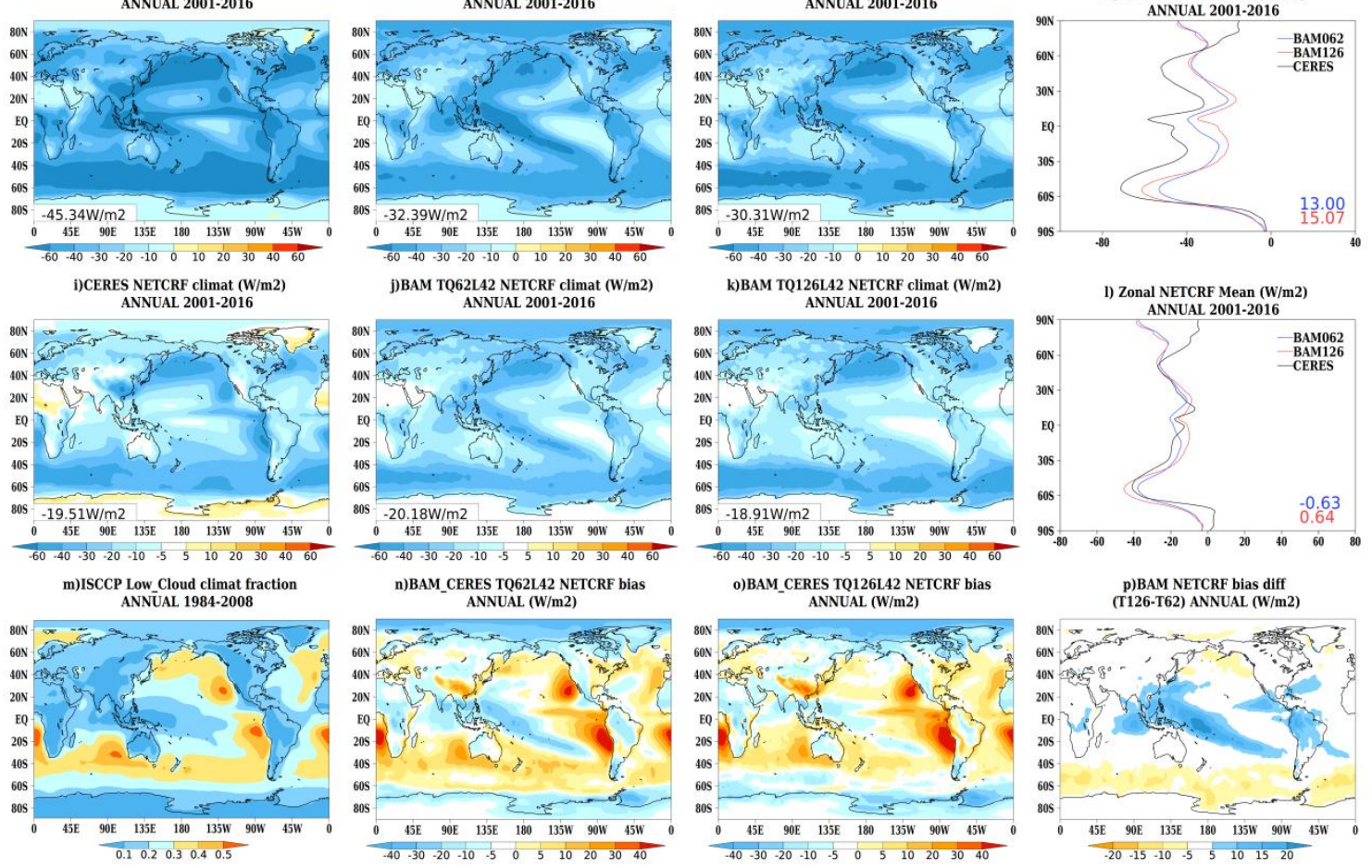

Figure 2: Global climatological (2001-2016) annual mean top of the atmosphere longwave cloud radiative forcing (LWCRF) a) derived from satellite (CERES, Loeb et al., 2018), b) simulated by BAM TQ62L42 $(\sim 180 \mathrm{~km}), \mathrm{c})$ simulated by BAM TQ126L42 $(\sim 100 \mathrm{~km})$, and d) zonal means of values shown in the maps of panels a), b) and c) for CERES (black line), BAM TQ62L42 (blue line), BAM TQ126L42 (red line). BAM results shown in this figure correspond to the ensemble mean of the performed 4-member simulations. Panels e) to h) are similar to panels a) to d) but for global climatological annual mean top of the atmosphere shortwave cloud radiative forcing (SWCRF). Panels i) to l) are similar to panels a) to d) but for global climatological annual mean top of the atmosphere net cloud radiative forcing (NETCRF). Panel $\mathrm{m}$ ) is the global climatological (1984-2008) annual mean low cloud fraction from ISCCP (Schiffer and Rossow 1983). Panels n) and o) are NETCRF biases for BAM TQ62L42 and BAM TQ126L42, respectively. Panel p) is the NETCRF bias difference between BAM TQ126L42 and BAM TQ62L42. The values shown at the bottom left hand corner of maps displayed in this figure are the global means (i.e. the mean of all values shown in the map). The values shown in the panels on the fourth column figures are the mean biases for BAM TQ62L42 (in blue) and BAM TQ126L42 (in red). Units in all panels are W. $\mathrm{m}^{-2}$, except for could fraction in panel $\mathrm{m}$ ) which is expressed in percentage. 


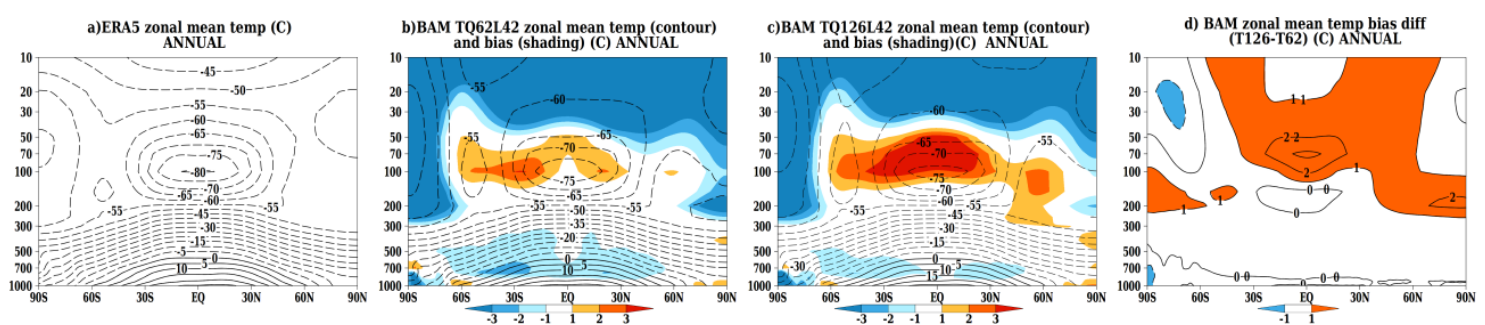

1 Figure 3: Vertical climatological (1981-2010) annual zonal mean temperature profile (isolines) from 1000 2 to $10 \mathrm{hPa}\left(\right.$ in $\left.{ }^{\circ} \mathrm{C}\right)$ a) derived from ERA-5 reanalysis (Hersbach et al., 2018, 2019), b) simulated by BAM 3 TQ62L42 $(\sim 180 \mathrm{~km})$, and c) simulated by BAM TQ126L42 $(\sim 100 \mathrm{~km})$. BAM results shown in this figure 4 correspond to the ensemble mean of the performed 4-member simulations. Shading in panels b) and c) are 5 temperature biases computed as differences between panels b) and c) vertical temperature zonal mean 6 profiles and panel a) vertical temperature zonal mean profile. Panel d) is the vertical profile of the zonal 7 mean temperature bias difference between BAM TQ126L42 (panel c) and BAM TQ62L42 (panel b). 

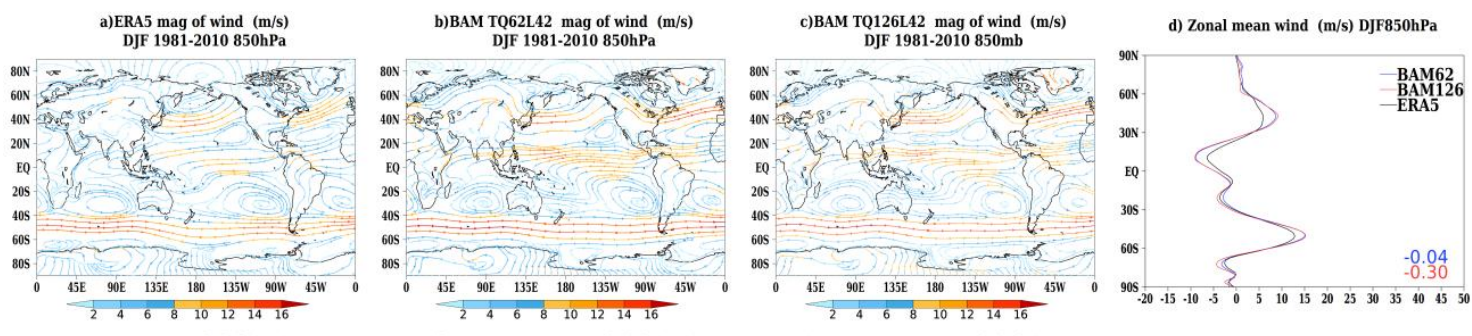

ERA5 mag of wind $(\mathrm{m} / \mathrm{s})$
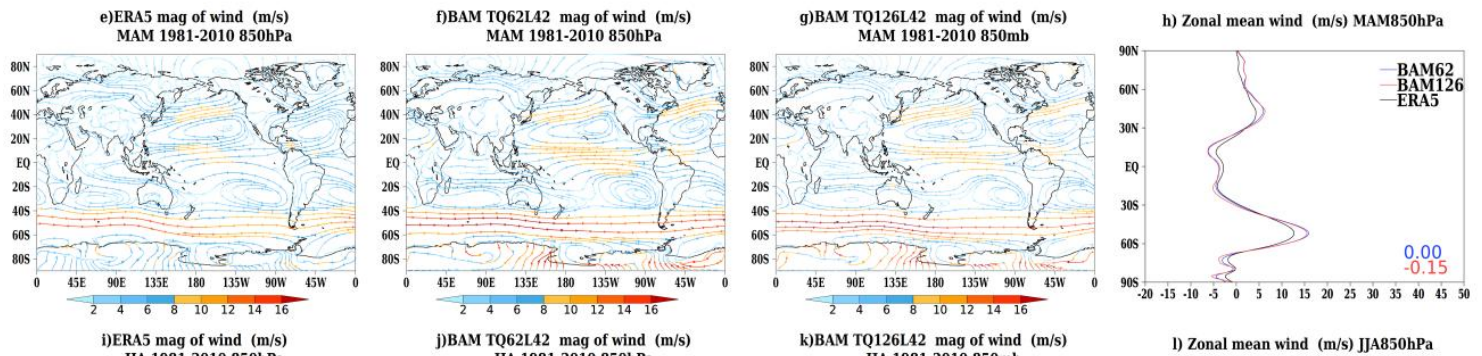

JJA 1981-2010 850hPa
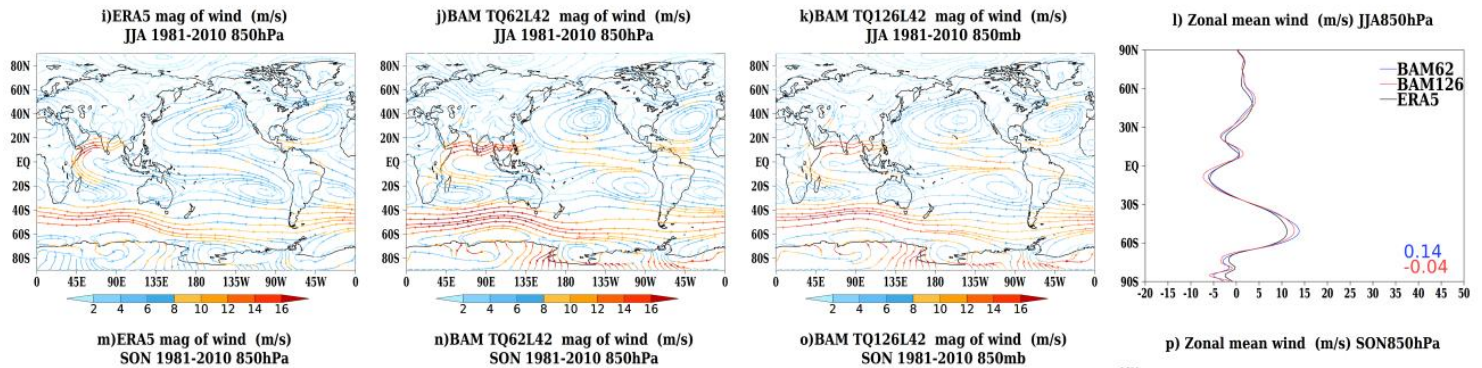

o)BAM TQ126L42 mag of wind $(\mathrm{m} / \mathrm{s})$
SON $1981-2010850 \mathrm{mb}$
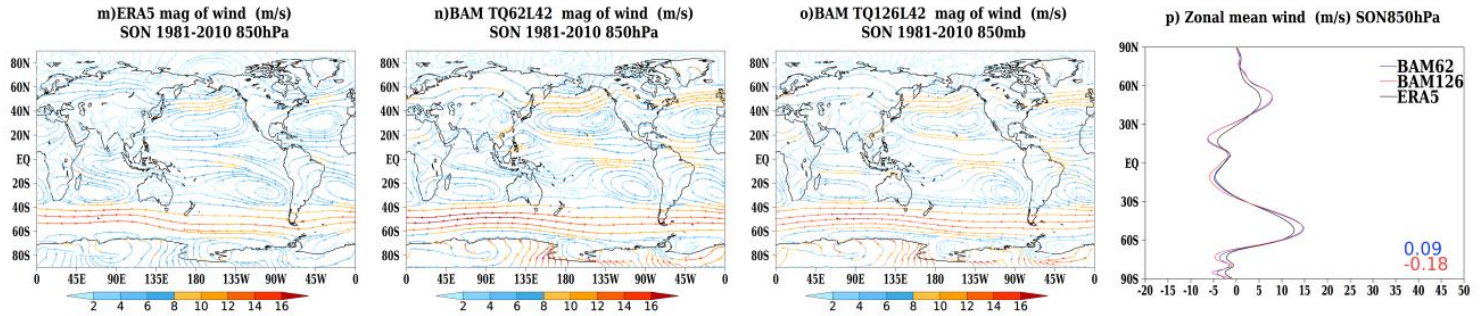

Figure 4: Low level (850 hPa) circulation climatological (1981-2010) mean represented by streamlines with magnitude in $\mathrm{m}_{\mathrm{s}} \mathrm{s}^{-1}$ (colors) for austral summer (DJF, first row), autumn (MAM, second row), winter (JJA, third row) and spring (SON, fourth row) derived from ERA-5 (Hersbach et al., 2018, 2019, first column), simulated by BAM TQ62L42 ( 180 km, second column), and simulated by BAM TQ126L42 ( $100 \mathrm{~km}$, third column). The fourth column contains the zonal mean of the zonal mean wind component (black line for ERA-5, blue line for BAM TQ62L42 and red line for BAM TQ126L42) used for producing the panels in the first 3 columns. The values shown in the bottom right of the panels on the fourth column figures are the mean biases for BAM TQ62L42 (in blue) and BAM TQ126L42 (in red) in $\mathrm{m} . \mathrm{s}^{-1}$. BAM results shown in this figure correspond to the ensemble mean of the performed 4-member simulations. 

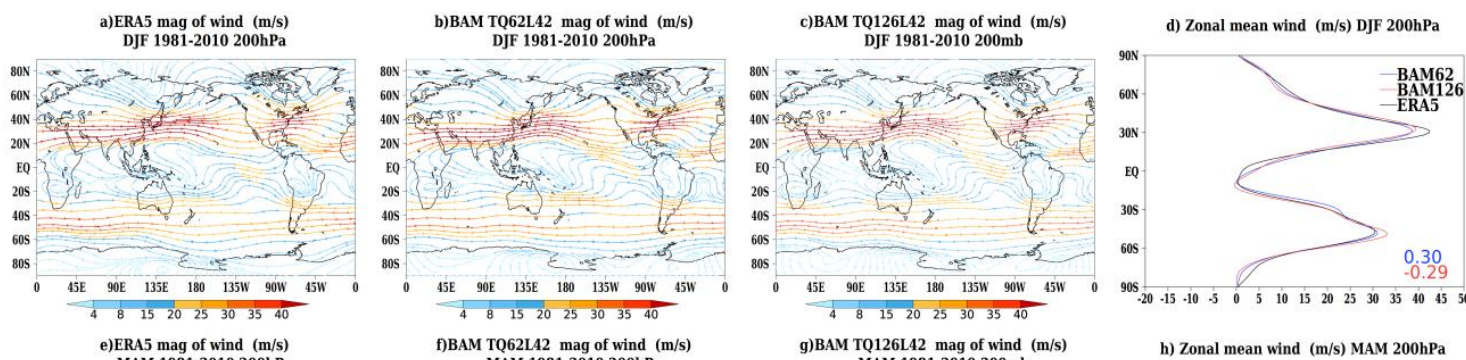

ERA5 $\mathrm{mag}$ of wind $(\mathrm{m} / \mathrm{s})$
MAM $1981-2010200 \mathrm{hPa}$
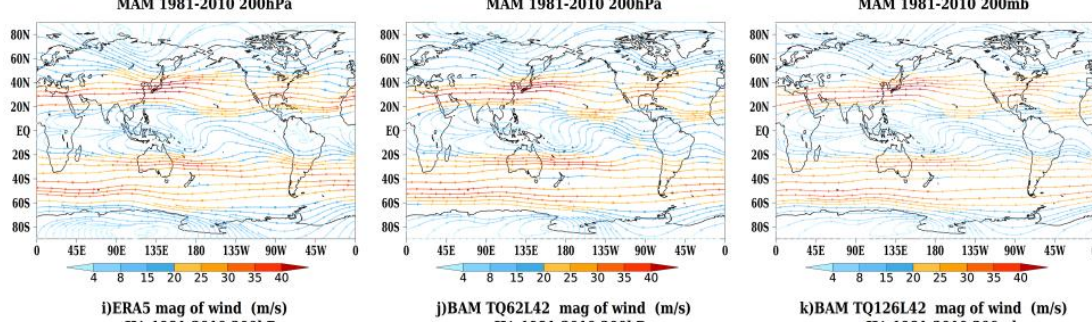
JIA 1981-2010 200hPa
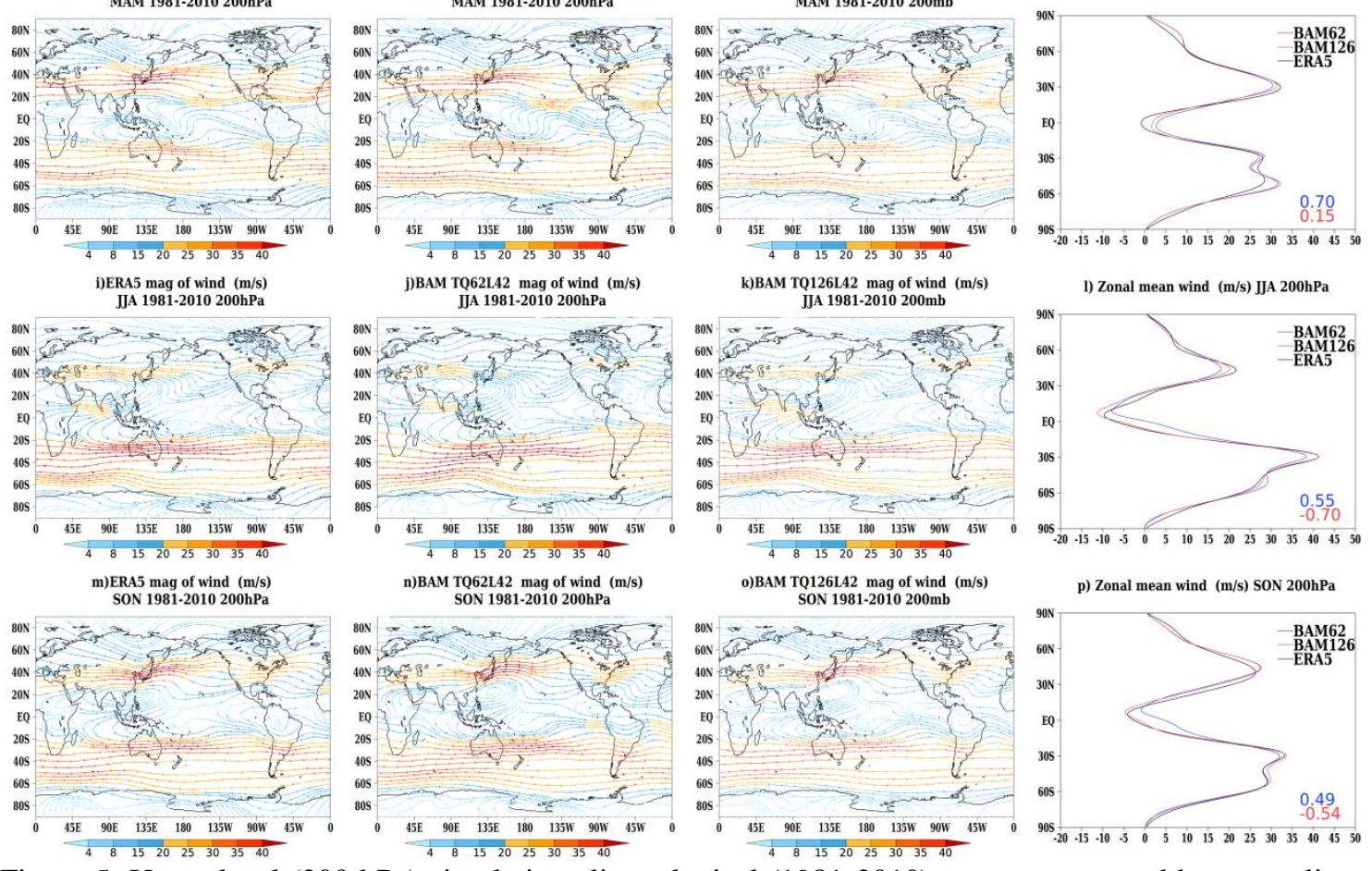

Figure 5: Upper level (200 hPa) circulation climatological (1981-2010) mean represented by streamlines

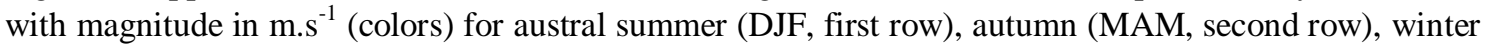
(JJA, third row) and spring (SON, fourth row) derived from ERA-5 (Hersbach et al., 2018, 2019, first column), simulated by BAM TQ62L42 ( 180 km, second column), and simulated by BAM TQ126L42 $(\sim 100 \mathrm{~km}$, third column). The fourth column contains the zonal mean of the zonal mean wind component (black line for ERA-5, blue line for BAM TQ62L42 and red line for BAM TQ126L42) used for producing the panels in the first 3 columns. The values shown in the bottom right of the panels on the fourth column figures are the mean biases for BAM TQ62L42 (in blue) and BAM TQ126L42 (in red) in $\mathrm{m} . \mathrm{s}^{-1}$. BAM results shown in this figure correspond to the ensemble mean of the performed 4-member simulations. 

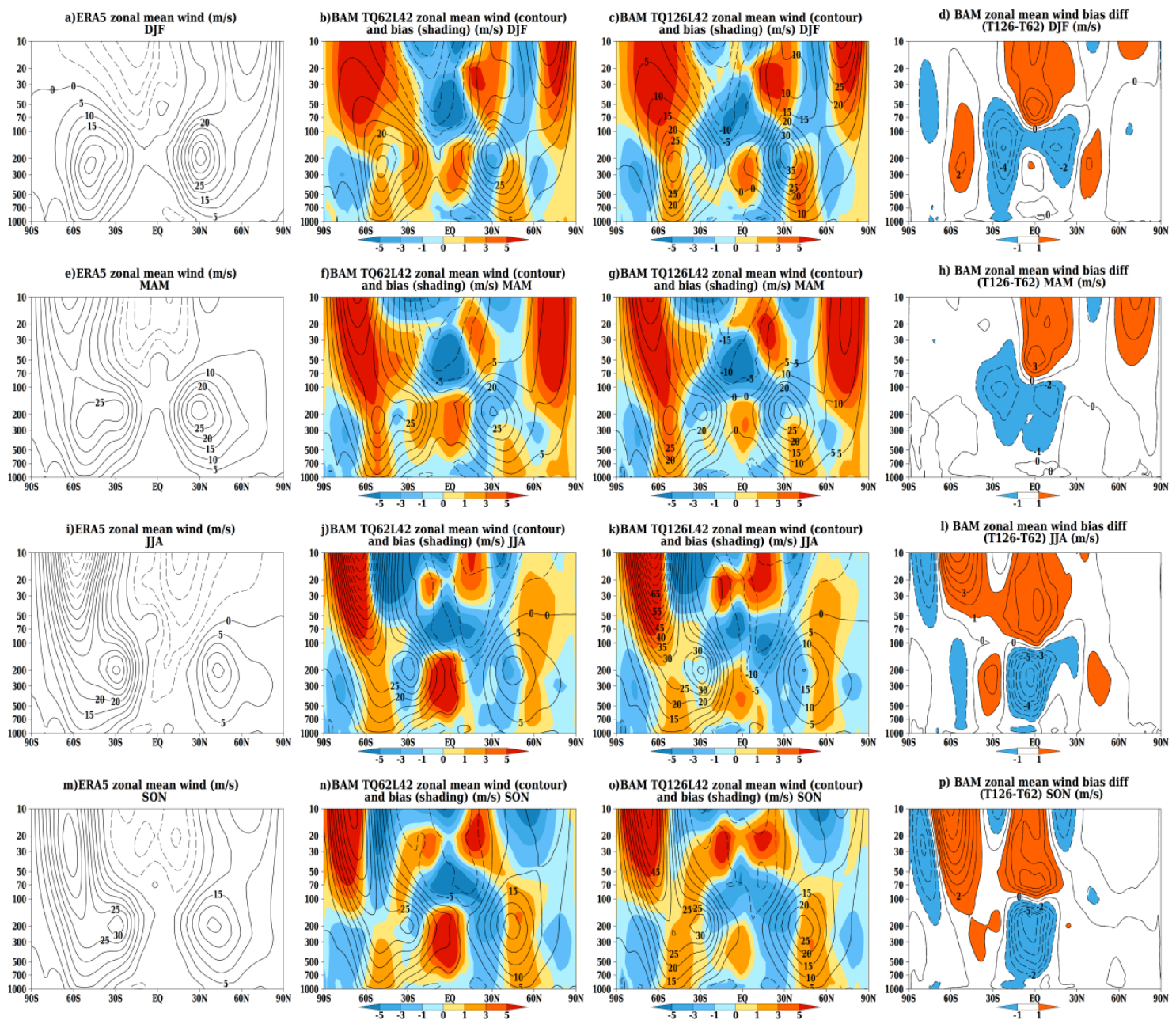

Figure 6: Vertical climatological (1981-2010) seasonal zonal mean profile of the zonal wind component (isolines) from 1000 to $10 \mathrm{hPa}$ (in $\mathrm{m}^{-1} \mathrm{~s}^{-1}$ ) for austral summer (DJF, first row), autumn (MAM, second row), winter (JJA, third row) and spring (SON, fourth row) derived from ERA-5 reanalysis (Hersbach et al., 2018, 2019, first column), simulated by BAM TQ62L42 ( 180 km, second column), and simulated by BAM TQ126L42 ( 100 km, third column). BAM results shown in this figure correspond to the ensemble mean of the performed 4-member simulations. Shading in the second and third column panels are zonal mean biases computed as differences between the second and third column panels vertical zonal mean profiles and the vertical zonal mean profile of the first column. The panels on the forth column are the vertical profiles of the zonal mean bias difference between BAM TQ126L42 (third column) and BAM TQ62L42 (second column). 

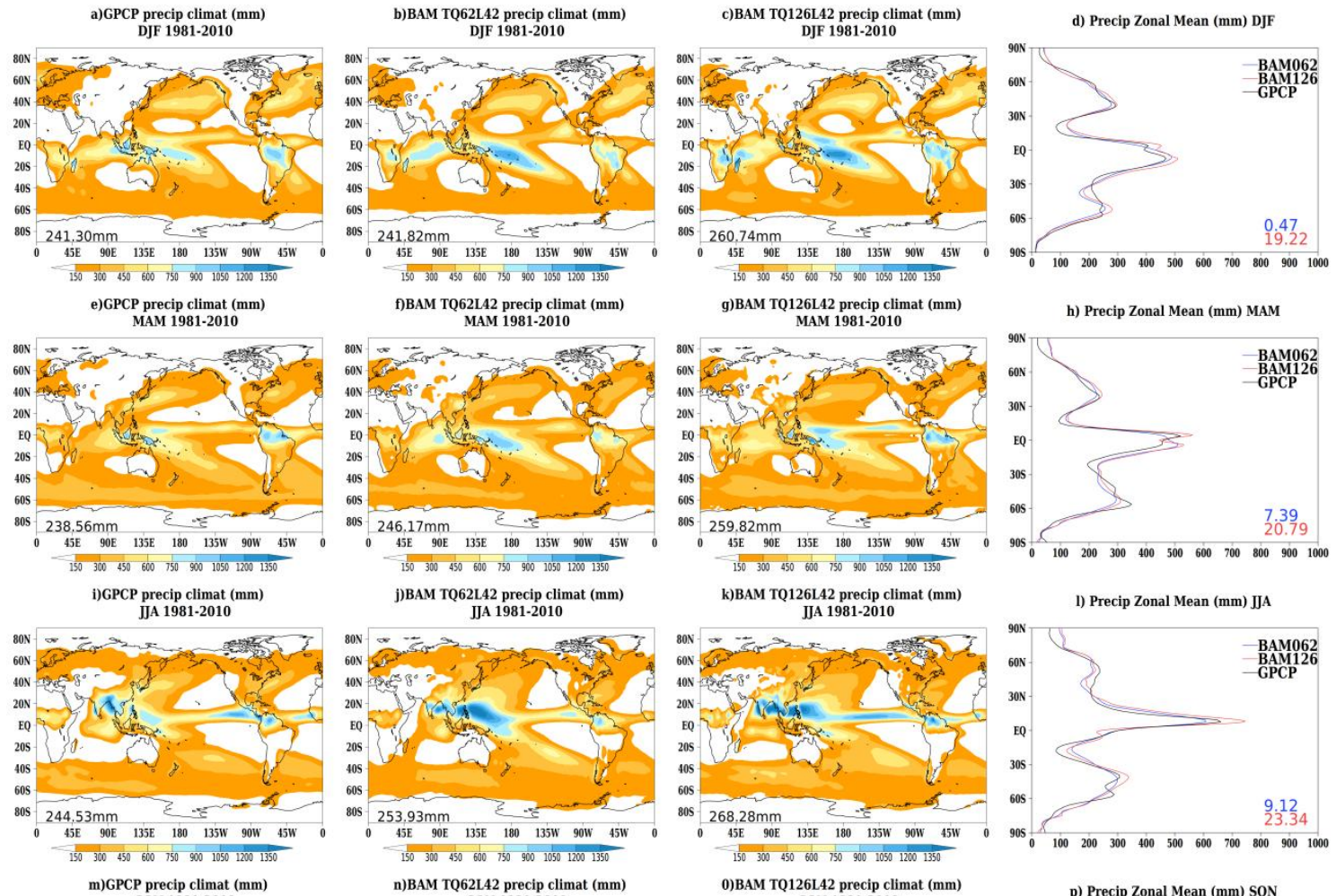

1) Precip Zonal Mean (mm) JJA
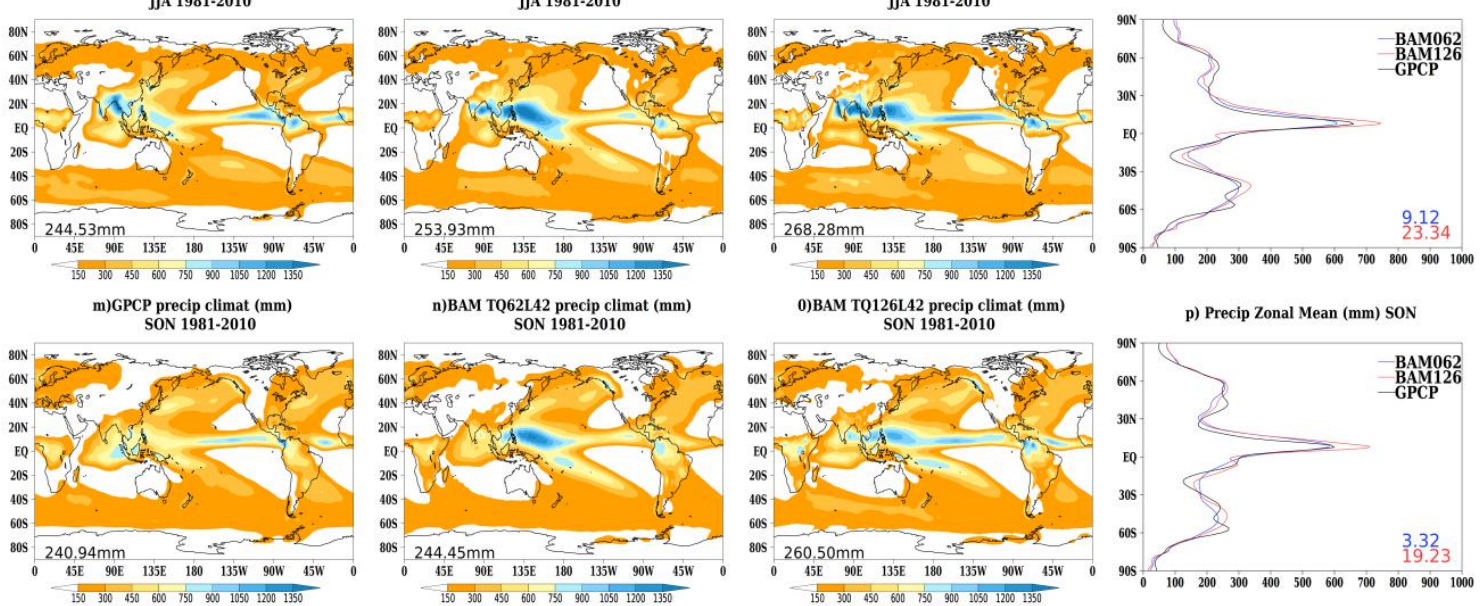

Figure 7: Accumulated precipitation climatological (1981-2010) mean (in mm) for austral summer (DJF, first row), autumn (MAM, second row), winter (JJA, third row) and spring (SON, fourth row) derived from GPCP (Adler et al. 2003, first column), simulated by BAM TQ62L42 ( 180 km, second column), and simulated by BAM TQ126L42 $(\sim 100 \mathrm{~km}$, third column). The values shown in the bottom left of the first three column figures are the global mean accumulated precipitation (in $\mathrm{mm}$ ) for the maps shown in each panel. The fourth column contains the zonal mean accumulated precipitation (black line for GPCP, blue line for BAM TQ62L42 and red line for BAM TQ126L42) used for producing the panels in the first 3 columns. The values shown in the bottom right of the panels on the fourth column figures are the mean biases (in mm) for BAM TQ62L42 (in blue) and BAM TQ126L42 (in red). BAM results shown in this figure correspond to the ensemble mean of the performed 4-member simulations. 

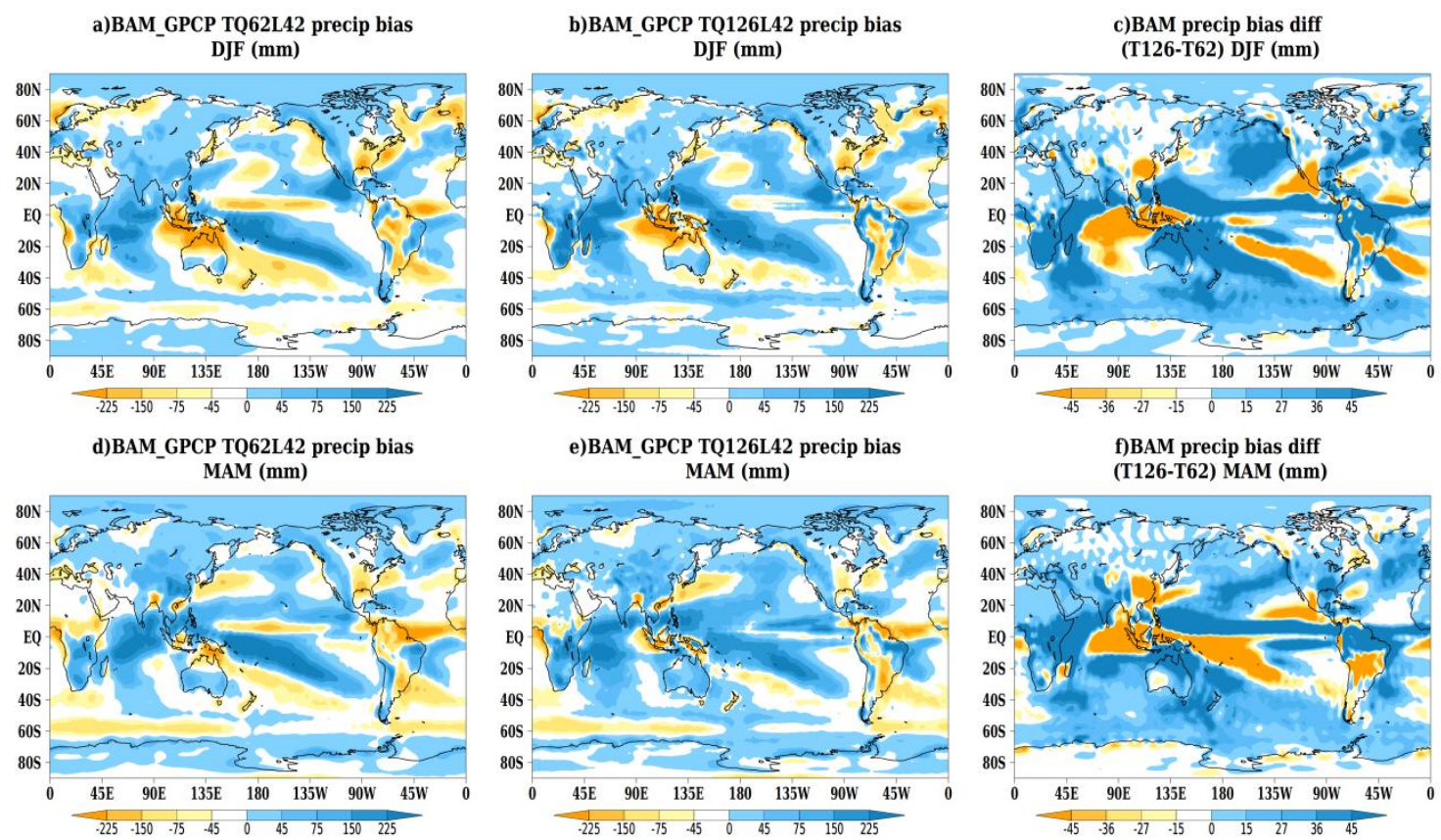

g)BAM GPCP TQ62L42 precip bias $\mathrm{JJA}(\mathrm{mm})$

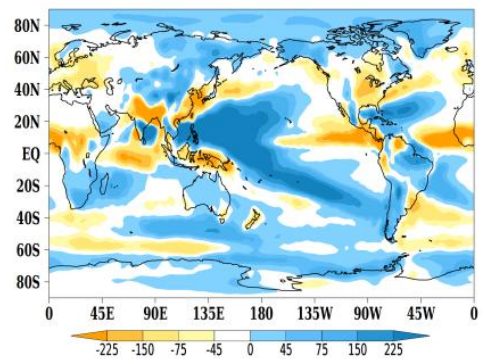

h)BAM GPCP TO126L42 precip bias JJA (mm)

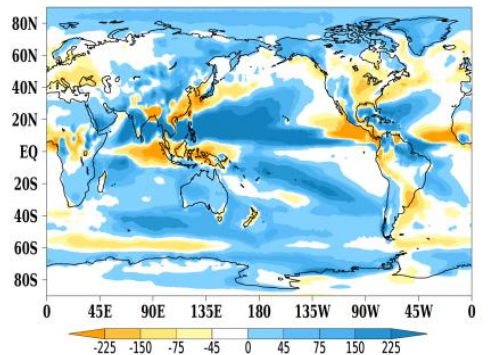

BAM precip bias diff (T126-T62) JJA (mm)

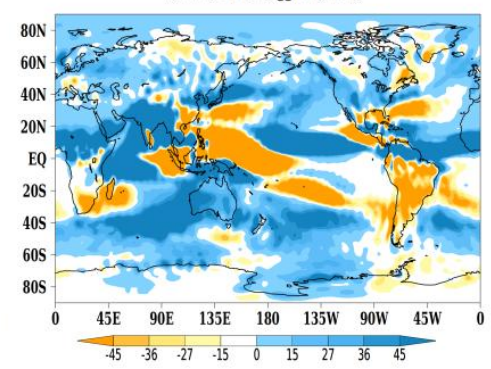

k)BAM_GPCP TQ126L42 precip bias SON (mm)

l)BAM precip bias diff SON (mm)
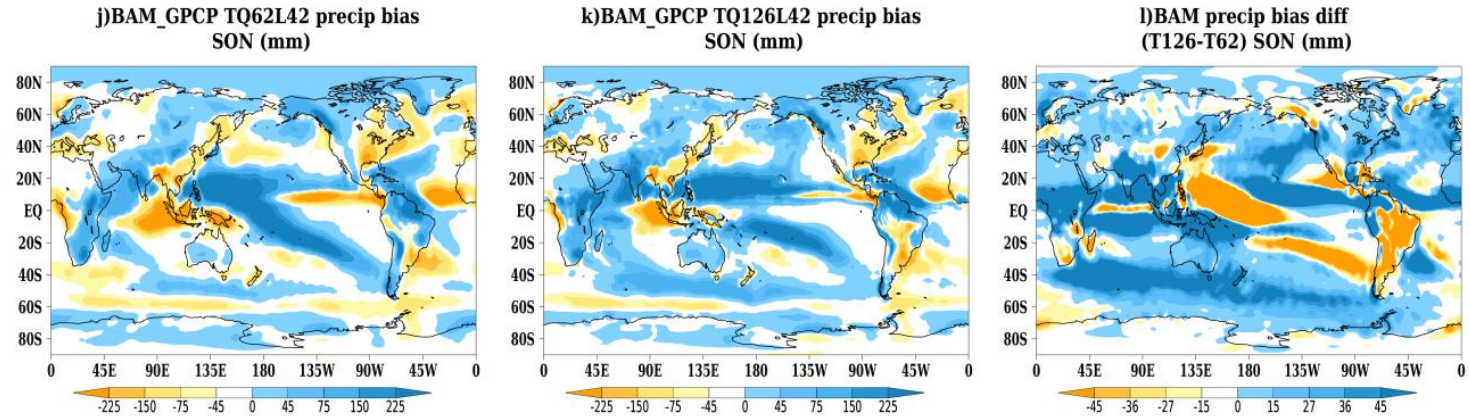

Figure 8: Accumulated precipitation mean bias (in $\mathrm{mm}$ ) over the 1981-2010 period for austral summer (DJF, first row), autumn (MAM, second row), winter (JJA, third row) and spring (SON, fourth row), for BAM TQ62L42 ( 180 km, first column) and BAM TQ126L42 ( 100 km, second column). Biases were computed as the difference between the model simulated climatological mean for BAM TQ62L42 (second column in Figure 7) and for BAM TQ126L42 (third column in Figure 7) and the corresponding GPCP climatological mean (Adler et al. 2003, first column in Figure 7). The panels on the third column are the mean bias differences between BAM TQ126L42 (second column) and BAM TQ62L42 (first column). 

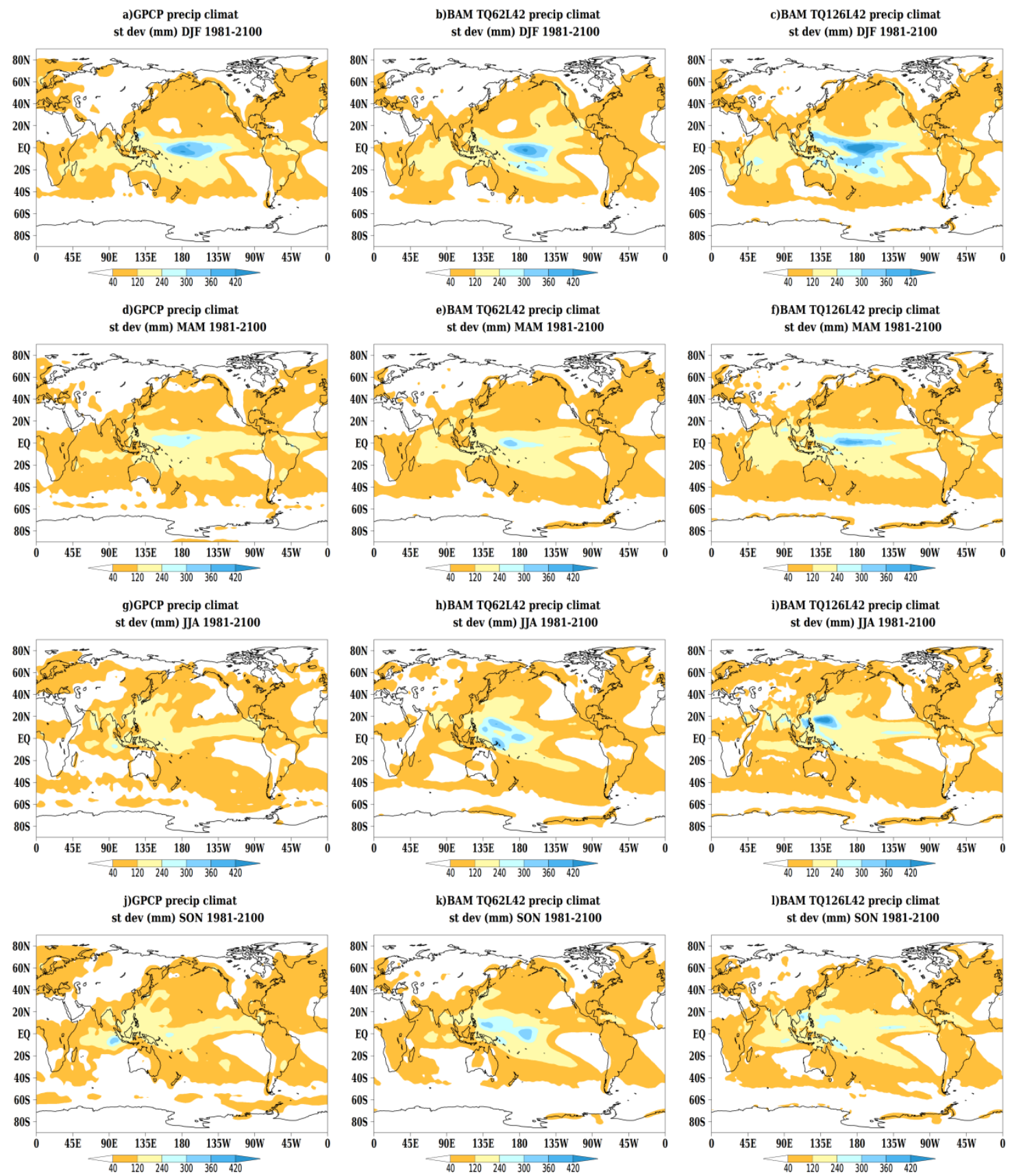

Figure 9: Accumulated precipitation standard deviation (in $\mathrm{mm}$ ) over the 1981-2010 period for austral summer (DJF, first row), autumn (MAM, second row), winter (JJA, third row) and spring (SON, fourth row), derived from GPCP (Adler et al., 2003, first column), and simulated by BAM TQ62L42 ( 180 km, second column) and by BAM TQ126L42 ( 100 km, third column). BAM standard deviations were computed using all four individual ensemble members (not the ensemble mean) for each investigated model spatial resolution in order avoid filtering out through the ensemble mean the model simulated precipitation inter-annual variability. 

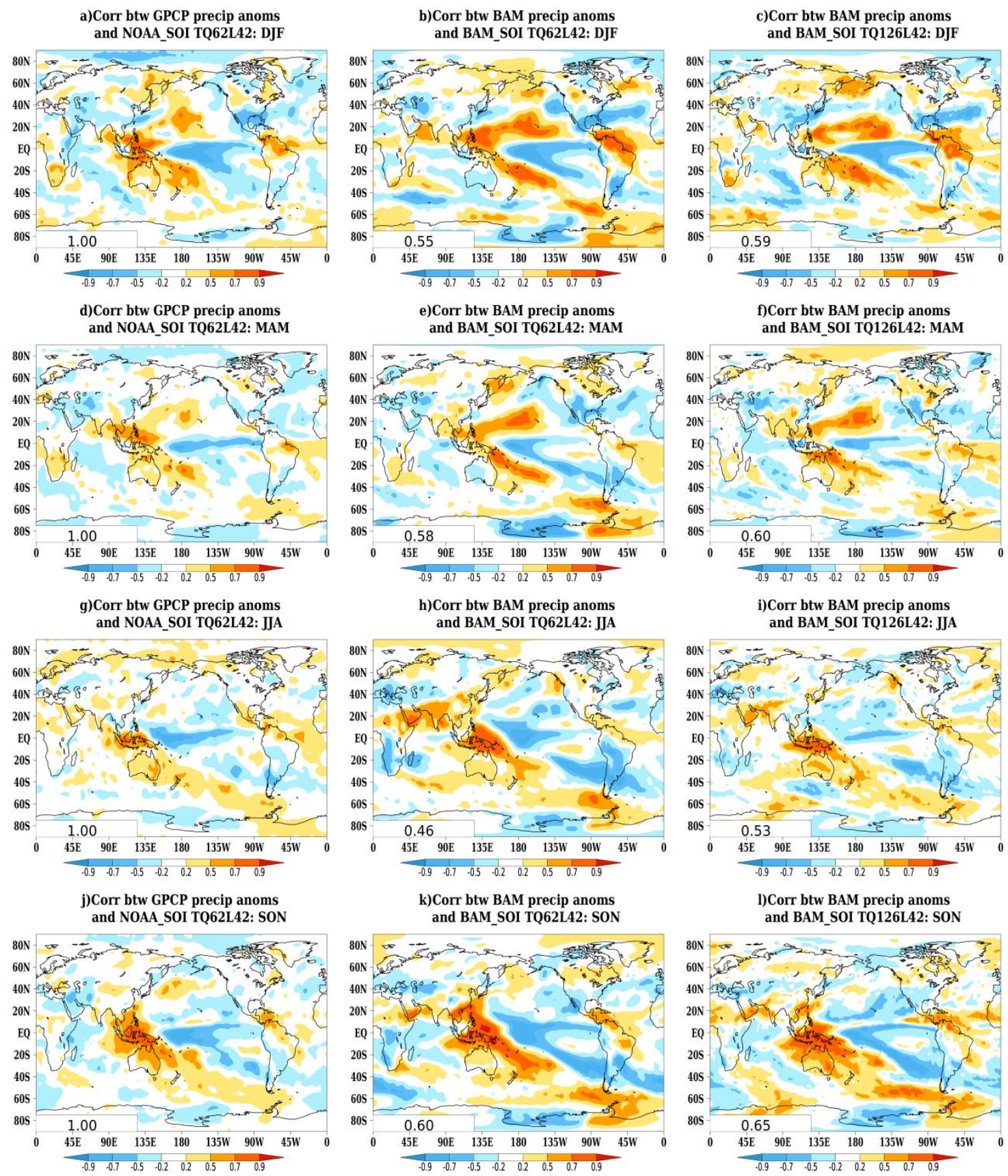

Figure 10: Correlation between the Southern Oscillation Index (SOI) and precipitation anomalies over the 1981-2010 period for austral summer (DJF, first row), autumn (MAM, second row), winter (JJA, third row) and spring (SON, fourth row), derived from observations (NOAA SOI and GPCP, first column) and simulated by BAM TQ62L42 ( 180 km, second column) and by BAM TQ126L42 $(\sim 100 \mathrm{~km}$, third column). The values shown in the bottom left panels are the pattern correlations with the observed pattern (first column). BAM results shown in this figure correspond to the ensemble mean of the performed 47 member simulations. 


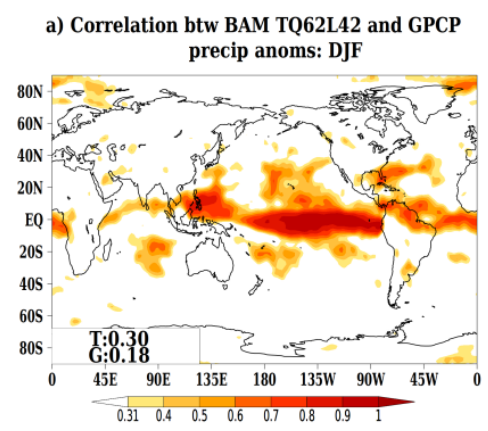

b) Correlation btw BAM TQ126L42 and GPCP precip anoms: DJF

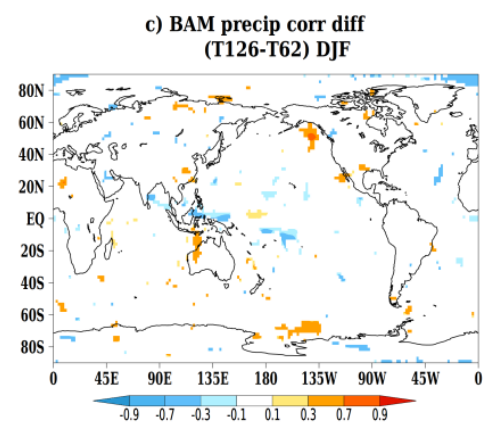

d) Correlation btw BAM TQ62L42 and GPCP precip anoms: MAM
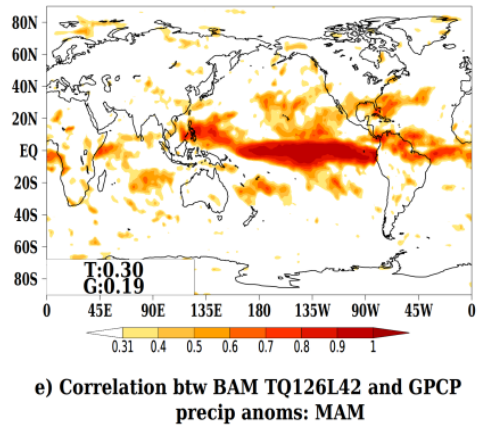

f) BAM precip corr diff precip anoms: MAM (T126-T62) MAM
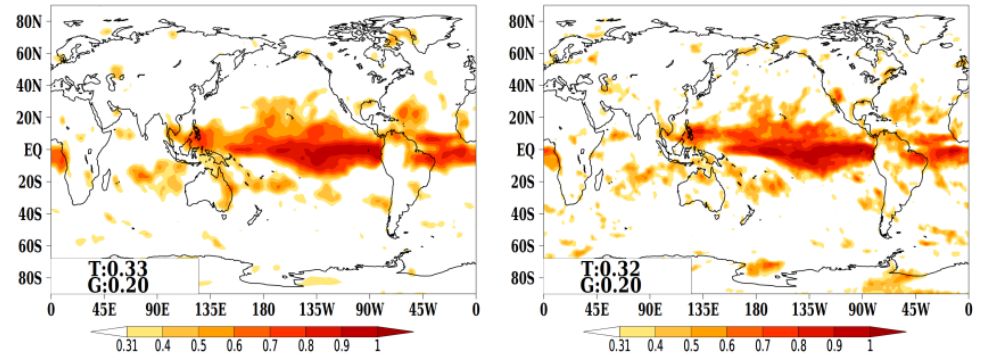

g) Correlation btw BAM TO62L42 and GPCP precip anoms: JJA

h) Correlation btw BAM TQ126L42 and GPCP precip anoms: JJA
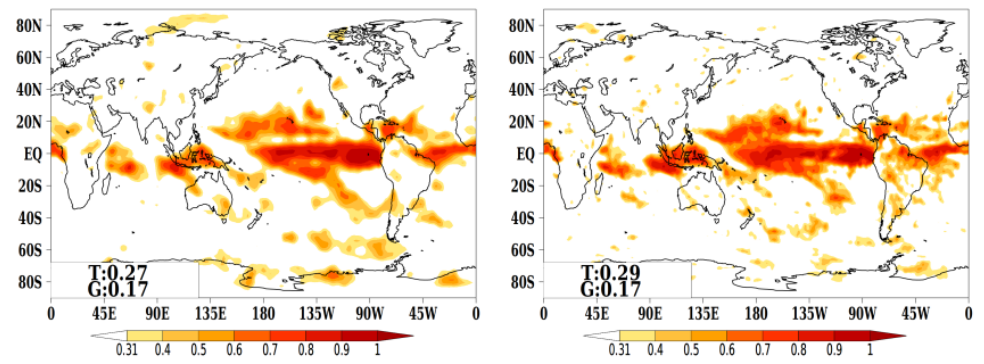

j) Correlation btw BAM TQ62L42 and GPCP precip anoms: SON

k) Correlation btw BAM TQ126L42 and GPCP precip anoms: SON

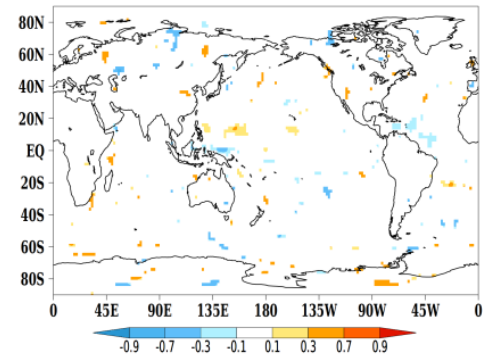

i) BAM precip corr diff (T126-T62) JJA

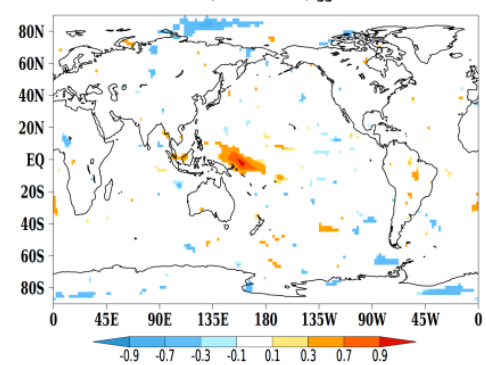

1) BAM precip corr diff (T126-T62) SON
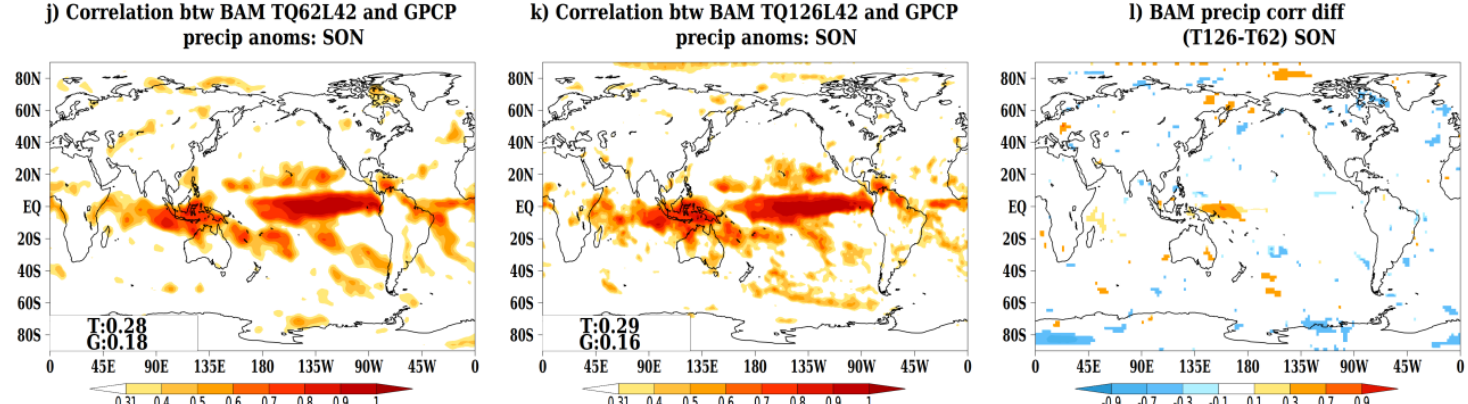

Figure 11: Correlation between observed precipitation anomalies (GPCP, Adler et al., 2003) and simulated precipitation anomalies by BAM TQ62L42 ( 180 km, first column) and BAM TQ126L42 ( $100 \mathrm{~km}$, second column), over the 1981-2010 period for austral summer (DJF, first row), autumn (MAM, second row), winter (JJA, third row) and spring (SON, fourth row). Correlation values above 0.36 are statistically significant and different from zero using the Student's t-test at the $10 \%$ level. The values shown in the bottom left panels of the maps in the first and second columns are the mean of the correlation values shown in the maps computed over the tropics ( $\mathrm{T}$, global mean between $30^{\circ} \mathrm{S}$ and $30^{\circ} \mathrm{N}$ ) and over the entire globe ( $\mathrm{G}$, global mean between $90^{\circ} \mathrm{S}$ and $\left.90^{\circ} \mathrm{N}\right)$. The maps shown in the forth column are the correlation differences between BAM TQ126L42 (second column) and BAM TQ62L42 (first column). Only statistically significant differences at the $10 \%$ level determined through a bootstrap resampling procedure with replacement computed with 1000 samples are shown. BAM results shown in this figure correspond to the ensemble mean of the performed 4-member simulations. 
a) MuO Life cycle composite

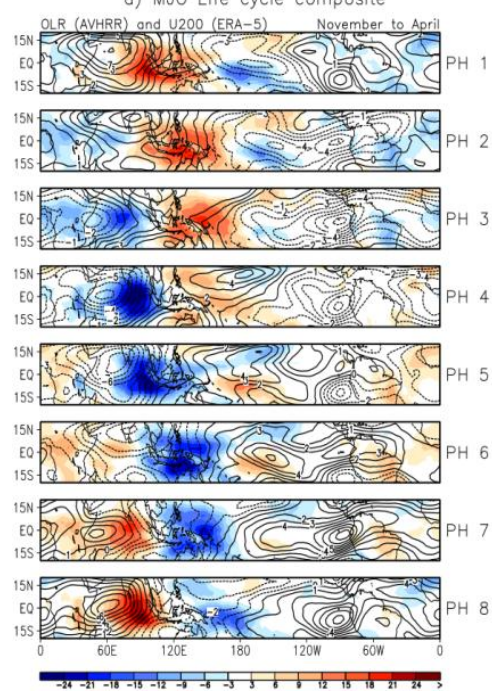

b) MJO Life cycle composite

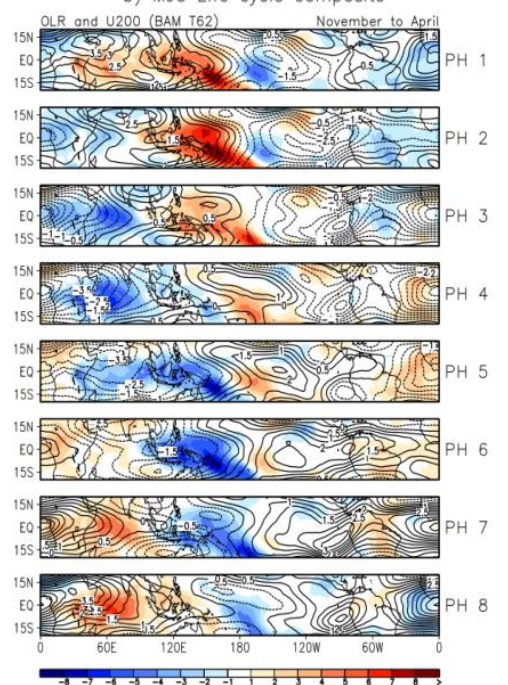

c) MJO Life cycle composite

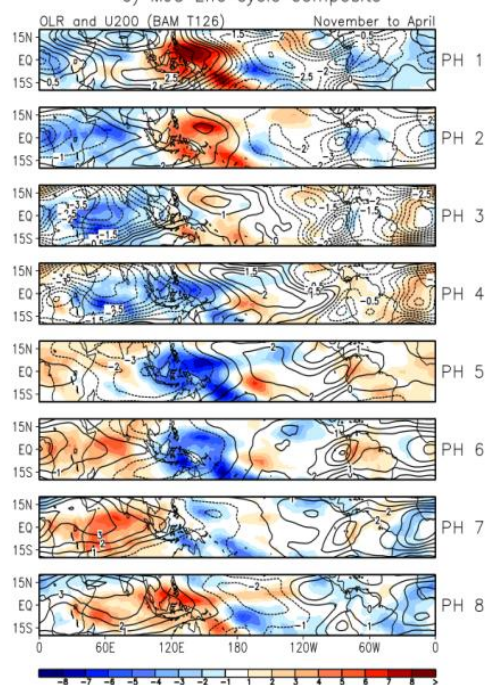

Figure 12: MJO life cycle composite represented by the mean of OLR (shading) and the zonal wind component at $200 \mathrm{hPa}$ (contours) anomalies of all days during the November to April 1981-2010 period when the MJO was in phases (PH) 1 to 8 (as defined by Wheeler and Hendon, 2004) derived from observations (NOAA OLR and ERA-5 $200 \mathrm{hPa}$ zonal wind, first column) and simulated by BAM TQ62L42 (second column) and BAM TQ126L42 (third column). MJO phases for both observations and model simulations were computed using the diagnostics package described in Waliser et al. (2009). BAM composites for each of the 8 phases were first computed for each ensemble member separately and next the mean of these composites were computed and are shown here in the panels of the second and third columns. Note that the OLR color scales for the observations and BAM simulations are different as indicated in the color bars. 
a. 2D PDF (colors) for TRMM at T62

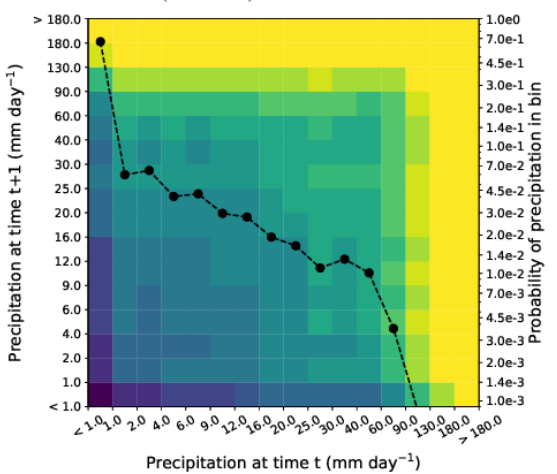

c. 2D PDF (colors) for TRMM at T126

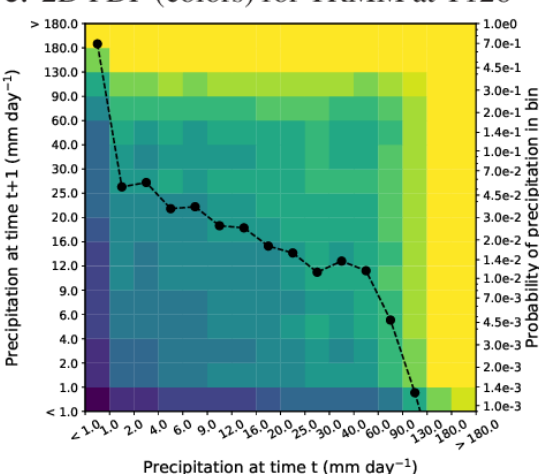

Precipitation at time $\mathrm{t}\left(\mathrm{mm} \mathrm{day}^{-1}\right)$

\section{b. 2D PDF (colors) for BAM at T62}

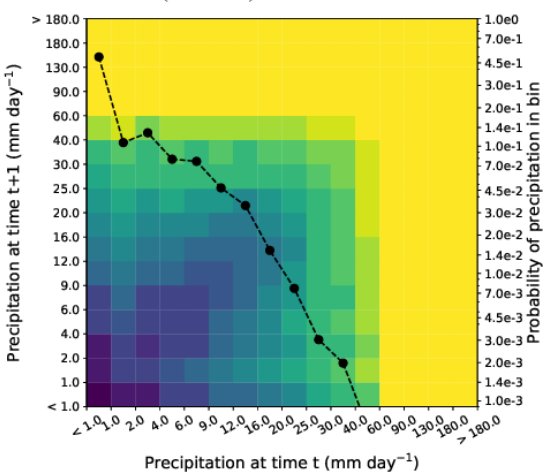

d. 2D PDF (colors) for BAM at T126

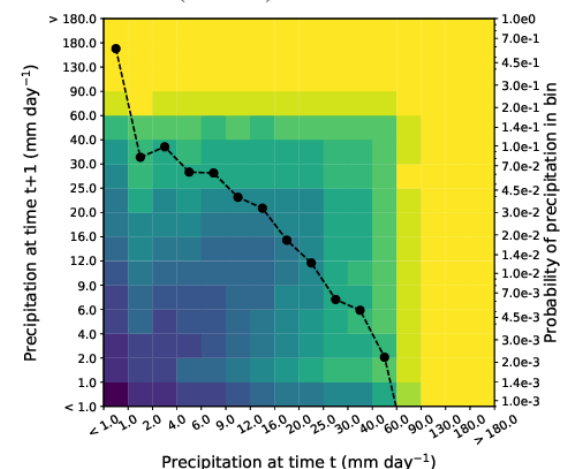

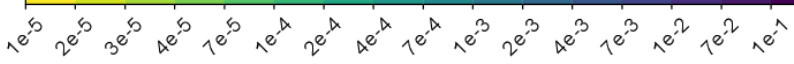

Probability

e. $7 \times 7$ regions for TRMM T62

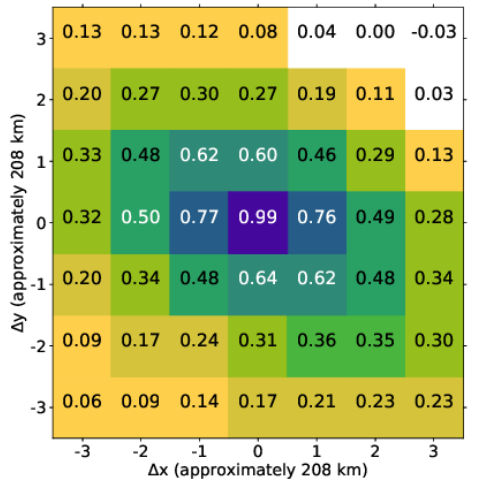

g. $7 \times 7$ regions for TRMM T126

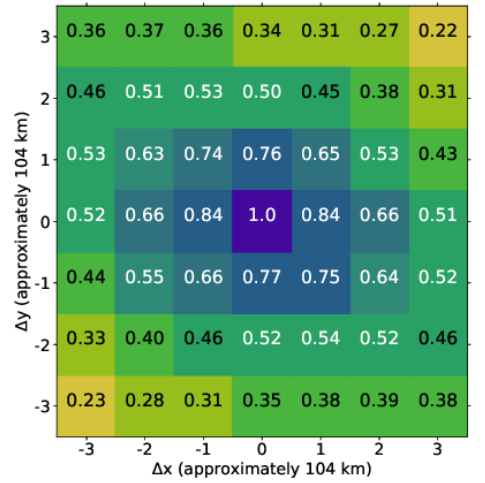

f. $7 \times 7$ regions for BAM T62

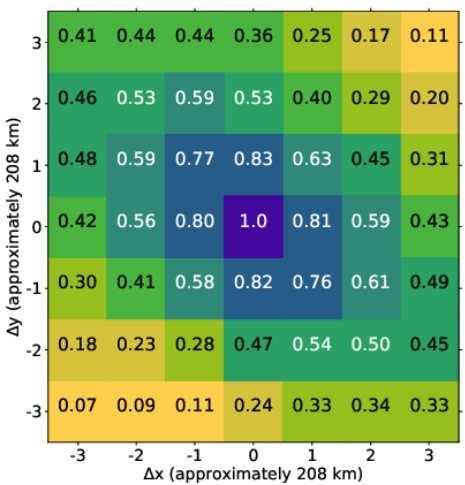

h. $7 \times 7$ regions for BAM T126

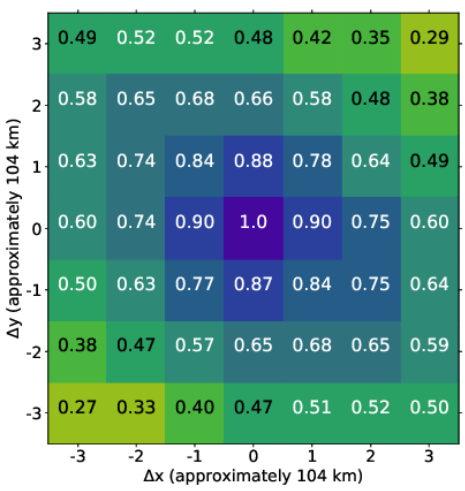

0.050 .150 .250 .350 .450 .550 .650 .750 .850 .95

Correlation with $(0,0)$ - mean over all sub-regions 
2 Figure 13: Joint (two-dimensional, 2-D) probability density function (colors, in logarithmic scale) of 3 binned values (bin intervals are shown in the horizontal and left vertical axes) of daily precipitation at the 4 same grid point on consecutive days, and one dimensional (1-D) probability density function (dashed 5 line) of daily precipitation using the right-hand side axis, aggregated over all grid points within the 6 southeast South America $\left(15-40^{\circ} \mathrm{S}, 60-35^{\circ} \mathrm{W}\right)$ for the period 1998-2017, a) derived from TRMM 7 (Kummerow et al., 1998; Huffman et al., 2007, 2010) interpolated to T62 spatial resolution ( 180 km), b) 8 simulated by all four BAM TQ62L42 $(\sim 180 \mathrm{~km})$ ensemble members, c) derived from TRMM interpolated 9 to T126 spatial resolution $(\sim 100 \mathrm{~km})$, and d) simulated by all four BAM TQ126L42 $(\sim 100 \mathrm{~km})$ ensemble members. Mean instantaneous (lag-0) correlations of daily gridded precipitation 1998-2017 time series at all grid points within a $7 \times 7$ grid point sub-region within the southeast South America region $\left(15-40^{\circ} \mathrm{S}\right.$, $60-35^{\circ} \mathrm{W}$ ), against the precipitation time series at the central grid point $(0,0)$ of each $7 \times 7$ grid point subregion, averaged over all possible non-overlapping $7 \times 7$ grid point sub-regions within the southeast South America region, e) derived from TRMM interpolated to T62 spatial resolution $(\sim 180 \mathrm{~km})$, f) simulated by BAM TQ62L42 $(\sim 180 \mathrm{~km}), \mathrm{g})$ derived from TRMM interpolated to T126 spatial resolution ( 100 $\mathrm{km})$, and h) simulated by BAM TQ126L42 $(\sim 100 \mathrm{~km})$. The values for BAM in panels f) and h) are averages of the mean instantaneous correlation values obtained for the four individual ensemble members. The printed values and filled blocks in panels e) to h) show the same data. See Klingaman et al. (2017) and Martin et al. (2017) for further information on how these figures are produced. 
This online resource contains supplementary figures for the paper: Evaluation of climate simulations produced with the Brazilian Global Atmospheric Model version 1.2

Journal: Climate Dynamics

Autors: Caio. A. S. Coelho ${ }^{1}$, Dayana C. de Souza ${ }^{1}$, Paulo Y. Kubota ${ }^{1}$, Simone M. S. C. Coelho ${ }^{1}$, Layrson Menezes ${ }^{1}$, Bruno S. Guimarães ${ }^{1}$, Silvio N. Figueroa $^{1}$, José P. Bonatti ${ }^{1}$, Iracema F. A. Cavalcanti ${ }^{1}$, Gilvan Sampaio ${ }^{1}$, Nicholas P. Klingaman ${ }^{2}$, and Jessica C. A. Baker ${ }^{3}$

${ }^{I}$ Centro de Previsão de Tempo e Estudos Climáticos (CPTEC), Instituto Nacional de Pesquisas Espaciais (INPE), Rodovia Presidente Dutra, Km 40, SP-RJ, Cachoeira Paulista, SP 12630-000, Brazil

${ }^{2}$ National Centre for Atmospheric Science-Climate and Department of Meteorology, University of Reading, Earley Gate, P.O. Box 243, Reading, Berkshire RG6 6BB, UK

${ }^{3}$ School of Earth and Environment, Institute for Climate and Atmospheric Science, University of Leeds, Leeds, UK

Corresponding e-mail address: caio.coelho@inpe.br 

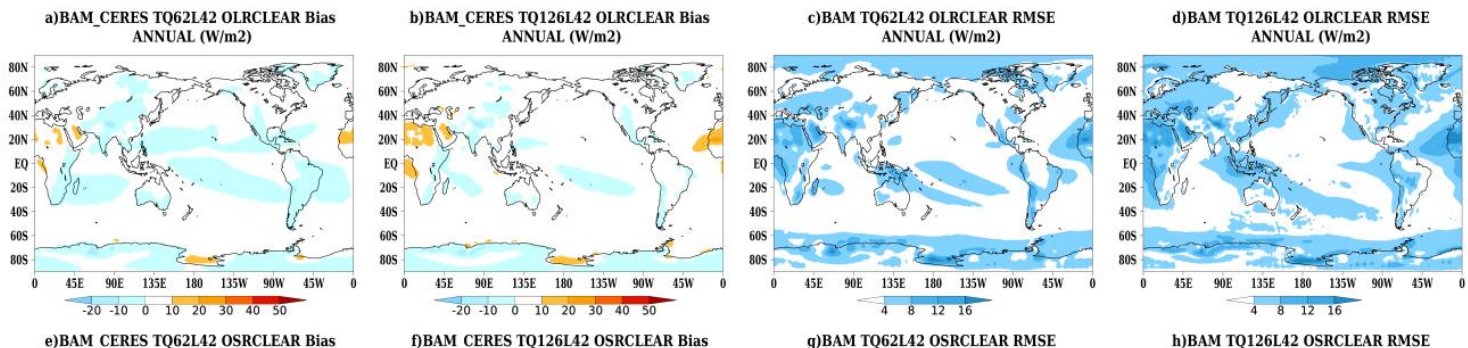

e)BAM_CERES TO62L42 OSRCLEAR Bias

f)BAM CERES TO126L42 OSRCLEAR Bias ANNUAL (W/m2)

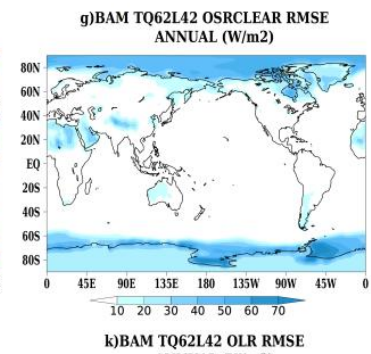

h)BAM T0126L42 OSRCLEAR RMSE

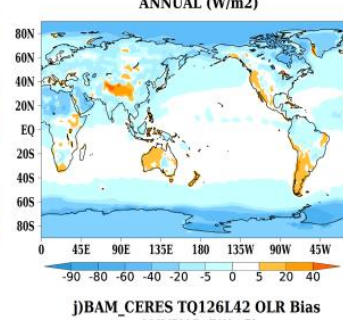
ANNUAL (W/m2)
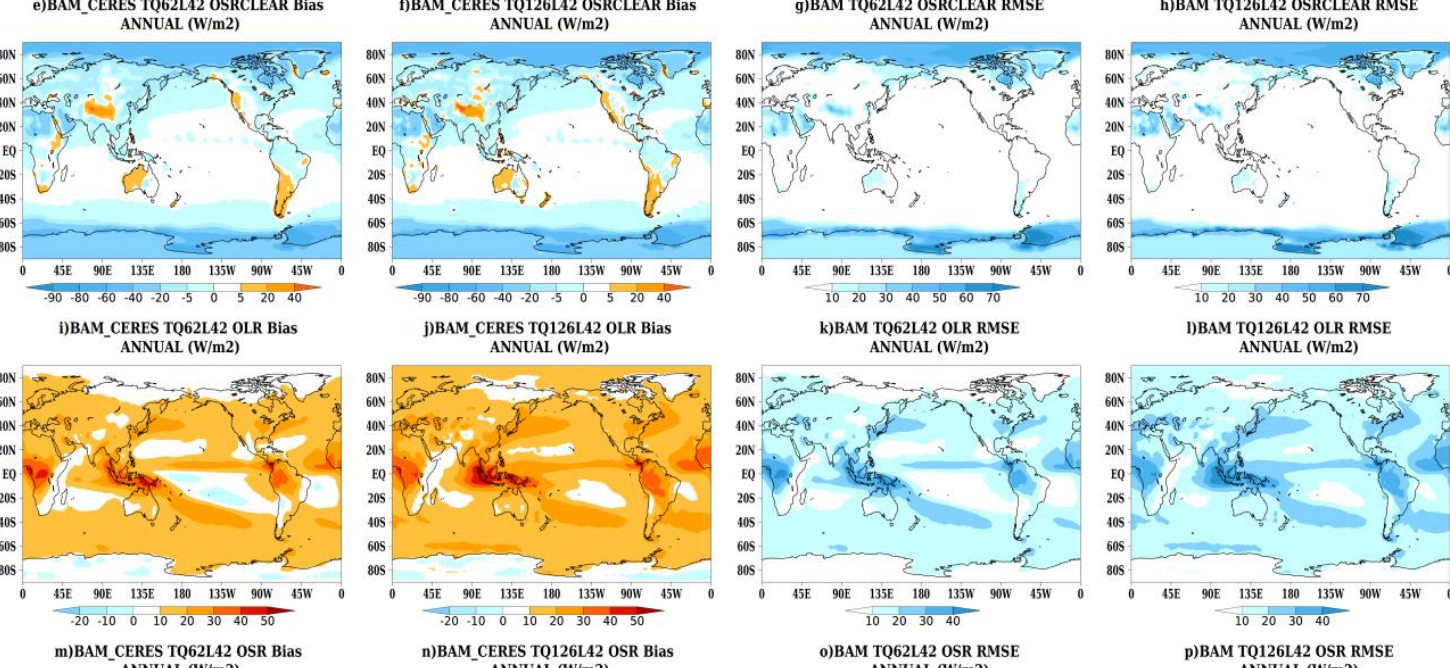
ANNUAL ( $(\mathrm{W} / \mathrm{m} 2)$

o)BAM TQ62LA2 OSR RMSE
ANNUAL (W/m2)

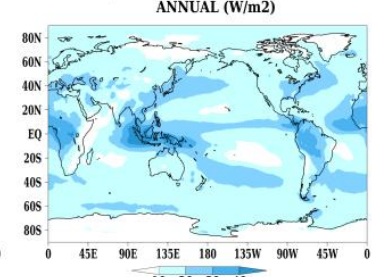
ANNUAL $(\mathrm{W} / \mathrm{m} 2)$
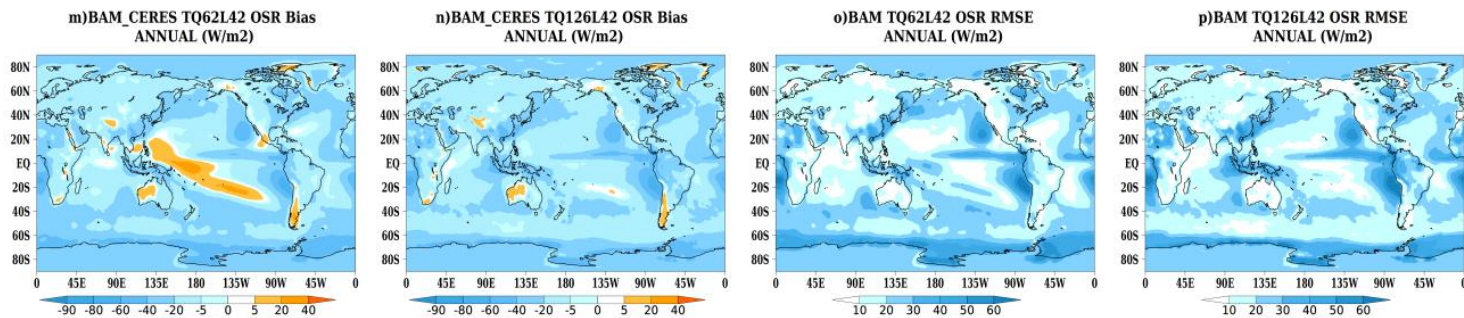

Figure S1: Global annual mean bias (first two columns) and root mean squared error (RMSE, last two columns) in W.m² ${ }^{2}$, for BAM TQ62L42 ( 180 km, first and third columns), for BAM TQ126L42 ( 100 $\mathrm{km}$, second and forth columns), computed with respect to satellite data (CERES, Loeb et al., 2018) over the 2001-2016 period, for: top of the atmosphere outgoing longwave radiation (OLR) under clear sky conditions (first row), top of the atmosphere outgoing shortwave radiation (OSR) under clear sky conditions (second row), top of the atmosphere OLR under cloudy conditions (third row), and top of the atmosphere OSR under cloudy conditions (forth row). BAM results shown in this figure correspond to the ensemble mean of the performed 4-member simulations. 

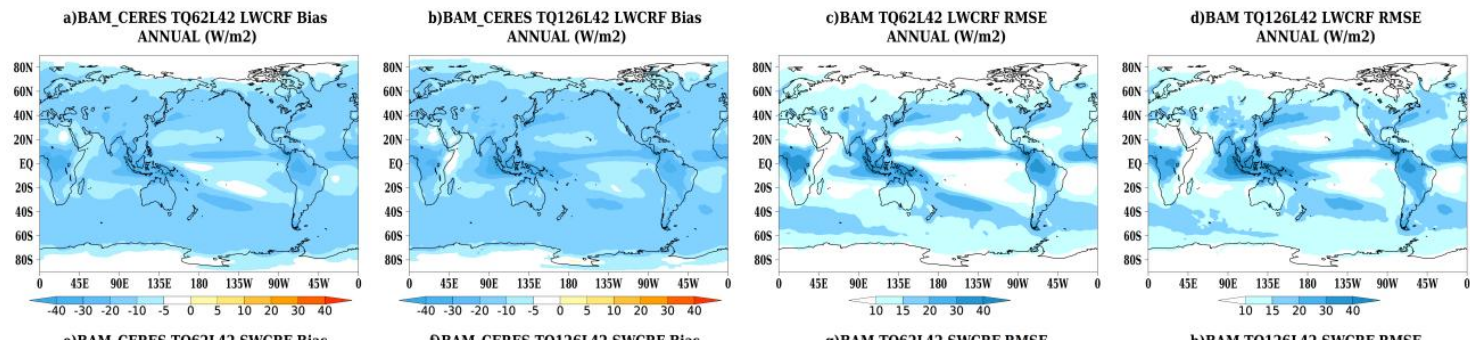

e)BAM_CERES TO62L42 SWCRF Bias f)BAM_CERES TQ126L42 SWCRF Bias
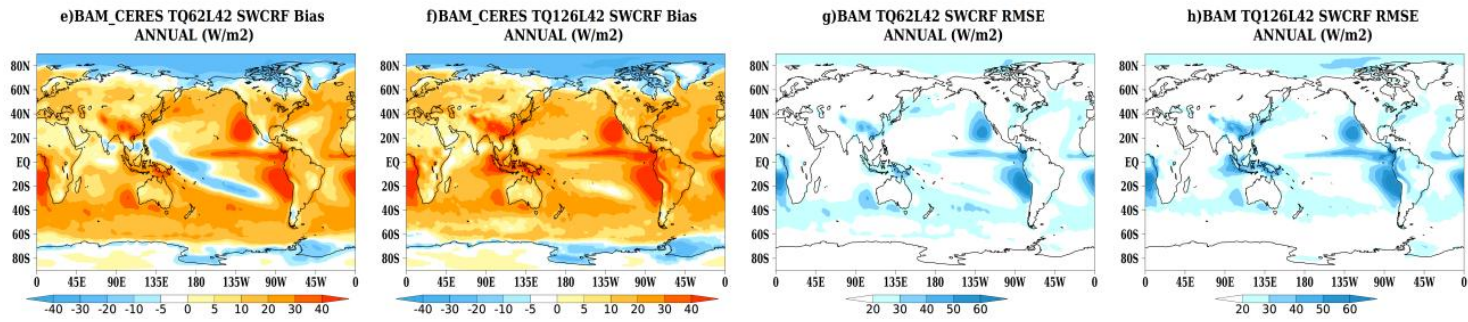

Figure S2 Global annual mean bias (first two columns) and root mean squared error (RMSE, last two columns) in W.m ${ }^{2}$, for BAM TQ62L42 ( 180 km, first and third columns), for BAM TQ126L42 ( 100 $\mathrm{km}$, second and forth columns), computed with respect to satellite data (CERES, Loeb et al., 2018) over the 2001-2016 period, for: top of the atmosphere longwave cloud radiative forcing (LWCRF, first row), and top of the atmosphere shortwave cloud radiative forcing (SWCRF, second row). BAM results shown in this figure correspond to the ensemble mean of the performed 4-member simulations. 
a)BAM_ERA5 TQ62L42 mag of wind BIAS (m/s) DJF 850hPa

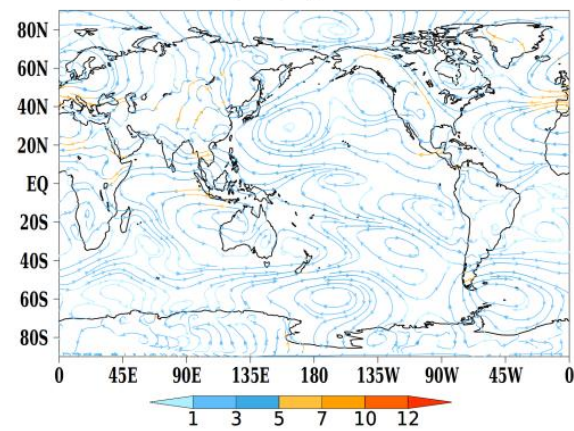

c)BAM_ERA5 TQ62L42 mag of wind BIAS (m/s) MAM 850hPa

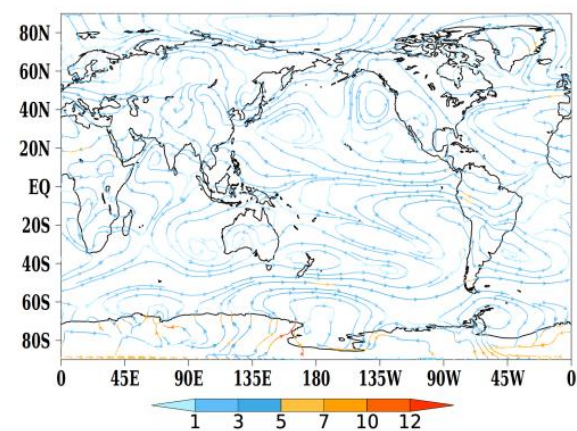

e)BAM ERA5 TQ62L42 mag of wind BIAS (m/s) JJA 850hPa

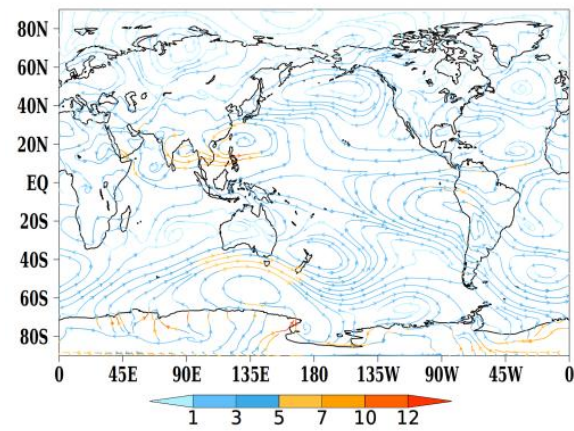

g)BAM ERA5 TQ62L42 mag of wind BIAS $(\mathrm{m} / \mathrm{s})$ SON 850hPa

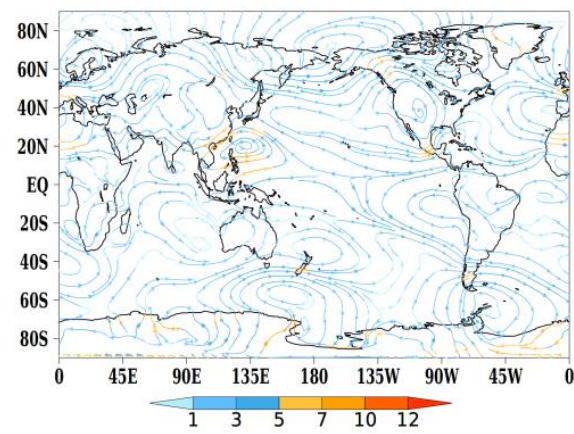

b)BAM_ERA5 TQ126L42 mag of wind BIAS $(\mathrm{m} / \mathrm{s})$ DJF 850hPa

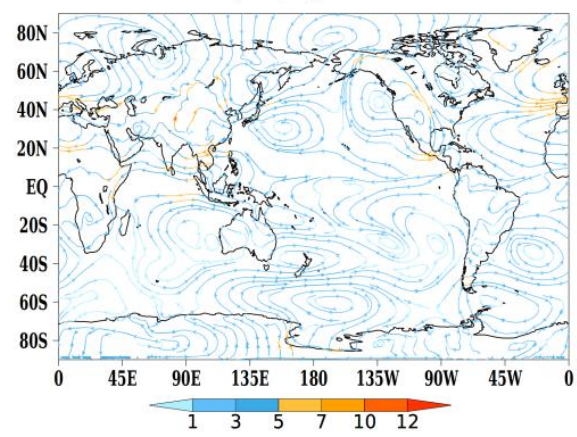

d)BAM ERA5 TQ126L42 mag of wind BIAS (m/s) MAM $850 \mathrm{hPa}$

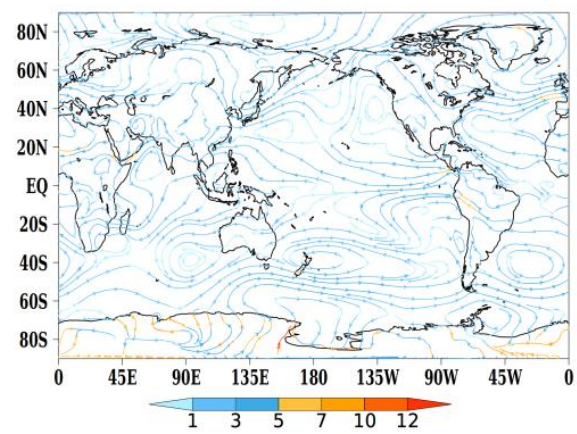

f)BAM ERA5 TQ126L42 mag of wind BIAS (m/s) JJA 850hPa

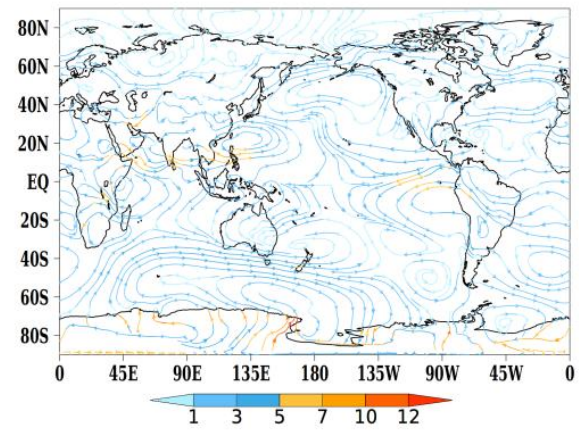

h)BAM ERA5 TQ126L42 mag of wind BIAS (m/s) SON 850hPa

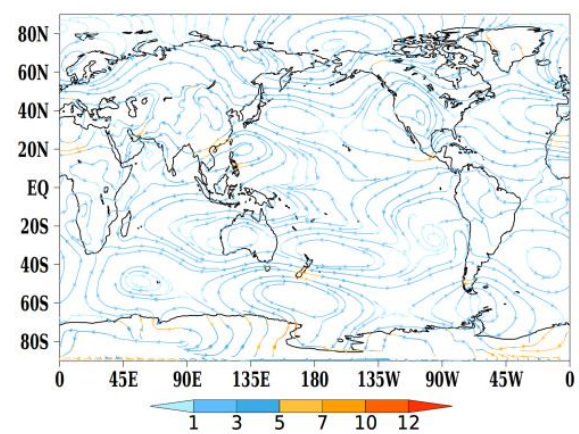

Figure S3: Low level $(850 \mathrm{hPa})$ circulation mean bias represented by streamlines with magnitude in $\mathrm{m} \cdot \mathrm{s}^{-1}$ (colors) for austral summer (DJF, first row), autumn (MAM, second row), winter (JJA, third row) and spring (SON, fourth row), for BAM TQ62L42 ( 180 km, first column), and BAM TQ126L42 ( 100 km, second column), computed with respect to ERA-5 (Hersbach et al., 2018, 2019) over the 2001-2016 period. BAM results shown in this figure correspond to the ensemble mean of the performed 4-member simulations. 
a)BAM_ERA5 TQ62L42 mag of wind BIAS (m/s) DJF 200hPa

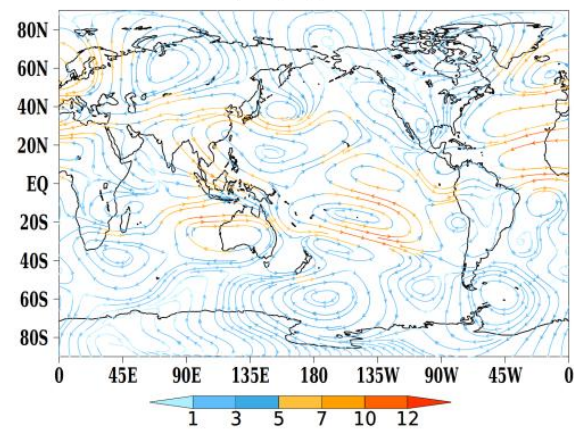

c)BAM ERA5 TQ62L42 mag of wind BIAS (m/s) MAM 200hPa

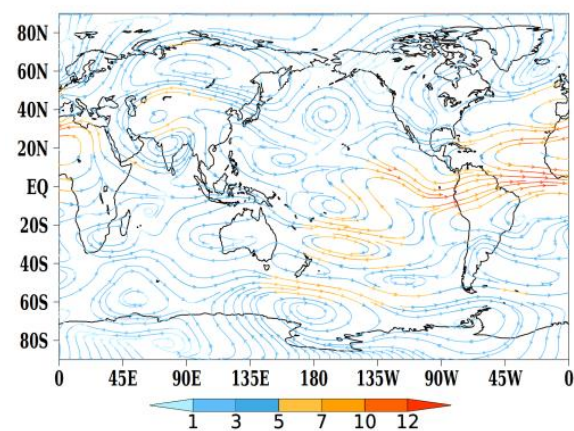

e)BAM ERA5 TQ62L42 mag of wind BIAS (m/s) JJA 200hPa

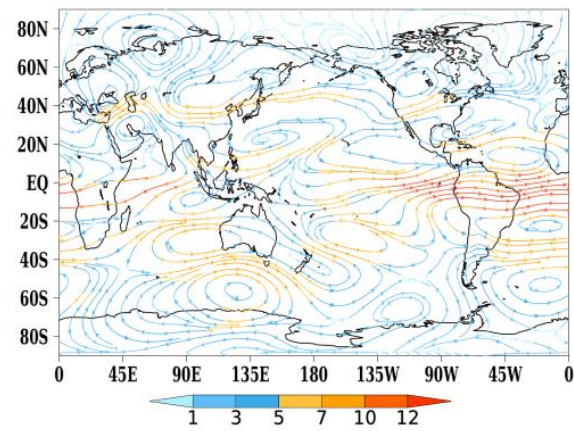

g)BAM ERA5 TQ62L42 mag of wind BIAS $(\mathrm{m} / \mathrm{s}) \mathrm{SON} 200 \mathrm{hPa}$

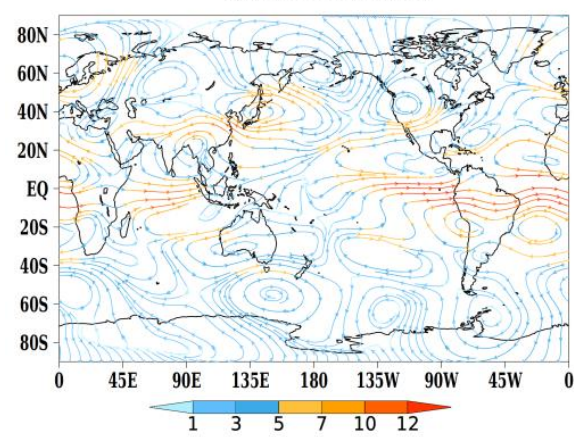

b)BAM_ERA5 TQ126L42 mag of wind BIAS (m/s) DJF 200hPa

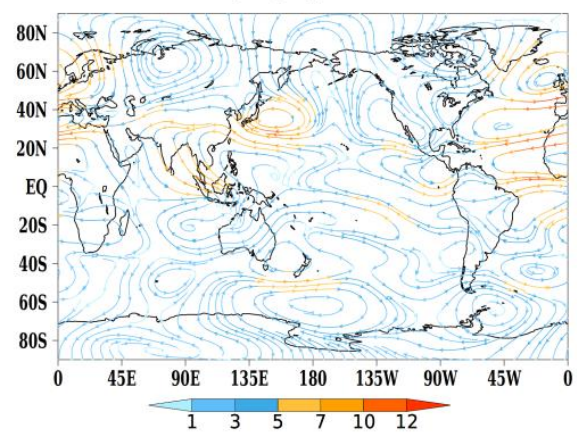

d)BAM_ERA5 TQ126L42 mag of wind BIAS (m/s) MAM $200 \mathrm{hPa}$

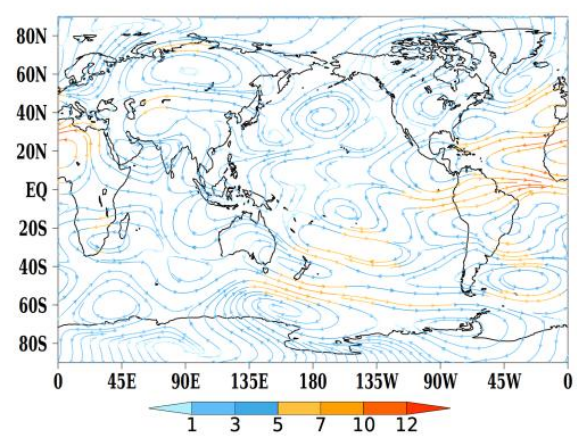

f)BAM ERA5 TQ126L42 mag of wind BIAS (m/s) JJA 200hPa

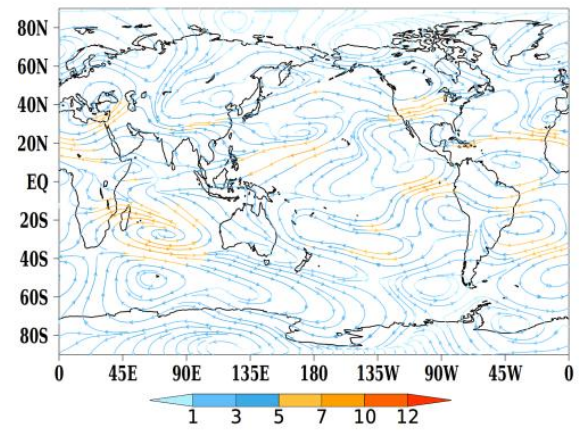

h)BAM ERA5 TQ126L42 mag of wind BIAS (m/s) SON 200hPa

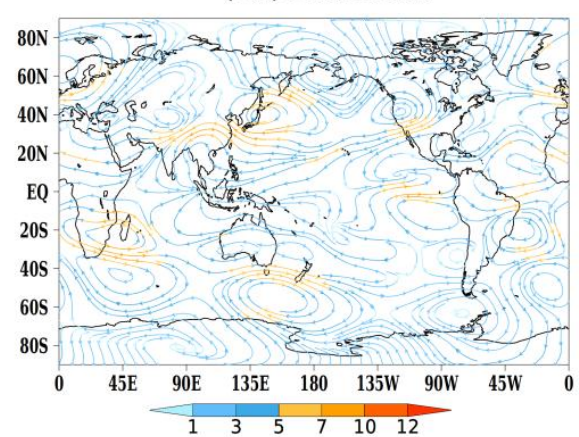

Figure S4: Upper level (200 hPa) circulation mean bias represented by streamlines with magnitude in $\mathrm{m} . \mathrm{s}^{-1}$ (colors) for austral summer (DJF, first row), autumn (MAM, second row), winter (JJA, third row) and spring (SON, fourth row), for BAM TQ62L42 ( 180 km, first column), and BAM TQ126L42 ( 100 $\mathrm{km}$, second column), computed with respect to ERA-5 (Hersbach et al., 2018, 2019) over the 2001-2016 period. BAM results shown in this figure correspond to the ensemble mean of the performed 4-member simulations. 

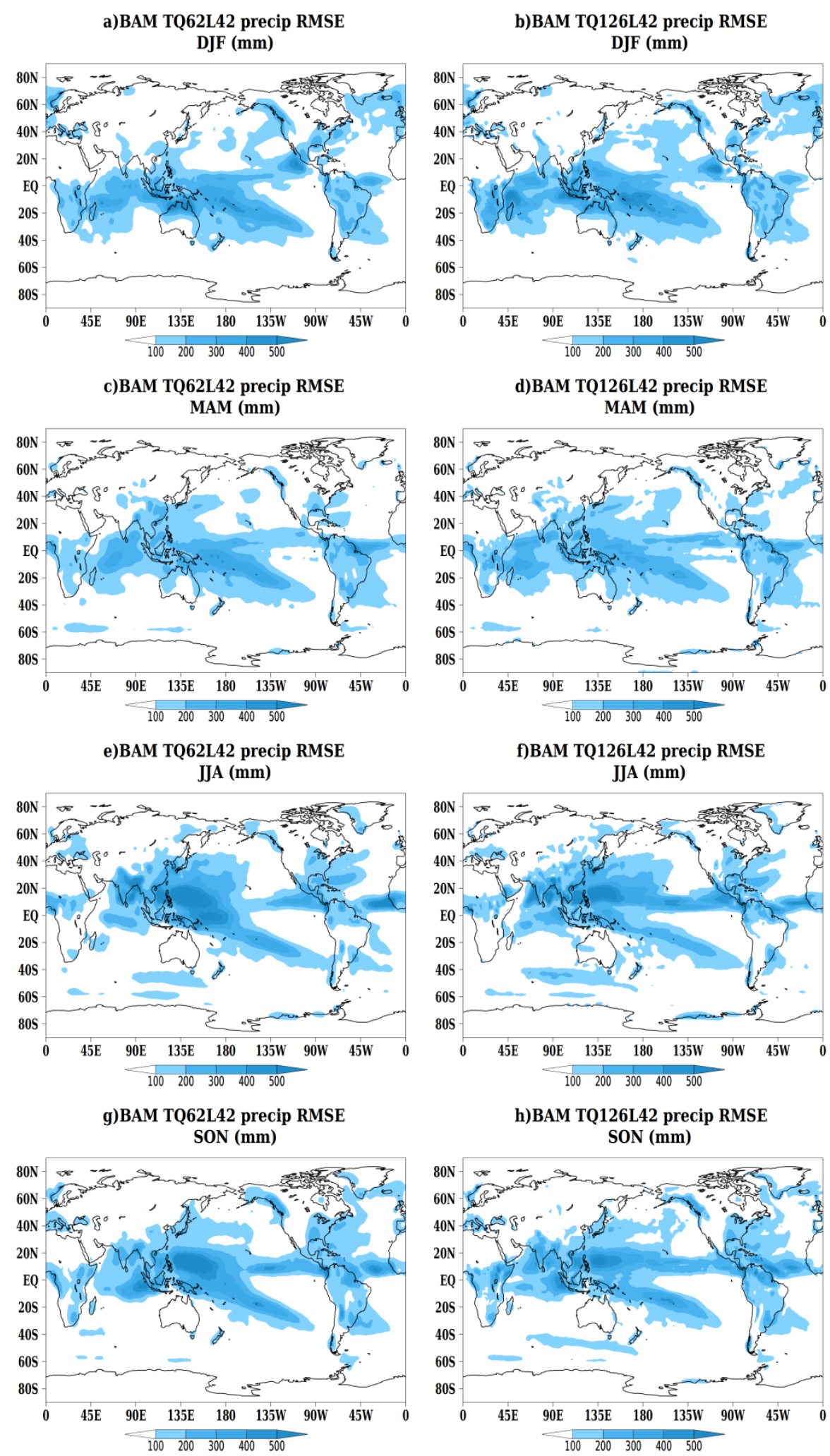

Figure S5: Accumulated precipitation RMSE (in mm) for austral summer (DJF, first row), autumn (MAM, second row), winter (JJA, third row) and spring (SON, fourth row), for BAM TQ62L42 ( 180 $\mathrm{km}$, first column), and BAM TQ126L42 $(\sim 100 \mathrm{~km}$, second column), computed with respect to GPCP (Adler et al. 2003) over the 1981-2010 period. BAM results shown in this figure correspond to the ensemble mean of the performed 4-member simulations. 

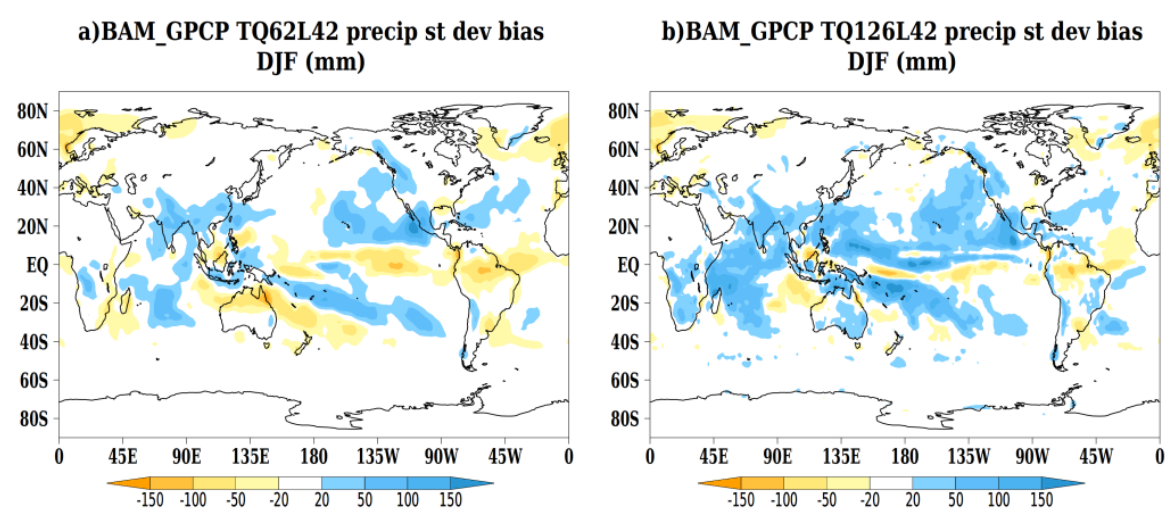

c)BAM_GPCP TQ62L42 precip st dev bias MAM (mm)

d)BAM_GPCP TQ126L42 precip st dev bias MAM (mm)

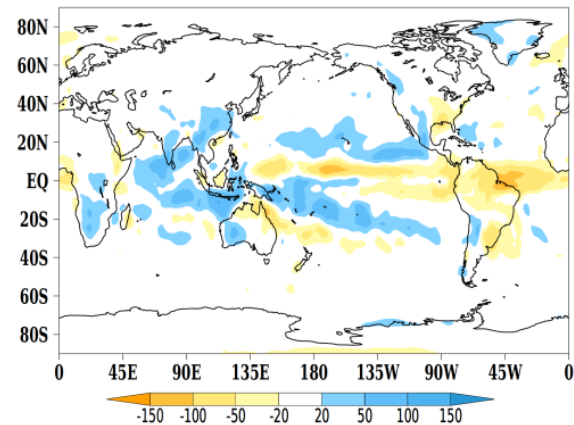

e)BAM_GPCP TQ62L42 precip st dev bias JJA (mm)
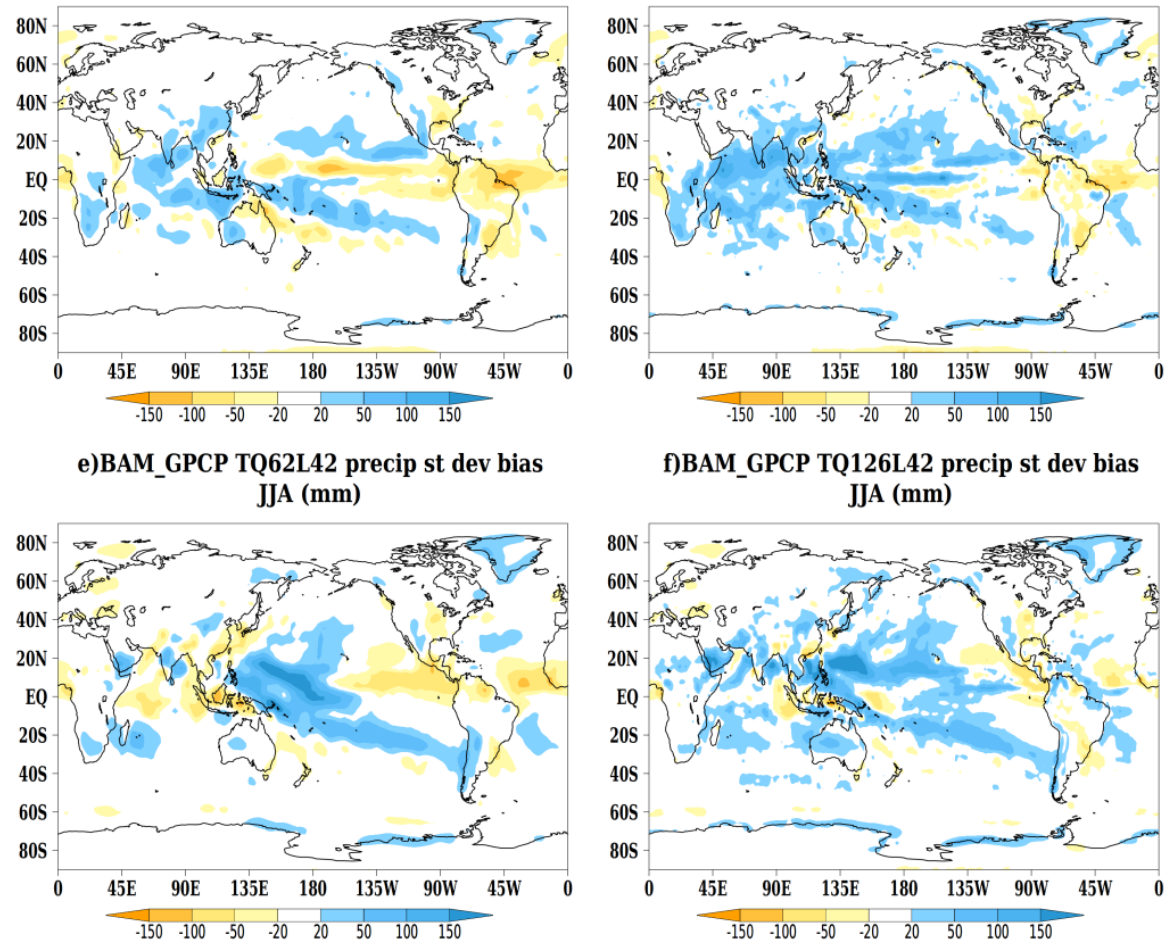

f)BAM_GPCP TQ126L42 precip st dev bias JJA (mm)

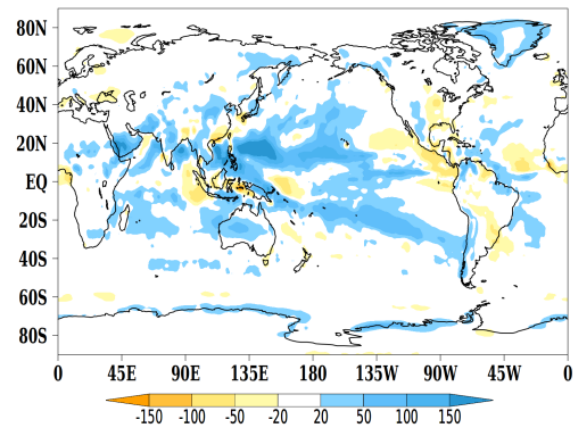

g)BAM_GPCP TQ62L42 precip st dev bias SON (mm)

h)BAM_GPCP TQ126L42 precip st dev bias SON (mm)
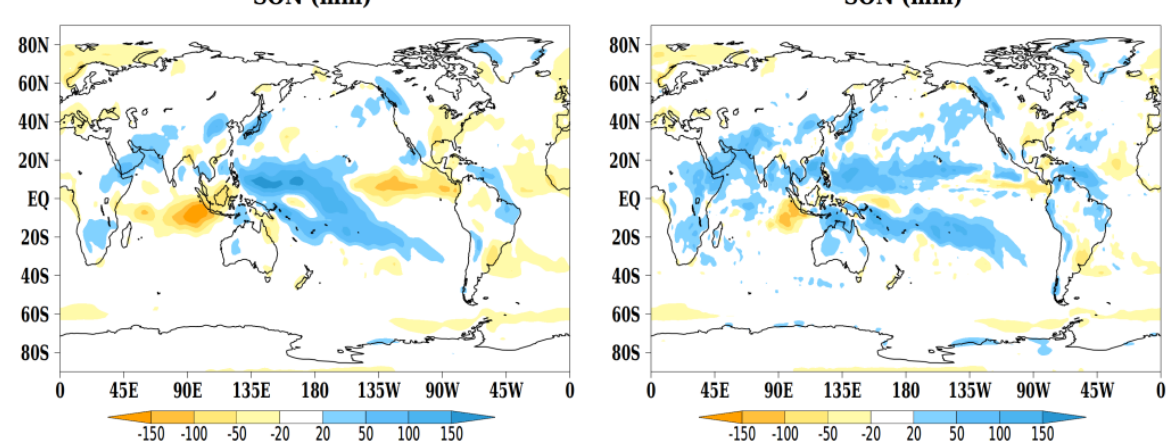

Figure S6: Accumulated precipitation standard deviation bias (in $\mathrm{mm}$ ) for austral summer (DJF, first row), autumn (MAM, second row), winter (JJA, third row) and spring (SON, fourth row), for BAM TQ62L42 ( 180 km, first column) and BAM TQ126L42 ( 100 km, second column), computed with respect to GPCP (Adler et al., 2003) over the 1981-2010 period. BAM standard deviations were computed using all four individual ensemble members (not the ensemble mean) for each investigated model spatial resolution in order avoid filtering out through the ensemble mean the model simulated precipitation inter-annual variability. 


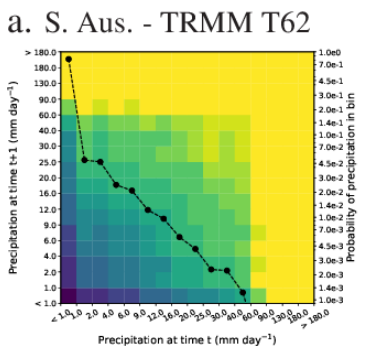

e. S. Afr. - TRMM T62

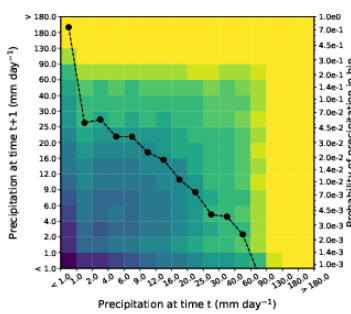

i. E. Asia - TRMM T62

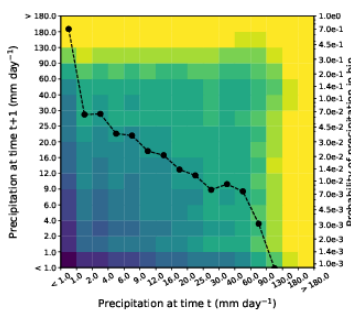

m. S. Eur. - TRMM T62

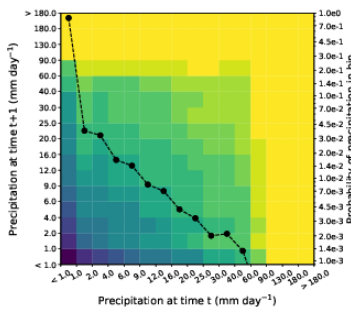

q. SE N. Am. - TRMM T62

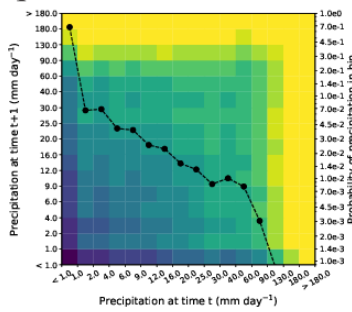

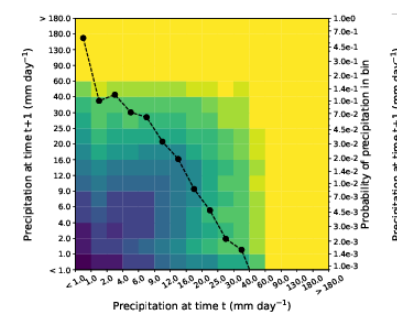

c. S. Aus. - TRMM T126

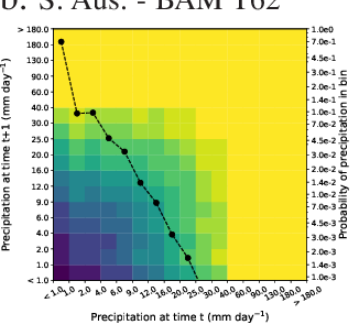

f. S. Afr. - BAM T62

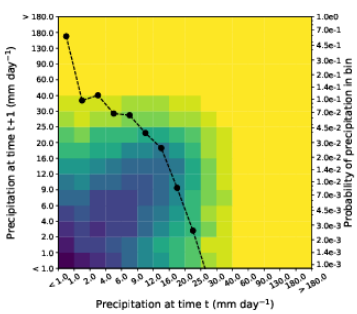

j. E. Asia - BAM T62

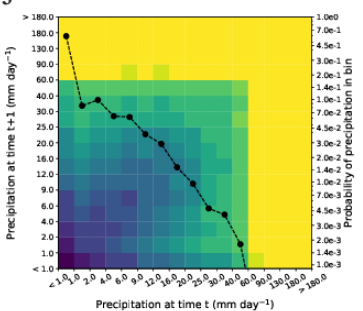

n. S. Eur. - BAM T62
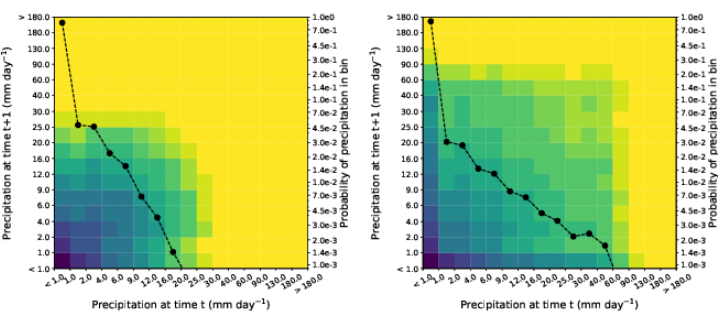

S. SE N. Am. - TRMM

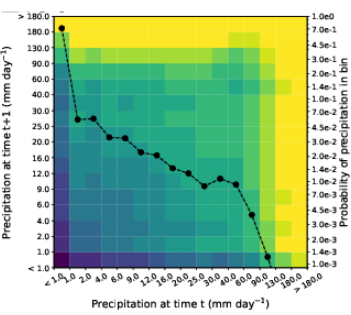

d. S. Aus. - BAM T126

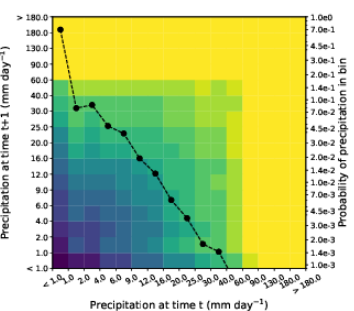

h. S. Afr. - BAM T126

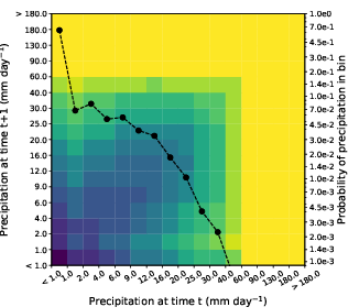

1. E. Asia - BAM T126

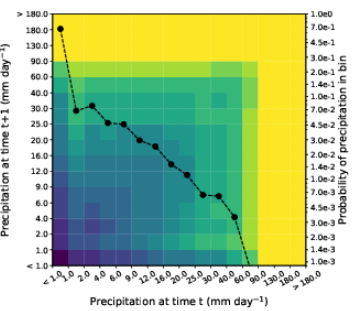

p. S. Eur. - BAM T126

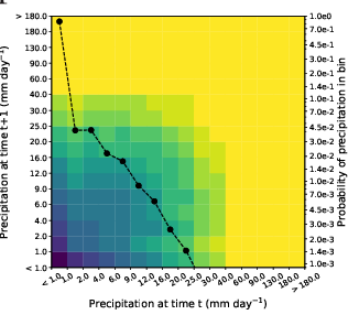

t. SE N. Am. - BAM T126

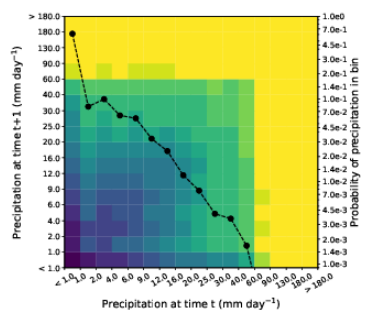

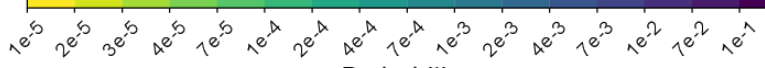

Probability

Figure S7: Joint (two-dimensional, 2-D) probability density function (colors, in logarithmic scale) of binned values (bin intervals are shown in the horizontal and left vertical axes) of daily precipitation at the same grid point on consecutive days, and one dimensional (1-D) probability density function (dashed line) of daily precipitation using the right-hand side axis, aggregated over all grid points during the 1998-2017 period, for 5 regions (rows): Southern Australia (S. Aus.) $\left[45-20^{\circ} \mathrm{S}, 110-135^{\circ} \mathrm{E}\right]$, Southern Africa (S. Afr.) $\left[35-10^{\circ} \mathrm{S}, 15-40^{\circ} \mathrm{E}\right]$, Eastern Asia (E. Asia) [20$\left.45^{\circ} \mathrm{N}, 105-130^{\circ} \mathrm{E}\right]$, Southern Europe (S. Eur.) [20-45 N, $\left.5^{\circ} \mathrm{W}-20^{\circ} \mathrm{E}\right]$ and Southeast North America (SE N. Am.) [20$45^{\circ} \mathrm{N}, 100-75^{\circ} \mathrm{W}$. The first column shows plots derived from TRMM (Kummerow et al., 1998; Huffman et al., 2007, $2010)$ interpolated to T62 spatial resolution $(\sim 180 \mathrm{~km})$, the second column for all four BAM TQ62L42 $(\sim 180 \mathrm{~km})$ ensemble members, the third column for TRMM interpolated to T126 spatial resolution $(\sim 100 \mathrm{~km})$, and the forth column for all four BAM TQ126L42 ( 100 km) ensemble members. See Klingaman et al. (2017) and Martin et al. (2017) for further information on how these figures are produced. 
a. S. Aus. - TRMM T62

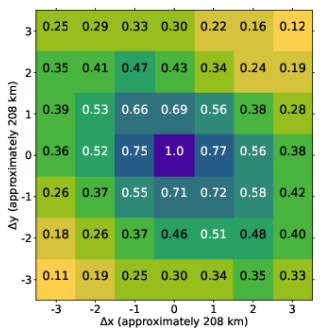

e. S. Afr. - TRMM T62

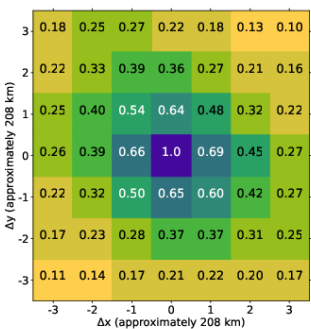

i. E. Asia - TRMM T62

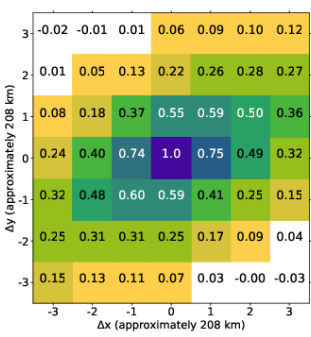

m. S. Eur. - TRMM T62

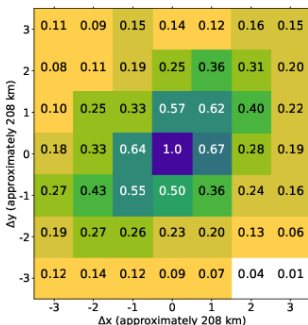

q. SE N. Am. - TRMM T62

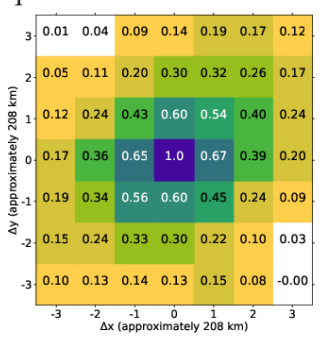

b. S. Aus. - BAM T62

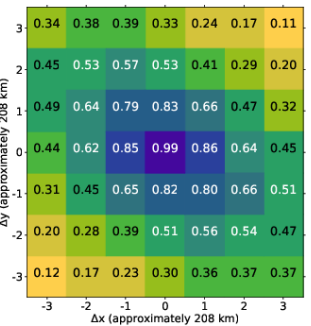

f. S. Afr. - BAM T62

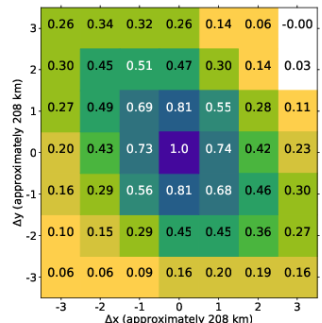

j. E. Asia - BAM T62

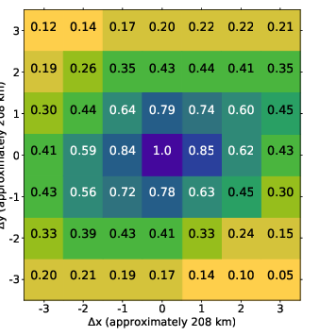

n. S. Eur. - BAM T62

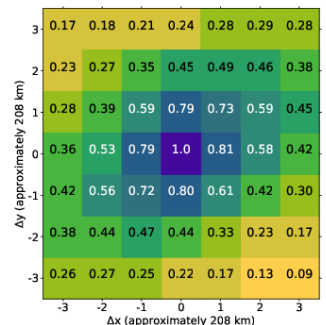

r. SE N. Am. - BAM T62

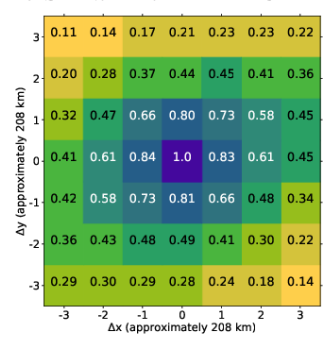

c. S. Aus. - TRMM T126

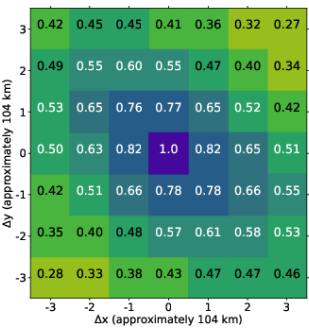

g. S. Afr. - TRMM T126

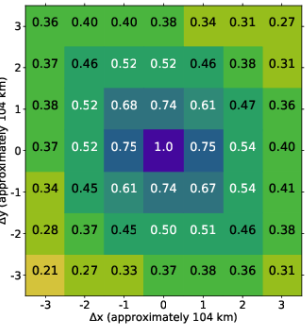

k. E. Asia - TRMM T126

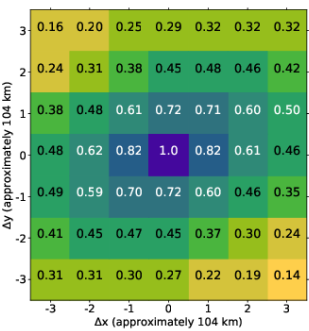

O. S. Eur. - TRMM T126

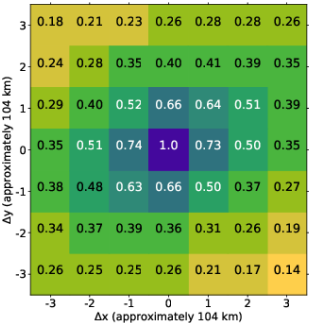

S. SE N. Am. - TRMM T126

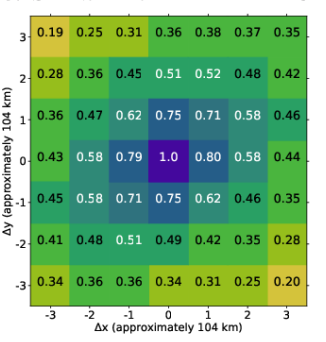

d. S. Aus. - BAM T126

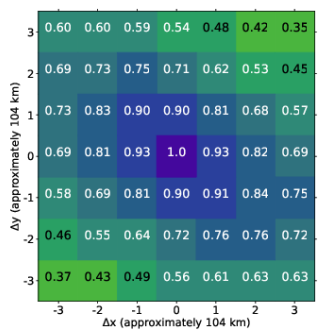

h. S. Afr. - BAM T126

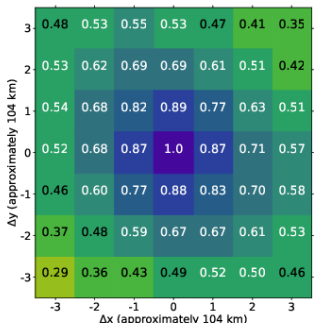

1. E. Asia - BAM T126

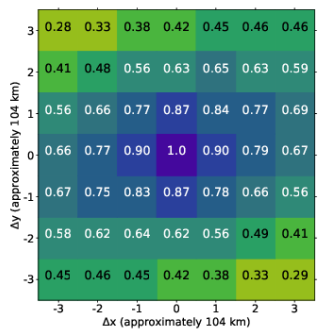

p. S. Eur. - BAM T126

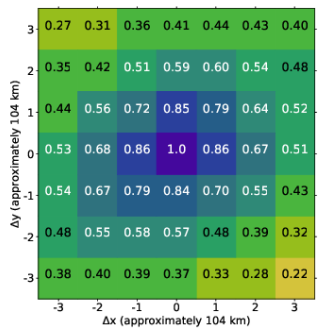

t. SE N. Am. - BAM T126

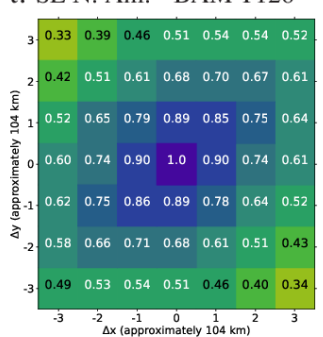

0.050 .150 .250 .350 .450 .550 .650 .750 .850 .95

Correlation with $(0,0)$ - mean over all sub-regions

Figure S8: Mean instantaneous (lag-0) correlations of daily gridded precipitation 1998-2017 time series at all grid points within a $7 \times 7$ grid point sub-region within 5 regions (rows), Southern Australia (S. Aus.) [45-20 $0^{\circ}, 110-$

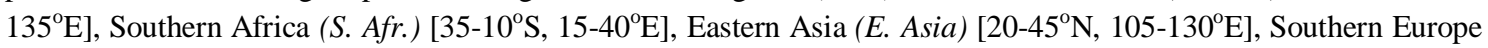
(S. Eur.) $\left[20-45^{\circ} \mathrm{N}, 5^{\circ} \mathrm{W}-20^{\circ} \mathrm{E}\right]$ and Southeast North America (SE N. Am.) [20-45 $\left.{ }^{\circ} \mathrm{N}, 100-75^{\circ} \mathrm{W}\right]$, against the precipitation time series at the central grid point $(0,0)$ of each $7 \times 7$ grid point sub-region, averaged over all possible non-overlapping $7 \times 7$ grid point sub-regions within the five investigated regions. The first column shows plots derived from TRMM interpolated to T62 spatial resolution $(\sim 180 \mathrm{~km})$, the second column for BAM TQ62L42 ( 180 $\mathrm{km})$, the third column for TRMM interpolated to T126 spatial resolution $(\sim 100 \mathrm{~km})$, and the forth column for BAM TQ126L42 ( 100 km). The values for BAM (second and forth columns) are averages of the mean instantaneous correlation values for the four individual ensemble members. The printed values and filled blocks in panels show the 
same data. See Klingaman et al. (2017) and Martin et al. (2017) for further information on how these figures are produced. 